University of South Florida

DIGITAL COMMONS

Digital Commons @ University of

@ UNIVERSITY OF SOUTH FLORIDA

South Florida

January 2013

\title{
Weather patterns associated with green turtle hypothermic stunning events in St. Joseph Bay and Mosquito Lagoon, Florida
}

Kelsey Roberts

University of South Florida, robertsk@mail.usf.edu

Follow this and additional works at: https://digitalcommons.usf.edu/etd

Part of the Environmental Sciences Commons

\section{Scholar Commons Citation}

Roberts, Kelsey, "Weather patterns associated with green turtle hypothermic stunning events in St. Joseph Bay and Mosquito Lagoon, Florida" (2013). USF Tampa Graduate Theses and Dissertations. https://digitalcommons.usf.edu/etd/4836

This Thesis is brought to you for free and open access by the USF Graduate Theses and Dissertations at Digital Commons @ University of South Florida. It has been accepted for inclusion in USF Tampa Graduate Theses and Dissertations by an authorized administrator of Digital Commons @ University of South Florida. For more information, please contact digitalcommons@usf.edu. 
Weather Patterns Associated with Green Turtle Hypothermic Stunning Events in St.

Joseph Bay and Mosquito Lagoon, Florida

by

Kelsey Elyse Roberts

A thesis submitted in partial fulfillment

of the requirements for the degree of

Master of Science

School of Geosciences

College of Arts and Sciences

University of South Florida

\author{
Major Professor: Jennifer Collins, Ph.D. \\ Joni Downs, Ph.D. \\ Robert Hardy
}

Date of Approval:

October 28, 2013

Keywords: Chelonia mydas, cold snap, rehabilitation, Arctic Oscillation, advection freeze

Copyright (C) 2013, Kelsey Elyse Roberts 


\section{Acknowledgments}

I am highly indebted to my committee members for their feedback and support: Dr. Jennifer Collins, Dr. Joni Downs, and Robert Hardy from FWC. I would like to extend my thanks and gratitude to Charlie Paxton. This research would not have been possible without his help and guidance. Finally, a special thanks to Robert Hardy and Rhonda Bailey from FWRI for providing data and resources for this project. 


\section{Table of Contents}

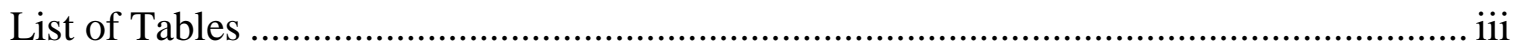

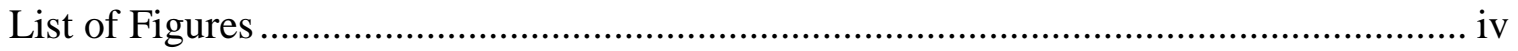

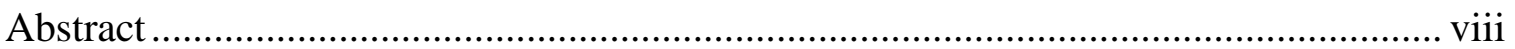

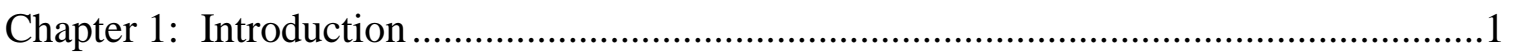

1.1 Life History for the Green Sea Turtle (Chelonia mydas) ....................................

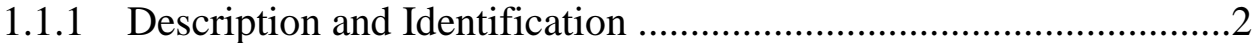

1.1.2 Distribution and Abundance .............................................................

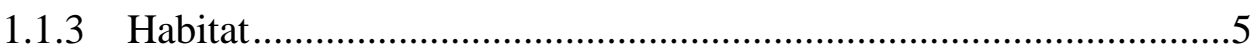

1.1.4 Home Range and Movements ..........................................................6

1.1.5 Reproduction and Recruitment ………………..........................

1.1.6 Diet and Nutrition .................................................................

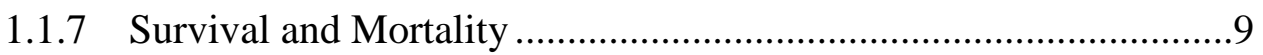

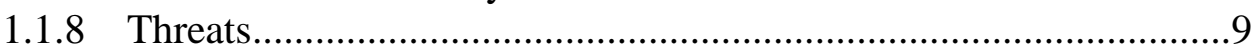

1.1.9 Conservation and Management......................................................11

1.2 Effect of Winter Weather Conditions on Marine Sea Turtles...........................14

1.2.1 Winter Freezes in Florida............................................................16

1.2.2 Winter Cold Snap of 2010 ..........................................................19

1.2.3 2010 Cold Stun Event …………………………....................21

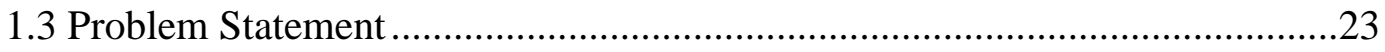

1.4 Objectives and Research Questions ...............................................................24

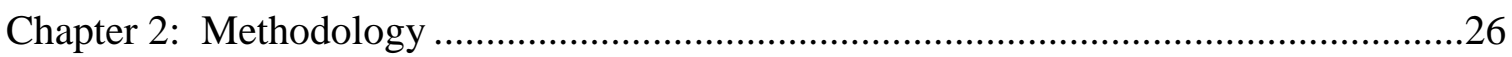

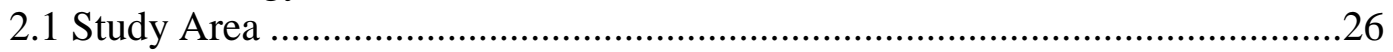

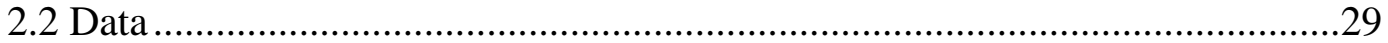

2.2.1 Sea Turtle Data ………………………………...................29

2.2.2 Atmospheric Data .....................................................................30

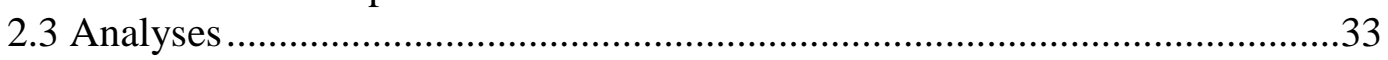

2.3.1 Weather Parameter Graphs ............................................................33

2.3.2 Arctic and North Atlantic Oscillations ..........................................34

2.3.3 NCEP Reanalysis Data Composites................................................35

2.3.4 NDBC and FWRI Buoy Comparison …………………….............36

2.3.5 Standard Event Pattern Composites.................................................36

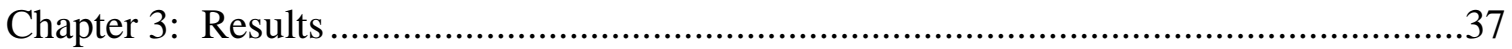

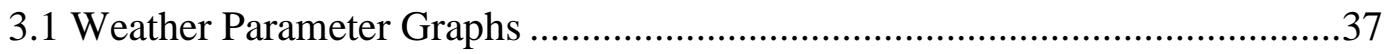




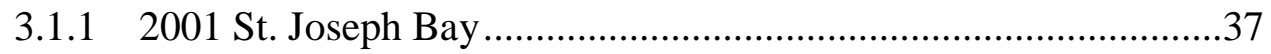

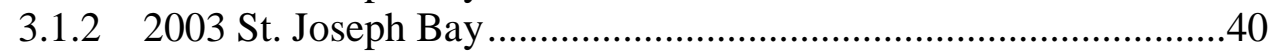

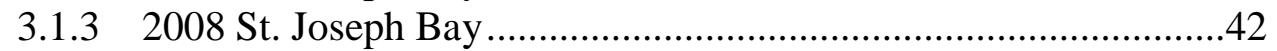

3.1.4 2009 St. Joseph Bay ............................................................44

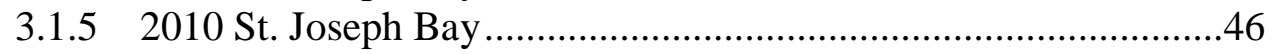

3.1.6 2010 Mosquito Lagoon .........................................................49

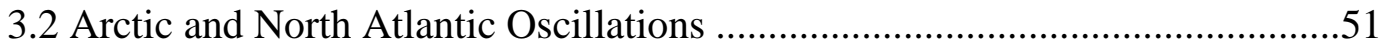

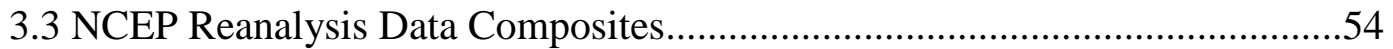

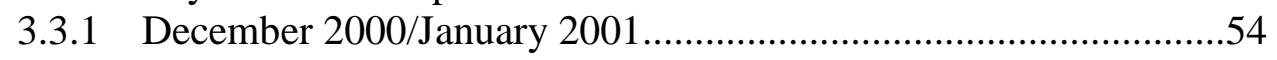

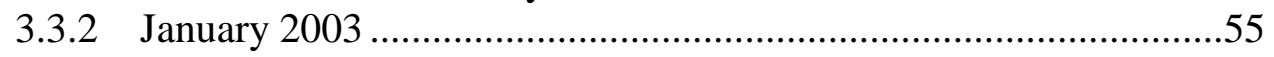

3.3.3 January 2010 ....................................................................56

3.4 NDBC and FWRI Temperature Data Comparison .....................................56

3.5 Standard Event Pattern Composites .........................................................58

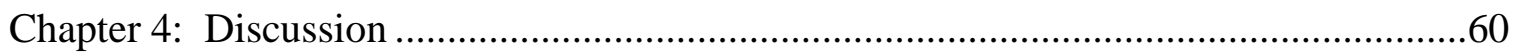

4.1 Analysis of Atmospheric Variables ........................................................60

4.2 Formation of a hypothermic stunning event ........................................62

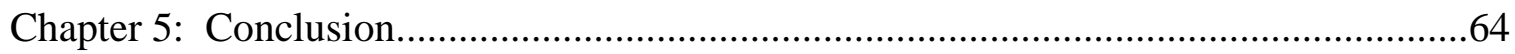

5.1 Limitations and Future Work .........................................................65

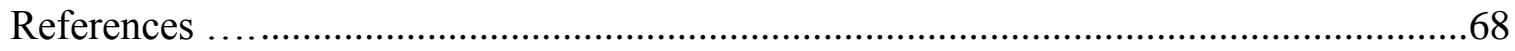

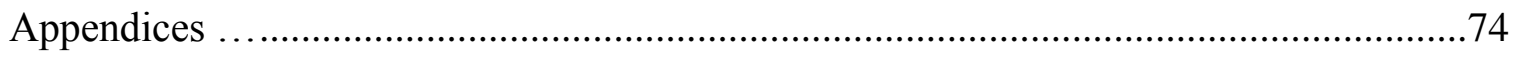

Appendix A: Surface Air temperature composites .......................................75

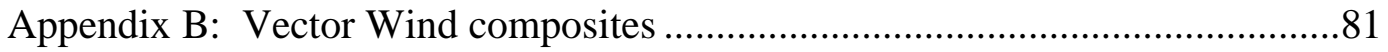

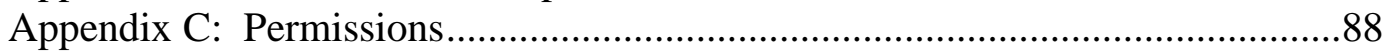




\section{List of Tables}

Table 1: Description of major vs. minor green turtle nest site locations .........................5

Table 2: Significant Florida impact freezes ..........................................................17

Table 3: Date and corresponding magnitude event for St. Joseph Bay, FL.....................30

Table 4: Daily water temperature comparison between NDBC's Apalachicola station and FWRI St. Joseph Bay transmitter 


\section{List of Figures}

Figure 1: Description of green turtle nesting sites on Florida beaches ...............................4

Figure 2: Low, medium and high conservation priorities for sea turtles ..........................12

Figure 3: A comparison of acute vs. chronic sea turtle cold-stunning

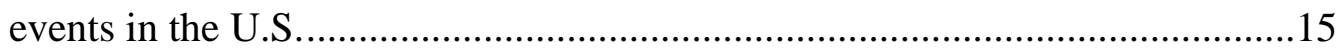

Figure 4: Mean geopotential height plot of U.S. January 1-10, 2010 ..............................21

Figure 5: Location of two study areas: St. Joseph Bay and Mosquito

Lagoon, Florida .26

Figure 6: Magnified images of St. Joseph Bay and Mosquito Lagoon, FL .......................27

Figure 7: Detailed map of sea turtle cold-stun search areas in St. Joseph

Bay, FL study area.

Figure 8: Location of Haulover Canal in relation to Mosquito Lagoon, FL......................31

Figure 9: Location of Cape Canaveral in relation to Mosquito Lagoon, FL .....................31

Figure 10: Location of Apalachicola in relation to St. Joseph Bay, FL.............................32

Figure 11: Location of Cape San Blas in relation of St. Joseph Bay, FL .........................32

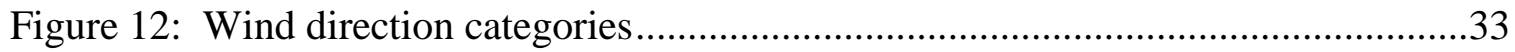

Figure 13: January 2001 St. Joseph Bay minimum air temperature with daily umber of cold-stunned sea turtles that were rescued

Figure 14: January 2001 St. Joseph Bay minimum air temperature with sea turtle cold-stun numbers on maximum scale used for Mosquito Lagoon 2010 .38 
Figure 15: January 2001 St. Joseph Bay air temperature and wind speed

Figure 16: January 2001 St. Joseph Bay air temperature and wind data (speed and surface vectors) for duration of the cold-stun event

Figure 17: January 2003 St. Joseph Bay minimum air temperature with daily umber of cold-stunned sea turtles that were rescued

Figure 18: January 2003 St. Joseph Bay minimum air temperature with sea turtle cold-stun numbers on maximum scale used for Mosquito Lagoon 2010 .41

Figure 19: January 2003 St. Joseph Bay air temperature and wind speed

Figure 20: January 2003 St. Joseph Bay air temperature and wind data (speed and surface vectors) for duration of the cold-stun event

Figure 21: January 2008 St. Joseph Bay minimum air temperature with daily umber of cold-stunned sea turtles that were rescued

Figure 22: January 2008 St. Joseph Bay minimum air temperature with sea turtle cold-stun numbers on maximum scale used for Mosquito Lagoon 2010 .43

Figure 23: January 2008 St. Joseph Bay air temperature and wind data (speed and surface vectors) for duration of the cold-stun event

Figure 24: Late December 2009 St. Joseph Bay minimum air and water temperature .45

Figure 25: Late December 2009 St. Joseph Bay average air and water temperature with wind data

Figure 26: January 2010 St. Joseph Bay minimum air temperature with daily umber of cold-stunned sea turtles that were rescued

Figure 27: January 2010 St. Joseph Bay minimum air temperature with sea turtle cold-stun numbers on maximum scale used for Mosquito Lagoon 2010 
Figure 28: January 2010 St. Joseph Bay air temperature, water temperature and wind speed.

Figure 29: January 2010 St. Joseph Bay air temperature, water temperature and wind data (speed and surface vectors) for the duration of the cold-stun event

Figure 30: January 2010 Mosquito Lagoon minimum air and water temperature with daily umber of cold-stunned sea turtles that were rescued

Figure 31: January 2010 Mosquito Lagoon air temperature, water temperature and wind speed.. .50

Figure32: January 2010 Mosquito Lagoon air temperature, water temperature and wind data including surface vectors for the duration of the hypothermic stunning event

Figure 33: Normalized Values of North Atlantic Oscillation 2000-2013.

Figure 34: Normalized values of Arctic Oscillation 2000-2013

Figure 35: Normalized values of Arctic Oscillation October 2009-

December 2010

Figure 36: Normalized values of Arctic Oscillation October 2000-

Decemeber 2001

Figure 37: Surface air temperature composite anomaly for high magnitude days .58

Figure 38: 500mb Geopotential height composite mean for high magnitude days

Figure A1: Surface air temperature composite anomaly December 30-

January 12, 2001

Figure A2: Surface air temperature composite anomaly January 23-28, 2003 
Figure A3: Surface air temperature composite anomaly Dec. 30, 2009 -

Jan. 16, 2010 .

Figure B1: Vector wind composite anomaly December 30-January 12, 2001 .82

Figure B2: Vector wind composite anomaly January 23-28, 2003 .85

Figure B3: Vector wind composite anomaly January 5-16, 2010 .86 


\section{Abstract}

January of 2010 brought record-breaking cold temperatures to Florida. Such freeze events can upset vulnerable populations of marine life and other species that rely on stable water temperatures. Sea turtles are one group of species that are particularly susceptible to abrupt drops in water temperature. When water temperatures drop below $10^{\circ} \mathrm{C}$, a mass hypothermic stunning, or cold-stunning, event for sea turtles can be expected, with many debilitated turtles washing onshore with a very limited time window to be rehabilitated (Foley et al. 2007). The species of sea turtle that appears to cold-stun with the most frequency is the green turtle, especially juveniles. The green turtle represented the vast majority of marine turtles that were rescued during the 2010 coldstun event.

Therefore, accurate weather pattern recognition of marine cold snaps, or freezes, can alert sea turtle rescue groups and rehabilitation facilities in advance of any event, improving their readiness and response times, and ultimately preventing population declines. The proposed research fills this need by providing a qualitative analysis of select years for comparable atmospheric processes that could result in moderate to severe hypothermic stunning events. The 2010 event, along with other significant events, were examined using in situ air temperature, water temperature and wind data near two locations in Florida where hypothermic stunning events occurred: St. Joseph Bay and Mosquito Lagoon. These atmospheric parameters were represented graphically, depicting how each variable contributed to shaping an event. 
Cold stunning events were found to be primarily driven by frigid air temperatures and a subsequent decrease in water temperatures. Differences between the two event classifications, moderate and severe, are contingent upon the duration of the cold spell, not necessarily how quickly the water temperature dropped below the $10^{\circ} \mathrm{C}$ threshold value. Results suggest that repeated, quick exposure to cold air temperatures may influence the severity of a hypothermic stunning event. This research could be utilized in the formation of a forecasting model or strategy to efficiently alert the Florida Sea Turtle Stranding and Salvage Network (STSSN) to a potential sharp drop in water temperatures and, consequently, many debilitated sea turtles. 


\section{Chapter 1: $\quad$ Introduction}

While uncommon, it is possible for severe cold spells to occur as far south as Florida. During the $20^{\text {th }}$ century there were over 50 significant freezes that impacted Florida (Henry et al. 1994). While most freeze events only last one day, they can still inflict serious damage to marine life that cannot tolerate cold temperatures. The loss of coral and marine life to severe cold temperatures can have profound impacts on the ocean environments that can take years to recover (Roberts et al. 1982). Sea turtles exhibit a seasonal response to water temperatures, marked by a lowered metabolic state during winter. Extremely low water temperatures (below $10^{\circ} \mathrm{C}$ ) may result in a mass hypothermic stunning, also known as cold-stunning, event for sea turtles (Schwartz 1978). The condition of thermal stress hypothermia in marine turtles causes a comatose condition and can often result in death if left untreated. The outcome of a severe event is many debilitated turtles washing onshore with a very limited time window to be rehabilitated (Foley et al. 2007).

A great aid to the Florida Sea Turtle Stranding and Salvage Network (STSSN) would be the ability to predict the specific winter weather patterns, which cause hypothermic stunning events. Meteorologists can often agree on the mechanisms that can cause freezing air to descend on Florida, although research has not attempted to analyze and predict hypothermic stunning events for green turtles. Therefore, this research explored the specific atmospheric and oceanographic parameters related to sea turtle cold stunning events in Florida. Weather and water data such as air temperature, water temperature, 
wind direction and speed were analyzed. The results were used to provide a baseline for future forecasting strategies that will indicate when this type of weather pattern is imminent. Such forecasting could better prepare rescue organizations and rehabilitation facilities to respond to cold-stunned sea turtles.

\subsection{Life History for the Green Sea Turtle (Chelonia mydas)}

\subsubsection{Description and Identification}

Sea turtles are prehistoric reptiles whose ancestors lived during the time of the dinosaurs. They evolved on land before making their way into the ocean over 100 million years ago. By outliving the dinosaurs, sea turtles gained the distinction of the one of the largest living reptiles (Lutz et al. 2003). The green turtle is one of seven species of sea turtles that occupy the planet's waters. The other six species include loggerhead, leatherback, Kemp's ridley, olive ridley, flatback, and hawksbill. While these species share similar characteristics, each species is unique. The green turtle reaches the largest size of any other hard-shelled turtle (Witherington et al. 2006). The color of its shell, or carapace, varies from brown to an olive green, depending on the subspecies (Spotilla 2004). The green turtle carapace is made up of five central scutes, similar to scales, lined by four separate pairs of lateral scutes. This species gets its name from the greenish color of its body fat, not from outward appearance (Witherington et al. 2006). Its head color is a greenish yellow with light brown patches. Unlike the other species of sea turtles, the green turtle's head is much smaller in relation to the rest of its body and has a pair of prefrontal scales apparent on the dorsal view (Hirth 1997). Males and females are not easily distinguished from each other except for the fact that males typically are larger than females and have a longer tail (Hirth 1997, Spotilla 2004). Currently, scientists have 
identified two separate groups of green turtles, the Atlantic and Eastern Pacific populations.

\subsubsection{Distribution and Abundance}

Green turtles are famous for their long distance migrations from widely dispersed feeding grounds in order to locate adequate nesting beaches for reproduction (Bouchard and Bjorndal 2000). These beaches are primarily located in temperate and tropical environments throughout the world (Bouchard and Bjorndal 2000). Green turtle in-water distributions are wide-ranging and difficult to study synoptically (Lutz et al. 2003).

Green turtle are distributed worldwide, primarily in tropical and subtropical waters. However, the green turtle, like all sea turtle species, are not randomly distributed. Hirth (1997) discovered that green turtles will stay within locations that meet their preferred sea surface temperature range and that these locations change depending on the season. Nesting locations are scattered throughout the southern U.S. and the Caribbean. Figure 1 indicates that a significant aggregation of green turtles is found along the coasts of Florida, with Brevard and Broward County accommodating the greatest amount of nesting activity (Witherington et al. 2006). Other important nesting locations include Costa Rica, Mexico, Bermuda, Belize, Panama, Puerto Rico, and the southern coast of South America (Table 1). Most of these locations are proximal to the green turtles productive seagrass beds, their preferred food (Lagueux 2001). A recent study conducted by Scott et al. (2012) that utilized green turtle satellite tracking data, revealed that green turtles were present in substantial numbers in Marine Protected Areas (MPAs). MPA use by nesting green turtles can provide valuable insight from a federal recovery standpoint for this imperiled species (Hart et al. 2013). Nesting beach surveys can inform of 
population sizes and are widely used for these purposes (Meylan 1982). Nesting counts in Florida have improved by the implementation of two complementary programs that includes a broad geographic range and most of Florida's beaches. However there are multiple limitations to the nesting count surveys including inconsistency, fluctuations in boundaries, and incompleteness in seasonal range (Witherington et al. 2009).

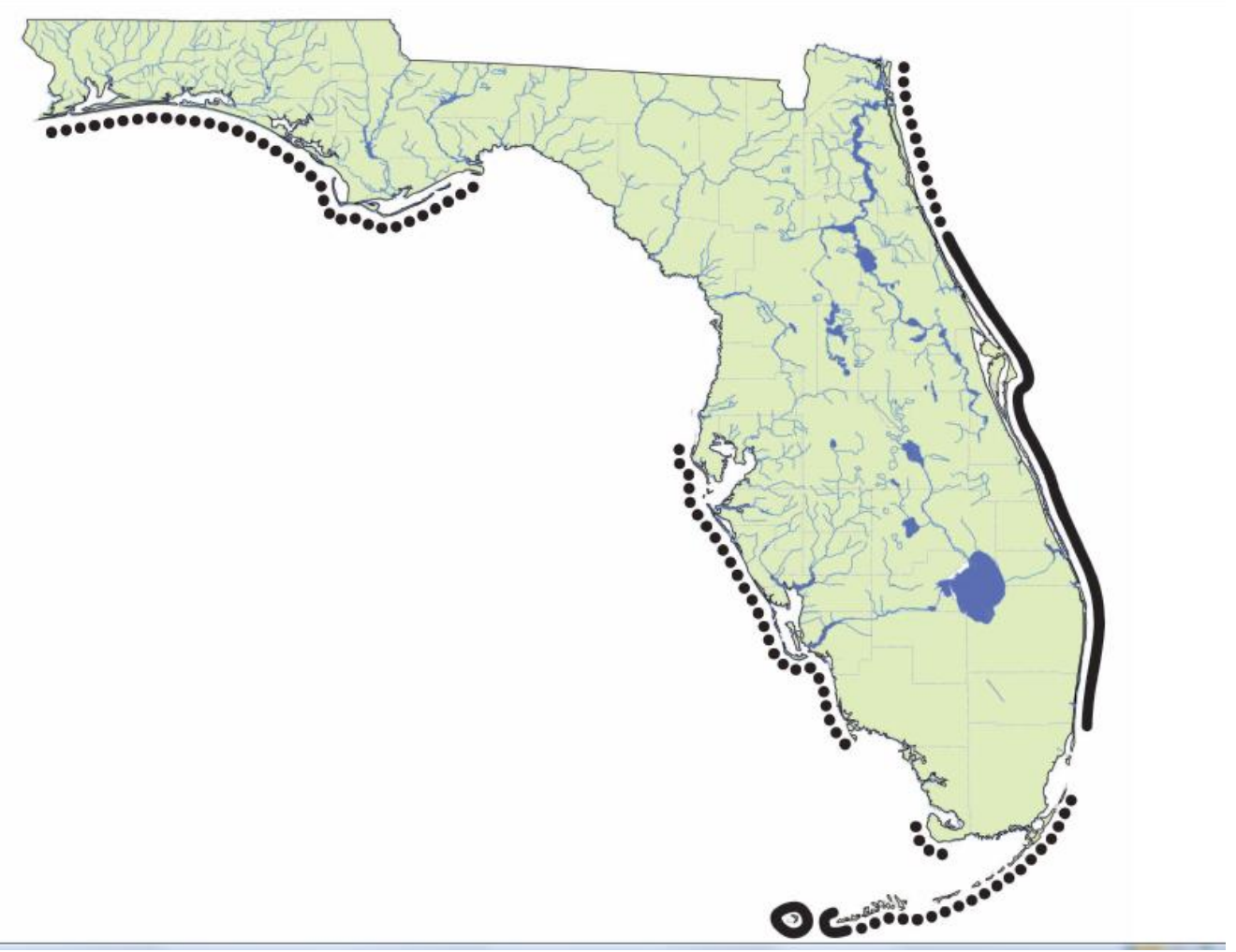

FIGURE 1. Distribution of green turtle nesting sites on Florida beaches. Solid lines specify more than one nest $/ \mathrm{km} /$ season. Dotted lines specify less than one nest $/ \mathrm{km} / \mathrm{season}$ for the years 2001-2005. (Witherington et al. 2006) 
Table 1. Description of Major vs. Minor Green Turtle Nest Site Locations (Meylan et al. 1990, Spotilla 2004)

\begin{tabular}{lc}
\hline Location & Major or Minor \\
\hline Andros Island, Bahamas & Minor \\
East Coast Florida & Major \\
Coastal & Major \\
Chiapas, Mexico \\
Clipperton Island & Minor \\
Canoa, Ecuador & Major \\
Costa Rica & Major \\
Suriname & Major \\
Hawaii & Major \\
\hline
\end{tabular}

\subsubsection{Habitat}

The habitat for post-hatchlings, once referred to as the 'lost year', was defined by Carr (1987). Carr (1987) observed that sea turtles in the early developmental stage would enter oceanic lines of drifting macroalgae (Sargassum spp.), and no longer have control over their geographic displacement (Carr 1987). Carr (1987) also stated that they would remain there for long periods of time. Surface-pelagic life stage is believed to exist entirely within the surface oceanic waters (Witherington et al. 2012). Early juvenile green turtles recruit from surface-pelagic environments to near shore, shallow water environments, such as bays, estuaries, inlets, or lagoons (Lutz et al. 2003). Upon reaching sexual maturity, a green turtle will migrate between foraging grounds and nesting habitats (Hirth 1997, Makowski et al. 2006). A suitable marine habitat for a green turtle is comprised of all their nutrition requirements, which require stable water temperature and 
adequate sunlight (Hirth 1997). Adult green turtles are frequent visitors to coral reef and mangrove habitats (Hirth 1997). A habitat for nesting requires a much more specific list of necessities. Minimal human encroachment is essential as well as a steep slope. Florida beaches with coarse sand, foredunes, and high wave energy typically see the majority of nesting green turtles (Witherington et al. 2006). Females will dig a deep nest cavity with her rear flippers a substantial distance from the water line to avoid inundation (National Marine Fisheries Service (NMFS) and US Fish and Wildlife Service (USFWS) 1991).This species does exhibit strong nest site fidelity and will often return to natal beaches (Balazas and Chaloupka 2003). However, as the human population moves closer and closer to the shoreline, crucial nest sites are in jeopardy. Artificial light can disorient hatchlings and beach projects can deter a female away from her chosen beach (Brock et al. 2007). Many studies have been performed on the effects of beach nourishment on sea turtle nest sites. Results from these studies demonstrate a reduction in reproductive output for many species directly after beach nourishment projects and suggest that a nonnourished beach with a more natural profile is more favorable for nesting females (Brock et al. 2007).

\subsubsection{Home Range and Movements}

The migration movements of the green turtle are very dependent on the life stage

of the individual (Carr 1987). While they are well-known for complex, extensive migrations through geographically distinct habitats, green turtles do not migrate continually (Hart et al. 2013; Witherington et al. 2006). They often exhibit fidelity to certain features of their environment and will undergo extensive periods of residency (Witherington et al. 2006). Telemetry data has shown that a juvenile green turtle will 
make scheduled movements between diurnal foraging areas and nocturnal resting areas (Mendonca 1983). In Mosquito Lagoon, juvenile green turtle home ranges were discovered by Mendonca (1983) to be quite small, only moving within a range of $3-10$ $\mathrm{km}$ depending on the sea surface temperature.

Green turtles undertake extensive developmental migrations (Meylan et al. 2011). As they continue to grow, green turtles will move among various foraging areas, discovering where the seagrass and algae are the most productive (NMFS and USFWS 1991). Witherington et al. (2006) reported that the adult migrations between selected foraging areas and natal nesting beaches are the most frequent long-distance migrations made by the green turtle.

\subsubsection{Reproduction and Recruitment}

Research is consistently conducted on the subject of green turtle male and female reproductive behaviors. More research has appeared in the literature on female mechanisms than males. This is due to two reasons; 1) survival of reproductively active females is important and 2) females are more easily encountered for study on the nesting beach (Richardson 1999). Nest season will vary depending on the location. Typically, the season begins in mid-summer and will last through late August to early September (Spotilla 2004). In the southeastern United States, particularly Florida, June and July are

the most critical months where lights out is enforced on public beaches (Butler 1998). Though all nesting beaches are of conservation importance, the east coast of Florida has consistently shown the largest green turtle breeding assemblage in the United States (NMFS and USFWS 1991). 
Yntema and Mrosovsky (1982) discovered that sexual differentiation in many species of marine turtles is dependent on the predominant temperature during egg incubation and that the effect of temperature is also permanent. If temperatures are below a threshold value, the nest will be comprised mostly of males. Subsequently, if temperature is above the threshold value, more females will be produced (NMFS and USFWS 2007). It has proven difficult in the past to predict the pivotal temperature in regards to number of each sex due to seasonal changes in temperature and year-to-year variance (Yntema and Mrosovsky 1982).

\subsubsection{Diet and Nutrition}

The green turtle's diet, like other marine turtle species, changes throughout its long life. Surface pelagic juvenile green turtles will feed on aquatic insects, worms and small crustaceans within drift habitats of the surface ocean (Carr 1987; Witherington et a1. 2013). Neritic juveniles and adult green turtles rely on a diet rich in seagrass and marine algae that can be found in shallow water bodies (Lutz et al. 2003; NMFS and USFWS 1991). Foraging grounds are carefully selected and can often take many years to locate. They were assumed up until recently to be only obligate herbivores (McKenzie et al. 1999). Wide scale tagging efforts of juvenile and adult greens have revealed much more than just their migrating patterns. Juvenile green turtles are known to be omnivorous but will shift to a primarily herbivorous diet when they reach the age to move to near-shore habitats (Hirth 1997). While surface pelagic, green turtles have been observed feeding on invertebrates, such as jellyfish and sponges, much like other sea turtle species like hawksbill and leatherbacks (Butler 1998, Lutz and Musick 1997). It is likely that these invertebrates are under-represented when a sea turtles' stomach content 
is observed as they are much more rapidly digested than sea grass (Blumenthal et al. 2009).

\subsubsection{Survival and Mortality}

Sea turtles are one of the world's longest-lived reptiles. They have survived for over 100 million years and have had to develop a variety of adaptation strategies (Butler 1998). While there are still quite a few gaps in the research on green turtle developmental biology, it is known that green turtles take longer to mature than any other sea turtle species (Lagueux 2001). This time length is approximated between 25 and 50 years (Lagueux 2001). Green turtles grow very slowly, taking approximately 17 years to grow 35 centimeters but have one of the longest lifespans of any vertebrate with the potential to live up to 80 years of age (Bjorndal and Bolten 1988, Wilbur et al. 1974).

\subsubsection{Threats}

Many species, including crabs and sea gulls, heavily prey on hatchlings (Fowler 1979). The harvest of sea turtle nests is also an ongoing problem on some critical beaches and is partially responsible for population declines in the past (Bugoni et al. 2001). The green turtle and the other sea turtle species have evolved to produce large clutch sizes per season as the mortality rate among juveniles is very high and only a small percentage survives to adulthood (Butler 1998).

The three primary hazards they face in their nesting environment are beach erosion, artificial lighting and beach nourishment projects. Green turtles heavily rely on healthy beaches with native vegetation that are free of human impacts such as armoring structures. Erosion of suitable nesting sites is becoming more and more problematic with the potential impacts of sea level rise (NMFS and USFWS 1991). Increasing 
development near the coastline has only exacerbated erosion rates. The results of artificial lighting on beaches can be fatal to green turtle hatchlings (Witherington 1992). Streetlights, building and vehicle lights can cause disorientation and expose newborn turtles to even more predators than under normal circumstances. Artificial lighting on beaches will also deter adult female green turtles from coming onshore to nest (Witherington 1992). This problem is profound in the southeastern United States. Beach nourishment projects have a direct negative impact to sea turtles by either disturbing or burying nests. Nest site selection can also be affected by these projects (Brock et al. 2007).

The biggest threats to their marine environment are pollution, fisheries by-catch and entanglement (Bugoni et al. 2001). As the human population expands closer to the shoreline, industrial and residential waste will often be deposited into the oceans. Green turtles thrive in shallow water bodies and depend on clean water for their food production. While the effects of pollution are difficult to assess, it is clear that pesticides and garbage can disrupt sea turtle behavior in more ways than one (Lutz and Musick 1997). Commercial fisheries, especially shrimp trawling, cause extensive damage to the marine turtle population. Incidental capture is responsible for the vast majority of juvenile green turtle mortalities (Butler 1998). In recent years, trawlers have expanded the size of their nets to capture other species besides shrimp. A consequence of this is young adult marine turtles will be captured along with juveniles. Both stages, juvenile and young adult, are vital for the recovery and stability of the green turtle population (NMFS and USFWS 1991). Green turtles are often affected by many forms of marine debris. Floating fishing gear may be mistaken as a food source and will result in 
entanglement. Netting and monofilament lines were discovered to the primary means of entanglement for this species as green turtles can often be found foraging around reefs (Gilman et al. 2006). Once a sea turtle becomes entangled, it will most often drown unless rescued (NMFS and USFWS 1991).

\subsubsection{Conservation and Management}

The green turtle is listed as an endangered species in the US as well as internationally by the International Union for the Conservation of Nature (IUCN). The US Endangered Species Act places this species on the threatened list with two breeding populations in Florida and the Pacific coast of Mexico listed as endangered (NMFS and USFWS 1991). In the past one hundred years, global green turtle population numbers have decreased between $48 \%$ and $67 \%$, emphasizing the negative anthropogenic impacts on this species (Seminoff 2004).

The conservation and management of this species has faced numerous challenges. Ehrenfeld (1982) suggests that this difficulty stems from limiting factors such as long migration across international borders, variable length of nesting cycles, and long maturation time. Threats to both their nesting and marine environment have elevated the green turtle to a cause of concern in the near future. The identification and protection of nesting beaches as well as near-shore habitats is an integral component of conservation and management strategies (NMFS and USFWS 2007; Figure 2). Such efforts have the highest potential for success and are not limited by the biology of the species (Ehrenfeld 1982). 


\begin{tabular}{|c|c|c|}
\hline Priority & Research & Conservation metbods \\
\hline High & $\begin{array}{l}\text { Life histories, especially migrations and } \\
\text { the non-nesting portions; population dy- } \\
\text { namics; critical habitats; effects of egg } \\
\text { manipulation (including temperature) } \\
\text { and other hatchery-related research; tax- } \\
\text { onomy and related population genetics; } \\
\text { simple, inexpensive, effective tagging } \\
\text { methods; improved fishing trawls; ef- } \\
\text { fects of nesting beach alterations; turtle } \\
\text { product species identification methods }\end{array}$ & $\begin{array}{l}\text { Protection of nesting grounds and } \\
\text { aquatic habitats, including minimization } \\
\text { of environmental disruption at these } \\
\text { sites and designation of critical habitats; } \\
\text { short-range transplantation of nests, use } \\
\text { of egg hatcheries; conservation educa- } \\
\text { tion; control of international trade; in- } \\
\text { tergovernmental and interorganizational } \\
\text { coordination of conservation strategies; } \\
\text { dissemination of improved trawls (when } \\
\text { available) }\end{array}$ \\
\hline Medium & $\begin{array}{l}\text { Control of infectious diseases and para- } \\
\text { sites in captive animals, especially juve- } \\
\text { niles; study of biological effects of pollu- } \\
\text { tants; nutritional research; fisheries } \\
\text { management research; effects of head- } \\
\text { starting and long-distance transplantation }\end{array}$ & $\begin{array}{l}\text { Long range transplantation of nests; } \\
\text { headstarting }\end{array}$ \\
\hline Low & $\begin{array}{l}\text { Effects of manipulations in closed-cycle } \\
\text { breeding systems; some high-technology } \\
\text { research (endocrinology, sensory physi- } \\
\text { ology, etc.) }\end{array}$ & $\begin{array}{l}\text { Fisheries management of turtle catch; } \\
\text { manipulation of sex ratios away from the } \\
\text { population norm; cottage industry } \\
\text { ranching; noncommercial captive breed- } \\
\text { ing to maintain gene pools }\end{array}$ \\
\hline
\end{tabular}

FIGURE 2. Low, medium and high conservation priorities for sea turtles (Reprinted from Bjorndal (1982) with permission of Smithsonian Institution)

Conservation efforts have focused on nest protection. If a nesting location is observed as critical for green turtles it can be set aside as a sanctuary by law or official regulation (Ehrenfeld 1982). It is often difficult to minimize or remove beach armoring structures in order to maximize habitat protection (Witherington et al. 2009). Local governments are attempting to move closer to 'living shorelines' and outlaw armoring A living shoreline uses natural ingredients such as native vegetation and biodegradable components for erosion control and can create suitable habitat for a variety of species (Ray-Culp 2007). If beach nourishment projects are scheduled, conservation agencies make sure to move nests prior to the date of new sand deposition or eliminate nourishment projects during nesting seasons (Witherington et al. 2009). 
The southeastern U.S. in particular is known for its high rate of disoriented hatchlings (Butler 1998). Many beach front communities have made a great deal of progress in 'lights out' initiatives (Witherington 1992). Property owners and the public are made aware of the start of nesting season and asked to remove all forms of artificial lighting at night. Florida has enacted lighting ordinances on many of its beaches due to the states importance for nesting habitat (Witherington 1992). The biggest effort to protect green turtles in their marine environment came in the form of turtle excluder devices (TED). After research proved that fisheries by-catch was causing population decline, various net designs that would allow turtles to escape were created (Crowder et al. 1994). The TED design was the most successful and six types have been developed since the original idea. The TED is a cage-like apparatus that is placed inside the trawl with an opening at either the top or bottom of the net (Crowder et al. 1994). It has been redesigned many times to allow for larger marine turtle that come across trawl nets. Gradually, many states have implemented TEDs and made them a requirement for bottom trawl fisheries (Crowder et al. 1994).

Understanding the green turtle in terms of biology and behavior will greatly assist in conservation and protection. By tagging individuals prior to release, sea turtle biologists can gain insight into their migration patterns and what areas should be preserved for the continued well-being of the species. Educating the public is an easy method of facilitating good management. By posting signs, creating bumper stickers and decals, and building children's activities, the general public can learn about marine turtles and how they can help in their survival. 


\subsection{Effect of Winter Weather Conditions on Marine Sea Turtles}

In most situations, sea turtles have the capability to migrate out of shallow areas when the water temperatures become too cold (Lutz and Musick 1997). Hypothermic stunning events that immobilize large numbers of sea turtles are rare in certain locations but can occur unexpectedly. The two shallow water areas in Florida where hypothermic stunning events occur most frequently are St. Joseph Bay, within the northeastern Gulf of Mexico, and Mosquito Lagoon on the central Atlantic coast (Witherington and Ehrhart 1989). The species of sea turtle that appears to cold stun with the most frequency is the green turtle, specifically juveniles (Witherington and Ehrhart 1989). Foley et al. (2007) classified hypothermic stunning events in the US as either acute or chronic (Figure 3). Events that are classified as acute, those that can occur in Florida where there are high aggregations of sea turtles, are typically short-lived and will occur during abnormally cold winters. Acute events typically have low mortality rates. Conversely, chronic cold stunning events will occur every winter, are long lasting, and produce high mortality rates. These events are documented in locations where sea turtles are only seasonal residents, such as Long Island Sound, NY (Foley et al. 2007).

The threshold temperature for marine turtles to cold-stun was discovered to be around $10^{\circ} \mathrm{C}$ (Schwartz 1978). When the water temperature drops below the $10^{\circ} \mathrm{C}$ threshold, the animal becomes lethargic and disoriented (Witherington and Ehrhart 1989). Hypothermia in sea turtles leads to a "disruption in metabolic pathways and an imbalance in blood chemistry" (Foley et al. 2007). Cold-stunned sea turtles may be observed floating at the surface or washed ashore. 


\begin{tabular}{|c|c|c|c|c|c|c|c|}
\hline $\begin{array}{l}\text { Type of cold } \\
\text { snuming enent }\end{array}$ & Sea turde resiciency in area & Water depch of area & Event occurrence periodikity & Duration of event & Mortality & Species primarily affected & Areas of oxcumence \\
\hline Acute & $\begin{array}{l}\text { Year-round (winter water } \\
\text { temperatures usually } \\
\text { warm enough for sea } \\
\text { turtles to occur year- } \\
\text { round) }\end{array}$ & $\begin{array}{l}\text { Extensive shallow } \\
\text { areas }(<2 \mathrm{~m}) \\
\text { that can cool } \\
\text { quickly }\end{array}$ & $\begin{array}{l}\text { Irregular (only } \\
\text { during unusually } \\
\text { cold winters) }\end{array}$ & Short $(<2$ wk) & Low $(<30 \%)$ & $\begin{array}{l}\text { green turtile. } \\
\text { loggerhead }\end{array}$ & $\begin{array}{l}\text { Mosquito I agrom, FT. } \\
\text { (Witherington and } \\
\text { Ehrhart, 1989; Schroeder } \\
\text { et al., 1990), Laguna } \\
\text { Maulue, TX (Stzaver, } \\
\text { 1990); St. Joseph Bay, FL } \\
\text { (present study) }\end{array}$ \\
\hline Chronic & $\begin{array}{l}\text { Seasonal (winter water } \\
\text { temperatures usually } \\
\text { drop below that } \\
\text { tolerated by sea turtles) }\end{array}$ & $\begin{array}{l}\text { Can include areas } \\
\text { of deeper water } \\
(>5 \mathrm{~m})\end{array}$ & Regular (every winter) & Long (1-3 mo) & High $(>60 \%)$ & $\begin{array}{c}\text { Kemp's ridley, } \\
\text { loggerhead }\end{array}$ & $\begin{array}{l}\text { Long Island Sound, NY } \\
\text { (Meylan and Sadove, } \\
\text { 1986; Morreale et al., } \\
\text { 1992; Gerle et al., 2000), } \\
\text { Cape Cod Bay. MA (Still et } \\
\text { al., 2002; Still et al., 2003) }\end{array}$ \\
\hline
\end{tabular}

FIGURE 3. A comparison of acute and chronic sea turtle cold-stunning events in the U.S. (Foley et al. 2007). 
These events usually have low mortality rates when animals are quickly rescued and rehabilitated. Due to a very specific set of atmospheric parameters necessary to produce a cold snap that could cause a hypothermic stunning event, both acute and chronic events are typically confined to small, distinct areas (Foley et al. 2207; Witherington and Ehrhart 1989).

Schwartz (1978) was among the first to define sea turtle survival rates in critically low water temperatures. Using a controlled setting where three species of sea turtles were exposed to frigid temperatures, he defined a condition he called the floater stage in which a sea turtle's carapace was exposed at the surface and the animal was no longer able to dive efficiently. In this stage, sea turtles also experience labored breathing and difficulty swimming or balancing (Schwartz 1978). For green turtles in particular, the floating stage occurred at $9^{\circ} \mathrm{C}$ with symptoms of cold-stunning such as lethargy present at $10^{\circ} \mathrm{C}$. Temperatures between 5 and $6^{\circ} \mathrm{C}$ were recorded as lethal for green turtles (Schwartz 1978). Schwartz (1978) also noted very little difference in terms of mortality rates between acute and chronic cold-stunning events, stating that a slower lowering of water temperature would kill just as rapidly as an abrupt or prolonged cold snap.

\subsubsection{Winter Freezes in Florida}

While rare, particularly farther south in Florida, significant freezes can have a major impact on living organisms. Freezes have even been severe enough during particularly harsh winters to cause extensive damage to citrus and other crops, coral reefs, and marine life. Table two shows that, from the late 1800s through the 1900s, many significant freeze events have impacted Florida with some being more influential than others (Henry et al. 1994). These freeze events may only last one day yet still inflict 
serious damage. Many factors contribute to a cold snap including air temperature, wind speed, solar radiation, pressure, and cloud cover. The passing of a cold front can bring freezing air temperatures, which creates a drop in water temperatures since the atmosphere and ocean are intimately related. Seawater temperatures in shallow bays and inlets can rapidly plummet below the lethal limit for many marine organisms during prolonged periods of extreme cold weather (Colella et al. 2012).

TABLE 2. Significant Florida Impact Freezes (Henry et al. 2004)

\begin{tabular}{llll}
\hline Freeze Event & $\begin{array}{l}\text { Tallahassee } \\
\left({ }^{\circ} \mathbf{C}\right)\end{array}$ & $\begin{array}{l}\text { Avon Park } \\
\left({ }^{\circ} \mathbf{C}\right)\end{array}$ & $\begin{array}{l}\text { Fort Myers } \\
\left({ }^{\circ} \mathbf{C}\right)\end{array}$ \\
\hline December 1894 & -9 & -4 & -2 \\
February 1899 & -18 & NA & NA \\
December 1934 & -6 & -6 & -1 \\
January 1940 & -9 & -3 & -1 \\
December 1962 & -6 & -4 & -2 \\
January 1977 & -8 & -6 & -1 \\
January 1981 & -13 & -7 & -2 \\
January 1982 & -10 & -7 & -1 \\
December 1983 & -10 & -5 & .5 \\
January 1985 & -14 & -6 & -1 \\
December 1989 & -10 & -6 & -2 \\
January 1997 & -7 & -4 & NA \\
\hline
\end{tabular}

What defines a winter cold snap is how quickly the air temperature drops and how low it drops (Roberts et al. 1982). For this research, the terms freeze and cold snap are used interchangeably. In Florida, there are two main methods by which temperatures fall below freezing: advection freezes and radiational freezes. These processes are complex and multi-dimensional. Charles Paxton, the Science and Operations Officer at the National Weather Service in Ruskin, FL provided the following overview of significant Florida freeze scenarios. Under high pressure, a nearly stationary and much colder than 
normal air mass develops in winter darkness of an Arctic source region. This cold air typically comes from regions such as Canada or Siberia, as steering currents amplify and become favorable to transport the frigid air mass southward into the United States (personal communication, Charles Paxton, March 2012). This transport of Arctic air into the state is known as an advection freeze and may persist under strong northerly surface winds for several days. Larger winter storms associated with low pressure typically developing near the land and ocean interface may also rapidly advect cold air into Florida (Winsberg et al. 2003). The clash of continental and maritime air masses is the primary means that winter storms obtain their energy (Hidore et al. 2010). Surface wind speeds may reach 40 miles per hour during the initiation of advection freezes (Roberts et al. 1982). The two jet streams that have the most impact on Florida are the polar and the subtropical. The polar front jet, which changes position depending on the season, is responsible for guiding cold air masses into Florida as the typical, west to east orientation dips south in the winter. When this wavy pattern occurs, a colder period can be expected in Florida. If the dip is very pronounced and associated with a frigid air mass, cities as far south as Miami may have freezing conditions. To the south, the subtropical jet stream may work in tandem with the polar jet to bring cold air masses into Florida but does not undulate as much as the polar front jet (Henry et al. 1994). Therefore, the subtropical jet has less influence on a winter cold snap in Florida. Often times when the most frigid of cold snaps occur it is because the two mechanisms of freezes are acting in tandem. The southward displacement of a cold air mass can occur very swiftly and can reach Florida over a period of several days (Mogil and Seaman 2008). If the United States has already experienced a snow-covered winter that air mass movement can occur on a faster 
timescale but, more importantly, the air mass will warm less over the snow-covered area. Northwestern Florida receives the full impact of the cold air displacement before it descends to the rest of the state (NOAA Weatherwise 2010).

As the advected cold air settles over the state and winds lessen, heat gained during the day will be radiated at night leading to subsequent "radiation freezes". The radiation freezes may be affected by areas of moisture; typically in the form of clouds. Clouds will act as a barrier to radiational cooling and keep temperatures warmer (Henry et al. 1994). Temperatures near the ground that are just above freezing may produce a frost that kills vegetation.

\subsubsection{Winter Cold Snap of 2010}

A severe cold snap in the winter of 2010 had damaging results across the U.S. Florida, in particular, experienced record-breaking cold temperatures not seen for many decades. However, the most remarkable characteristic of this winter was not its record low temperatures but its unusual duration. Much of central and northern Florida experienced below freezing temperatures for 12 days and inshore water temperatures dropped below $10^{\circ} \mathrm{C}$ for ten consecutive days (Foley et al. 2012). This rare climatic episode was associated with negative values of the North Atlantic Oscillation (NAO) index that created rapid southward advection of cold arctic air and northerly surface wind anomalies (Lirman et al. 2011). Similar low NAO anomaly values, around -4, were seen in other years with harsh winters as well.

In a statement released by the National Weather Service of Miami, meteorologists observed "a blocking pattern in the middle and upper levels of the atmosphere allowed for a continued flow of arctic air to sweep across the eastern half of the country" (NWS 
2010, Figure 4). The first cold wave did not arrive until early January when two arctic cold fronts moved into Florida. Multiple daily low temperature records were broken and/or tied during this event (NWS 2010). Areas such as Gainesville and Apalachicola experienced air temperatures below $-3^{\circ} \mathrm{C}$. Frozen precipitation was seen across central Florida around the third week in January (NOAA Weatherwise 2010). A record in Florida was set for the number of successive freezes in a single month, an event that has not occurred in the state since the 1960s. Tallahassee recorded 14 freezes in January alone (NOAA Weatherwise 2010). This record cold event took a huge toll on the crops and tropical plants of Florida. Over $\$ 500$ million was lost in crop damage (NWS 2010). May coral reef systems in Florida were also heavily impacted as many tropical reef taxa were exposed to water temperatures well below their reported thresholds of $16^{\circ} \mathrm{C}$, resulting in rapid coral declines of unprecedented severity (Lirman et al. 2011; Colella et al. 2012). For the Florida Reef Tract (FRT), the winter of 2010 was one of the most destructive on record and long term impacts will likely take years to fully ascertain (Lirman et al. 2011). These conditions persisted into a chaotic February. Charles Paxton commented that storm systems were carried by an active subtropical jet stream all across the country (personal communication, March 15, 2012). On February 12, 2010, a news report released from New York was entitled "Color America White." On this day, 49 of 50 states had snow on the ground. Hawaii was the only state that managed to avoid the rare and intriguing winter of 2010 (NY Daily News 2010). 


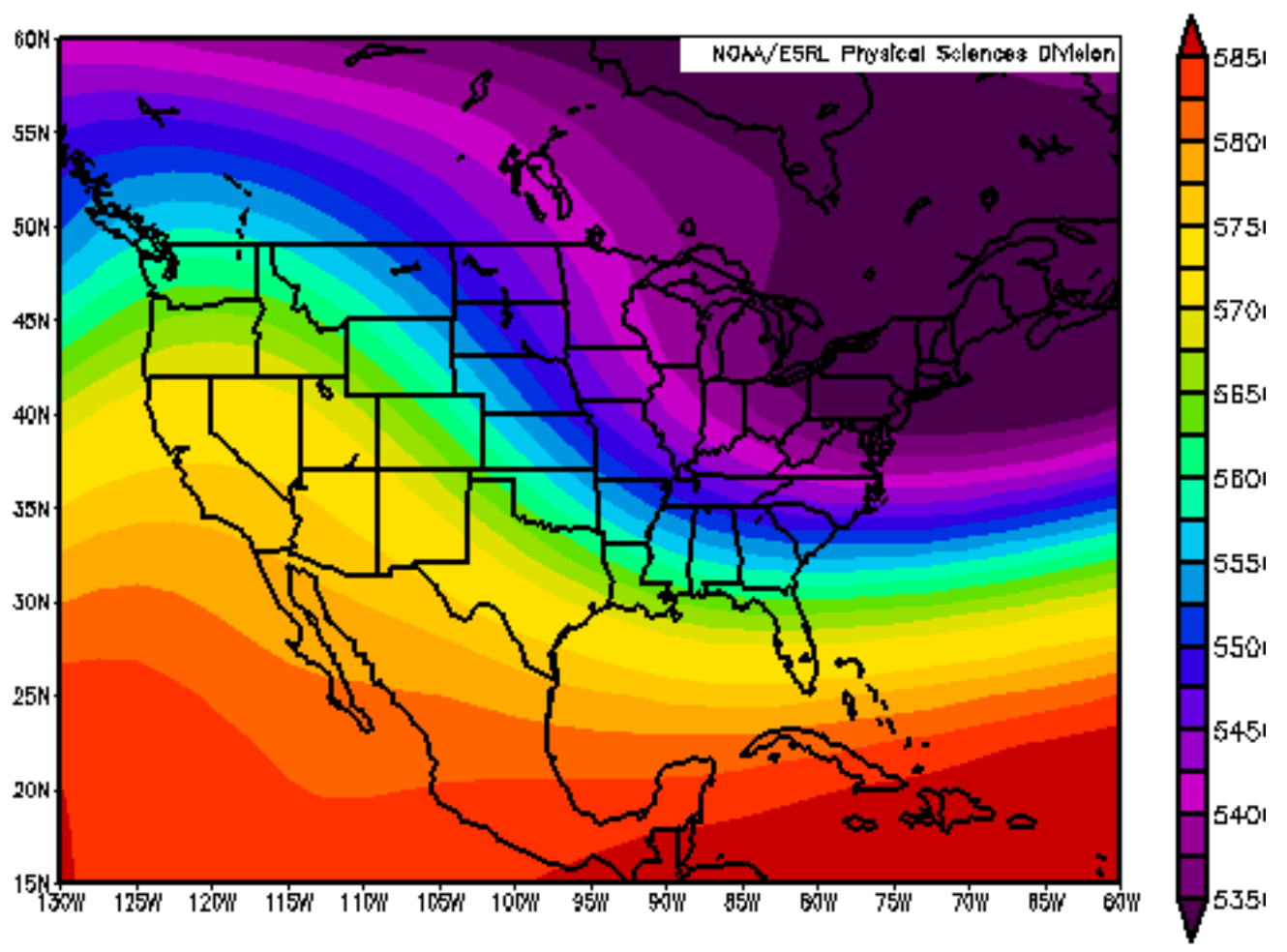

FIGURE 4. Mean geopotential height plot of U.S. for January 1-10, 2010. Map depicts mean 500 millibar (mb) heights. "Deep low pressure over NE U.S. and high pressure over the western U.S. provided a steady NW steering flow over the central and eastern U.S., including Florida" (NWS 2010).

\subsubsection{Cold Stun Event}

The severe weather conditions in January of 2010 caused an unprecedented coldstunning event in Florida. During the first two weeks of this month, approximately 5000 sea turtles, primarily juvenile greens, cold-stunned and stranded (Avens et al. 2012). This is a magnitude ten times greater than the last hypothermic stunning event of 2001, where over 400 sea turtles were found in St. Joseph Bay (Foley et al. 2007). The majority of individual turtles represented in the 2001 event were neritic juvenile green turtles (Foley et al. 2007). Green turtles comprised about $95 \%$ of the species represented in the 2010 event. Loggerheads, Kemp's ridleys, and hawksbills were also found (Foley et al. 2012). St. Joseph Bay in the Florida panhandle was the focus of this mass stunning event. While 
cold stun events have previously occurred here in the past, none have reached the magnitude of 2010 (Belskis et al. 2012). Mosquito Lagoon on the Atlantic coast also experienced an extensive duration of cold-water temperatures and over 2000 marine turtles cold-stunned in this area (Provancha et al. 2012).

The severity of the 2010 event can be directly related to the minimum water temperatures recorded in St. Joseph Bay and Mosquito Lagoon as well as the length of the event and exposure times. Most cold stunned turtles, approximately $83 \%$, were still alive when rescued and required immediate rehabilitation (Foley et al. 2012). The Florida Sea Turtle Stranding and Salvage Network responded immediately, but the number of cold stunned turtles exceeded available space in nearby primary sea turtle rehabilitation facilities. The animals were sent to rehabilitation centers all across the state, where room was available to effectively care for them. The majority of sea turtles rescued that winter were later released, resulting in only a 22\% mortality rate for Mosquito Lagoon and 20\% mortality rate for St. Joseph Bay for this hypothermic stunning event (Avens et al. 2012; Provancha et al. 2012).

Florida's Sea Turtle Stranding and Salvage Network (STSSN) participants did not anticipate the large number of debilitated turtles placed in their care. Further complicating planning and response, was the uncertainty surrounding the time that water temperatures would remain below 10 degrees. Because of this concern, many turtles were released further south from the location they were found. The STSSN selected these release locations with warmer waters by examining sea surface temperatures and distance from the shore (Provancha et al. 2012). Robert Hardy, a biological scientist at the Florida Fish and Wildlife Research Institute (FWRI), states that it is rarely advisable to relocate 
individuals; however it was necessary due to the fact that primary rehabilitation facilities were at capacity and turtles were continuing to cold-stun in St. Joseph Bay and Mosquito Lagoon (personal communication, October 2013). While this event did provide valuable insight from an ecological and population perspective, climate constraints and the lifethreatening condition of most turtles did not allow for a wide array of sampling possibilities typical of most sea turtle research projects (Provancha et al. 2012).

\subsection{Problem Statement}

The cold snap of January 2010 resulted in unparalleled frigid temperatures all across the country. As the cold air invaded Florida, water temperatures plunged below the tolerable limit for many marine organisms, particularly sea turtles. A water temperature value of $10^{\circ} \mathrm{C}$ was declared as the threshold for the green turtle to exhibit symptoms of thermal stress hypothermia, or cold stunning. A severe cold-stun event can result in a mass stranding event, during which incapacitated turtles float at the surface or wash up onshore, dependent on sea turtle rescue groups for rehabilitation. This condition, if left untreated, can be fatal.

The purpose of this study is to analyze synoptic weather patterns associated with documented cold-stunning events that caused extensive chaos to the green turtle population of Florida and the agencies designated to respond to stranded sea turtles. By highlighting specific atmospheric patterns and processes associated with past events, rescue groups and rehabilitation facilities can recognize the potential onset of a future event and increase their preparedness. The mass hypothermic stunning event of 2010 received substantial media attention although research has not yet attempted to define the incident meteorologically. The proposed research fills this need by examining air 
temperature, water temperature and wind data in two locations in Florida during the duration of selected cold-stun event years.

Substantial problems exist in terms of data availability (discussed further in section 5.1). Consistent water temperature data for both study sites was unavailable prior to 2004. Inferences were be made in regard to water temperature by analyzing air temperature and wind speed for selected years preceding 2004. In addition, a buoy associated with the accessible National Data Buoy Center (NDBC) has not been deployed in St. Joseph Bay, although there is considerable need for one. Therefore, all atmospheric data was obtained from nearby a site Apalachicola, which is most representative of the sea surface temperature of St. Joseph Bay.

\subsection{Objectives and Research Questions}

The objectives of this study are listed as follows:

1. Prepare an observed hypothermic stunning event data set of dates, species and location obtained from the Florida Fish and Wildlife Research Institute reports for all available years

2. Analyze the weather patterns and water conditions of the two locations in Florida (St. Joseph Bay and Mosquito Lagoon)

3. Graphically depict atmospheric parameters (air temperature, water temperature, wind speed and wind direction) for January 2010 and other notable events along with sea turtle cold-stun numbers for selected years

4. Communicate and seek feedback on the results from FWC, Mote Marine and NWS and contribute to the future development of a predictive model to forecast sea turtle cold-stunning events 
The results of this study addressed the following questions:

1. How do weather patterns evolve over the northern hemisphere during a hypothermic stunning event?

2. What is the phase of the Arctic Oscillation and North Atlantic Oscillation associated with observed hypothermic stunning events?

3. What is the evolution of the cold air mass that creates the event?

4. What are the air and water temperature trends observed during hypothermic stunning events?

5. What are the wind direction and speed trends observed during a hypothermic stunning event?

6. Can a determination be made with respect to differences in the meteorological progression of what is categorized as a low, moderate and high hypothermic stunning events? 


\section{Chapter 2: $\quad$ Methodology}

\subsection{Study Area}

The two locations in Florida that were analyzed for this study are St. Joseph Bay on the Gulf coast and Mosquito Lagoon on the Atlantic coast (Figure 5).

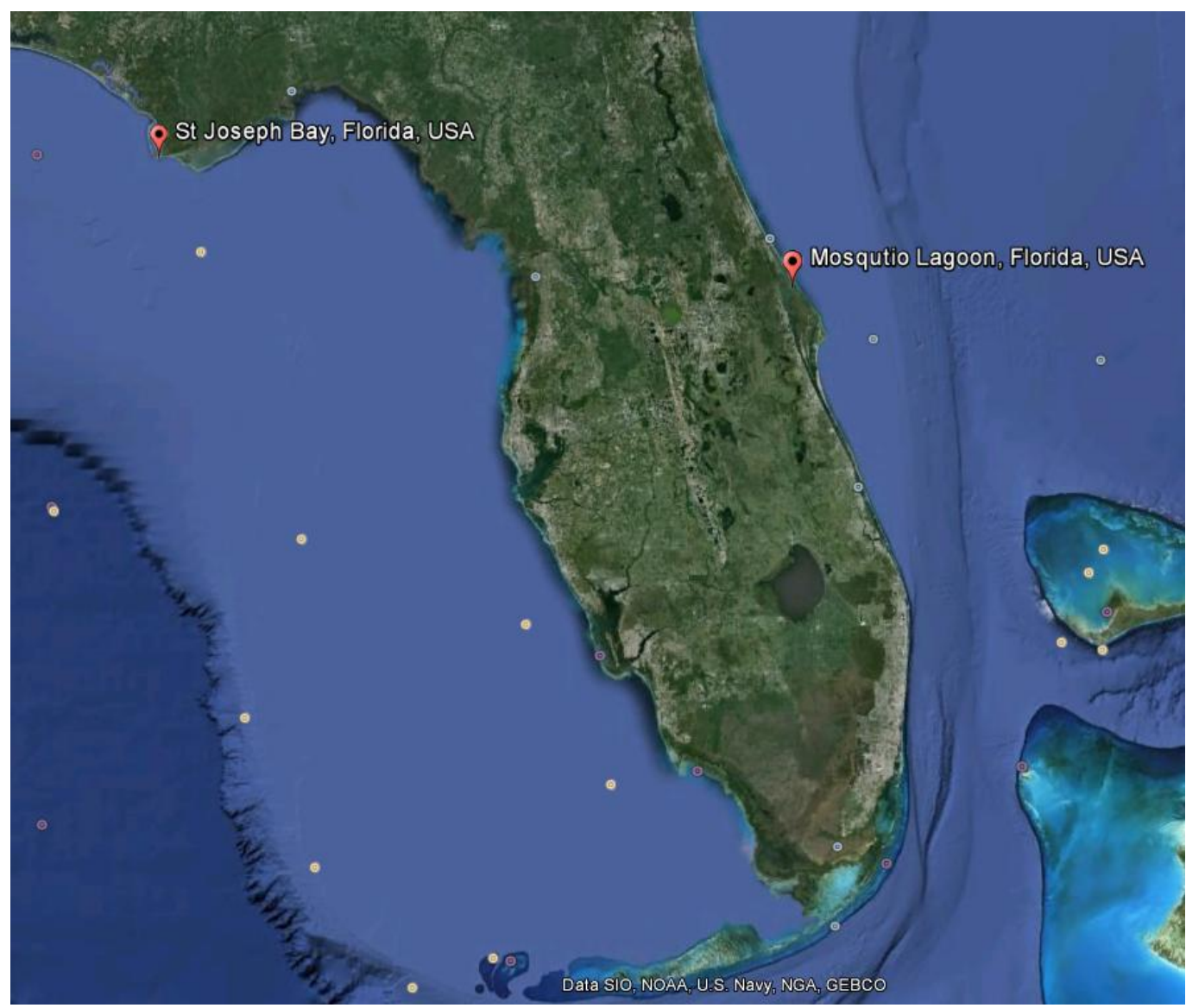

FIGURE 5. Location of two study areas: St. Joseph Bay and Mosquito Lagoon, Florida (Google Earth Imagery) 

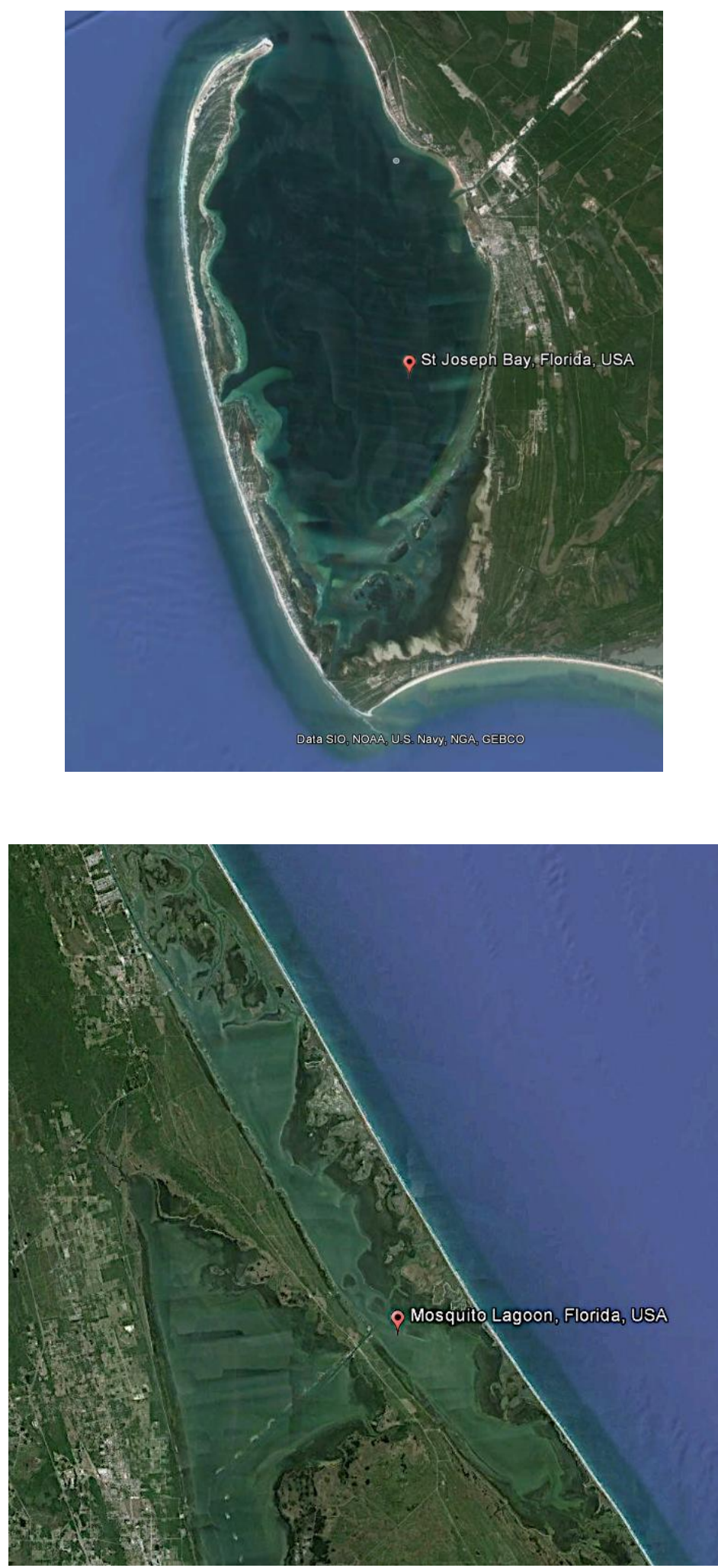

FIGURE 6. Magnified images of St. Joseph Bay and Mosquito Lagoon, Florida (Google Earth Imagery) 
The food-rich habitats of St. Joseph Bay and Mosquito Lagoon are critical for green turtle developmental stages (Still et al. 2005). Both these locations contain extensive seagrass beds and are therefore visited frequently by many sea turtle species. Cold stun events have occurred in these two areas due to their unique topography and configuration (Witherington and Ehrhart 1989). They are shallow water environments with an average depth of only 1.5 meters with no readily accessible exit. In Mosquito Lagoon and St. Joseph Bay, the only exit is to the north (Figure 6). A large hook of land surrounds St. Joseph Bay and the only opening to the Gulf of Mexico is located to the far northwest (Belskis et al. 2012; Figure 6). Ponce Inlet and Haulover Canal are the only exits in Mosquito Lagoon. These waters cool quite rapidly when exposed to a cold front. It is likely that the animals become trapped when attempting to travel south when water temperatures drop below their tolerable limit of $10^{\circ} \mathrm{C}$ (Foley et al. 2007). The marine turtle research team at the Fish and Wildlife Research Institute (FWRI) in St. Petersburg has divided St. Joseph Bay into search areas for minor, moderate or severe events since the 2010 cold-stun event (Figure 7). Currently, St. Joseph Bay and Mosquito Lagoon are granted some level of environmental protection by way of establishment of state parks or national wildlife refuge by the EPA. However, sea grass beds in both locations have accrued severe damage by human activity, primarily boat propellers (Foley et al. 2007). 


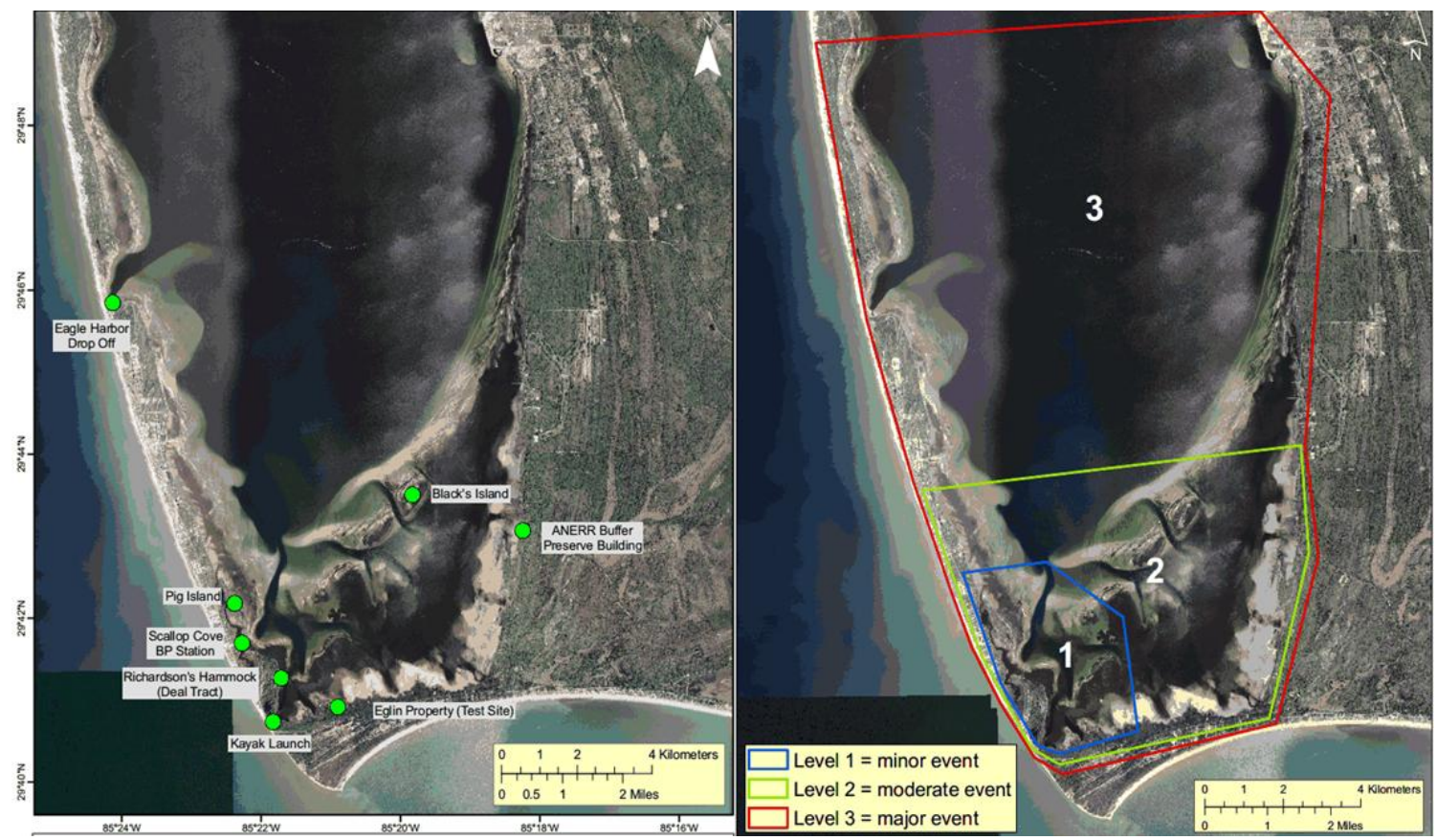

FIGURE 7. Detailed map of cold stun sea turtle search areas in St. Joseph Bay, FL study area (FWC_FWRI Marine Turtle Research)

\section{$2.2 \quad$ Data}

\subsubsection{Sea Turtle Data}

A data set was obtained from the Florida Fish and Wildlife Research Institute (FWRI) in St. Petersburg, FL on the January 2010 mass hypothermic stunning event as well as significant past events. This data is divided into east coast and west coast strandings and contains the following information: date, species and general location. The 2010 cold stunning event is the only one considered in this study for Mosquito Lagoon (east coast set) while events for St. Joseph Bay (west coast set) are documented back to 2001. As there is no way of approximating the number of individual turtles within each location prior to a cold stunning event, this data was used with the resulting atmospheric data to compare and contrast the years designated as low, moderate, or severe (high) cold stunning events (Table 3). These categories were chosen arbitrarily as it was the most feasible and inclusive way of analyzing the data. A severe or high magnitude event was 
categorized as such if over 200 marine turtles are documented as cold stunned. If 30-200 turtles are documented, it was categorized as a moderate event and fewer than 30 turtles was designated as a low event. Sea turtle cold stun records are inconsistent for Florida due to the fact that the numbers are dependent on the resources and personnel available during a rescue initiative.

TABLE 3. Date and corresponding magnitude event for St. Joseph Bay, Florida (FWC_FWRI Marine Turtle Research)

\begin{tabular}{lc}
\hline \multicolumn{1}{c}{ Date } & Magnitude \\
\hline January 1-12, 2001 & High \\
January 25-27, 2003 & Moderate \\
January 11, 2004 & Low \\
December 29, 2005 & Low \\
January 3-23, 2008 & Moderate \\
January 21-22, 2009 & Low \\
January 7-14, 2010 & High \\
January 14-16 and 22-29, 2011 & Low \\
\hline
\end{tabular}

\subsubsection{Atmospheric Data}

In order to provide the most comprehensive assessment of the parameters associated with a hypothermic stunning event in Florida, atmospheric data was obtained through many different sources. Water temperature data for Mosquito Lagoon were acquired from the U.S. Geological Survey (USGS) Haulover Canal Station. A thermometer at this site records temperature every 15 minutes and is available from 2004 to present (Figure 8). Air temperature and wind data, both direction and speed, for Mosquito Lagoon were acquired through a NDBC buoy near Cape Canaveral, with historical data available from 2006-2012 (Figure 9). 


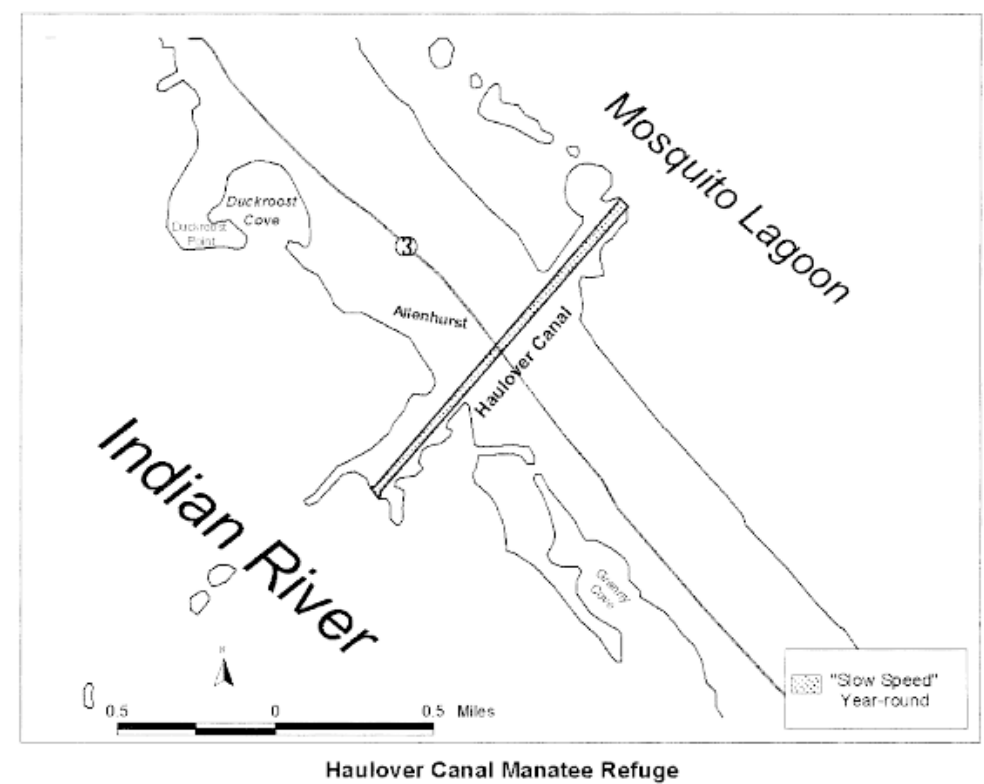

FIGURE 8. Location of Haulover Canal in relation to Mosquito Lagoon, Florida. (http://www.law.cornell.edu/cfr/text/50/17.108)

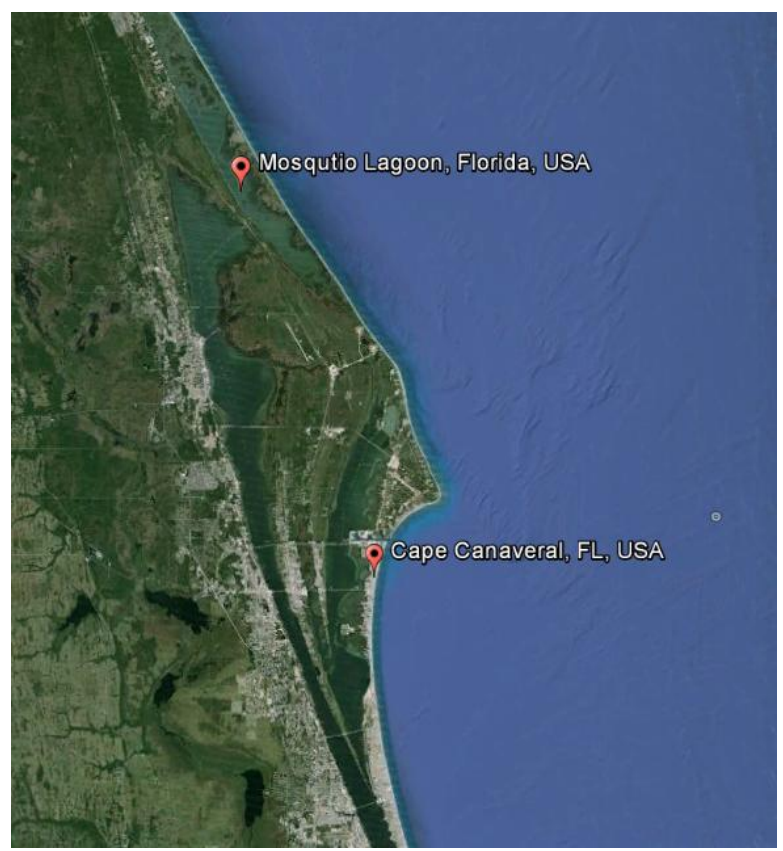

FIGURE 9. Location of Cape Canaveral in relation to Mosquito Lagoon, Florida (Google Earth Imagery)

Acquiring atmospheric data pertaining to St. Joseph Bay proved challenging. The NDBC has yet to deploy a buoy in or adjacent to the bay. Apalachicola is approximately 30 miles east of Port St. Joseph and contains a buoy situated in a shallow environment. 
As the landscape and configuration is similar to St. Joseph Bay, the Apalachicola buoy was utilized to represent the bay for this study (Figure 10). This site records air temperature, water temperature and wind parameters every six minutes and contains historical data back to 2005. As several hypothermic stunning events were documented in St. Joseph Bay prior to 2005, weather data was obtained from Cape San Blas, a peninsula separating St. Joseph Bay and the Gulf of Mexico (Figure 11). This site does not document water temperature and was therefore only utilized for air temperature and wind speed records for the years 2001 and 2003.

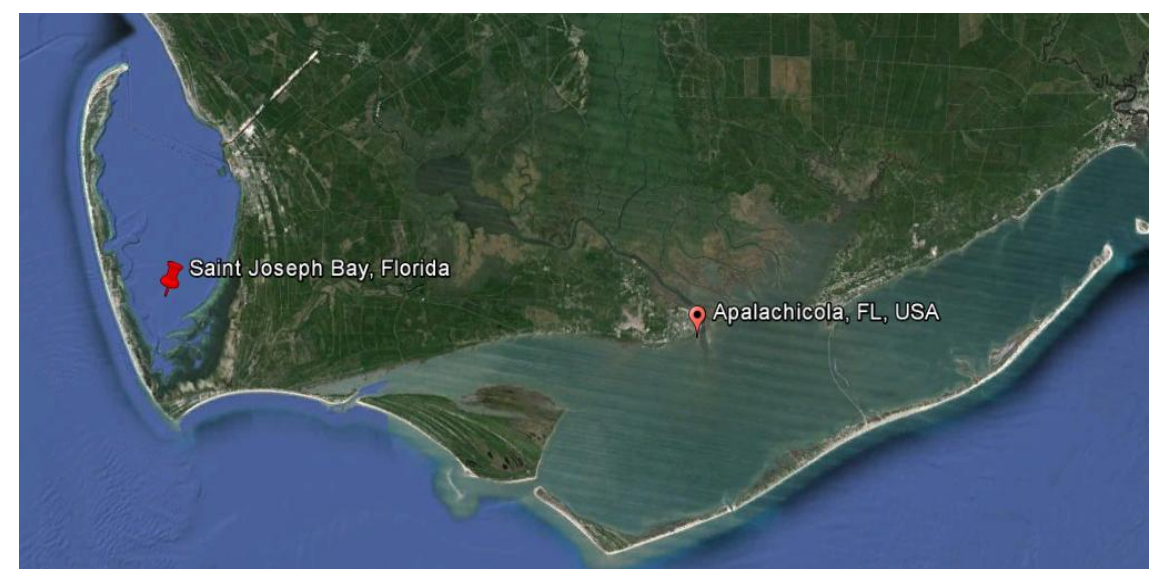

FIGURE 10. Location of Apalachicola in relation to St. Joseph Bay, Florida (Google Earth Imagery)

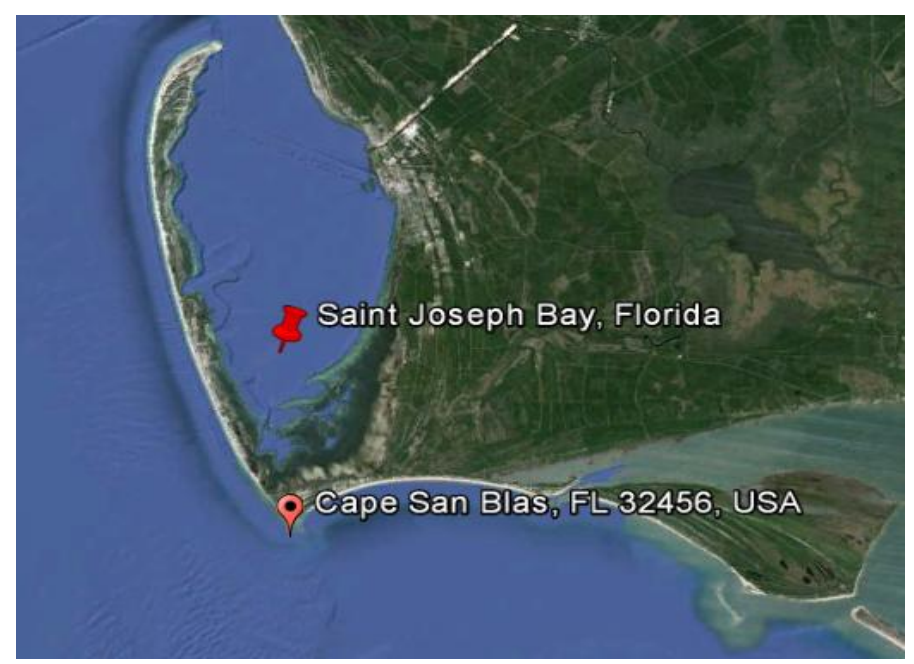

FIGURE 11. Location of Cape San Blas in relation to St. Joseph Bay, Florida (Google Earth Imagery) 


\subsection{Analysis}

\subsubsection{Weather Parameter Graphs}

All atmospheric data was converted into an Excel file. Spreadsheets were separated by year and location. The mass hypothermic stunning event of 2010 was the only one analyzed for Mosquito Lagoon as no other recent events are documented for this location. Stunning events categorized as either moderate or high in St. Joseph Bay were selected for analysis. These occurred in January of 2001, 2003, 2008, and 2010. December 2009 was examined as well to better comprehend the weather patterns associated with the January 2010 severe cold-stun event. Air temperature was included both as a minimum and average value per a 24 hour time period. Water temperature, both minimum and average values, was accessible and consistent for 2009 Apalachicola (St. Joseph Bay), 2010 Apalachicola (St. Joseph Bay) and 2010 Haulover Canal (Mosquito Lagoon) only. Wind speed was incorporated into the analysis as an average value per a 24-hour time period. Surface wind direction was categorized into one of four quadrants after calculating the mode, most frequent, direction per a 24 hour time period (Figure 12). This parameter was depicted as wind vector arrows with a corresponding value for wind speed.
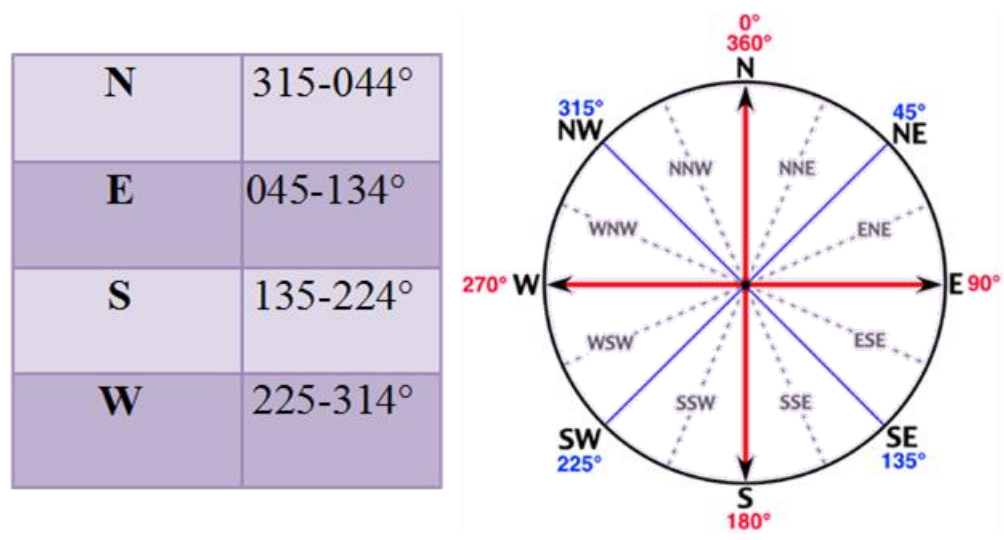

Figure 12. Wind direction categories. 
Graphs were generated using Microsoft Excel and Adobe Illustrated to depict weather parameters defining each cold stunning event. A bold red line at the threshold value of $10^{\circ} \mathrm{C}$ can be seen on select graphs, indicating how far water temperature fell below this value and, importantly, how long it remained below the threshold value. Additionally, using the cold stun data set retrieved from FWC_FWRI, a bar graph depicting the number of individual turtles stunned per day of each event was over-laid onto one weather parameter graph per location and year. This graph was also replicated using the same turtle count scale for the 2010 event in Mosquito Lagoon to indicate the varying scales and severity of selected event years. This demonstrates the negative impact that a particularly harsh winter can have on Florida green turtle populations. Each graph for the selected events was evaluated to determine why certain years were classified as moderate or high magnitude for green turtle cold-stun events.

\subsubsection{Arctic and North Atlantic Oscillations}

Graphs were also created illustrating the fluctuations between negative and positive phases of the North Atlantic Oscillation (NAO) and the Arctic Oscillation (AO) during a specified time period. The NAO and AO are typically highly correlated but have distinct differences (Ambaum et al. 2001). The NAO and AO indexes flip between two separate modes, positive and negative, that can indicate a shift in atmospheric circulation (Baldwin and Dunkerton, 1999). A negative phase AO, and often a negative phase NAO, is associated with an increased likelihood of Arctic cold air maneuvering into the eastern U.S. If the eastern U.S. experiences a mild winter, it is likely due to a positive phase NAO (Henson and Gallon, 2011). One notable difference between the two is the NAO reveals parallels between variability in surface pressure whereas the AO does not 
(Ambaum et al. 2001). These two indexes have yet to be considered as influential processes that could contribute to a sea turtle cold-stunning event. A daily NAO and AO index value data set was obtained from the Climate Prediction Center website. A daily index value corresponds to patterns specific to each oscillation. While this data set records a daily index value from 1950 to 2013 for both oscillations, only 2000-2013 was examined for this study. An analysis of each graph produced will illustrate the phase of each oscillation during a hypothermic stunning event.

\subsubsection{NCEP Reanalysis Data Composites}

Data composites were generated using NCEP Reanalysis Data from the Earth System Research Laboratory web interface. The NCEP/NCAR Reanalysis project is a joint effort between the National Centers for Environmental Protection and the National Center for Atmospheric Research. By using historical data, 1948 - present, new atmospheric analyses can be constructed for both past and present atmospheric states through this data assimilation system. By entering the specific day of a severe hypothermic stunning event and then viewing several days prior to the event, it can be determined where individual parameters originated and precursor patterns can be examined. NCEP/NCAR Reanalysis maps were created for the duration of the cold stun event for the following severe event years: 2001 and 2010. A moderate event year, 2003, was also included for comparison purposes. The variables air temperature and vector winds were analyzed for anomaly plot types. Sea surface temperature was inconsistent for the selected years and could therefore not be included. The differences between the magnitude days were documented as well as any major departures from the average. 


\subsubsection{NDBC and FWRI Temperature Data Comparison}

Additionally, a comparison was drawn between recent data collected from a sensor deployed by FWRI in St. Joseph Bay to NDBC's Apalachicola buoy, where archived data was obtained for this research, to determine whether or not Apalachicola was an adequate proxy for St. Joseph Bay. Water temperature data was collected in St. Joseph Bay by a sensor during January and February of 2012 at 5 minute intervals. Gaps exist in both records, most likely due to satellite interruption or corrupt data. Average water temperature values for a 24-hour period were calculated for both, followed by the difference between the two values per day.

\subsubsection{Standard Event Pattern Composites}

After receiving feedback from community partners, the results were used to develop a basic sea turtle cold-stun event composite. This composite was generated using NCEP Reanalysis for surface air temperature anomaly and a 500 millibar (mb) geopotential height mean on 'high magnitude days'. Geopotential height is the height of a pressure level above mean sea level. These values naturally decrease from the equator to the poles (personal communication, Charles Paxton, September 2013). High magnitude days are those in which a considerable number of marine turtles, $80+$, were rescued from hypothermic stunning. The following dates were selected to generate a forecasting paradigm: January 9, 11-13, 2010 and January 3-4, 2001.These days were identified from the cold stun event data set obtained from FWC/FWRI. The composite weather patterns will serve as analogs for future forecasts for mass cold-stunning events. 


\section{Chapter 3: Results}

\subsection{Weather Parameter Graphs}

The graphs produced for selected cold-stun event years proved very telling in terms of the effect atmospheric variables have on shaping a moderate or severe green turtle stunning event. Graphs were analyzed in the following order: 2001, 2003, 2008, and 2009/2010.

\section{St. Joseph Bay}

A severe hypothermic stunning event occurred from January $1^{\text {st }}$ until January $12^{\text {th }}$, with over 400 marine turtles involved. Minimum air temperature dropped into the negatives on January $2^{\text {nd }}$ and $3^{\text {rd }}$, and again on the $10^{\text {th }}$ (Figure 13). Turtles were rescued beginning on the $1^{\text {st }}$, with the majority $(\mathrm{N}=238 ; 60 \%)$ cold-stunning between the $2^{\text {nd }}$ and $5^{\text {th }}$ (Figure 14). Minimum air temperature steadily rose to $12.7^{\circ} \mathrm{C}$ on January $8^{\text {th }}$. Between the $6^{\text {th }}$ and $9^{\text {th }}, 88$ turtles were rescued. Most likely this number is attributed to still intolerable water temperatures, even though air temperature was increasing during those few days. Minimum temperature fell again to $-1{ }^{\circ} \mathrm{C}$ on the $10^{\text {th }}$ and 32 turtles were recovered. Average air temperature demonstrated a similar pattern as the minimum value, although never dropping below $3^{\circ} \mathrm{C}$ and peaking on the $8^{\text {th }}$ at $15.3^{\circ} \mathrm{C}$ (Figure 15). Only 19 turtles were salvaged during the final two days of the event when air temperature, and likely water temperature, began escalating again. During the first four days of January, a northerly wind was present with wind speeds between 2.5 and $4.4 \mathrm{~ms}^{-1}$ (Figure 16). This 
pattern was also evident from the $8^{\text {th }}$ through the $10^{\text {th }}$. Wind speed peaked on the $8^{\text {th }}$ at 5.9 $\mathrm{ms}^{-1}$.

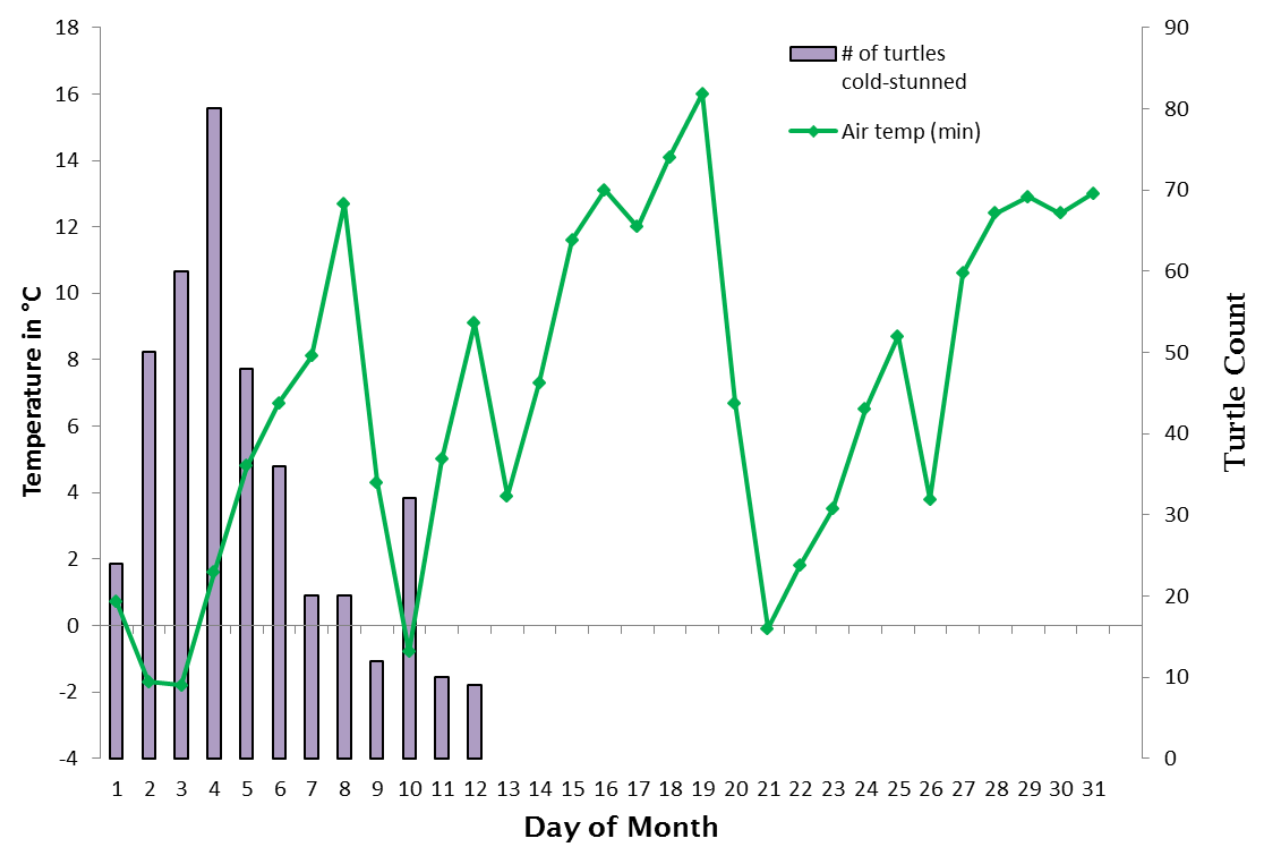

FIGURE 13. January 2001 St. Joseph Bay minimum air temperature with daily number of cold-stunned sea turtles that were rescued

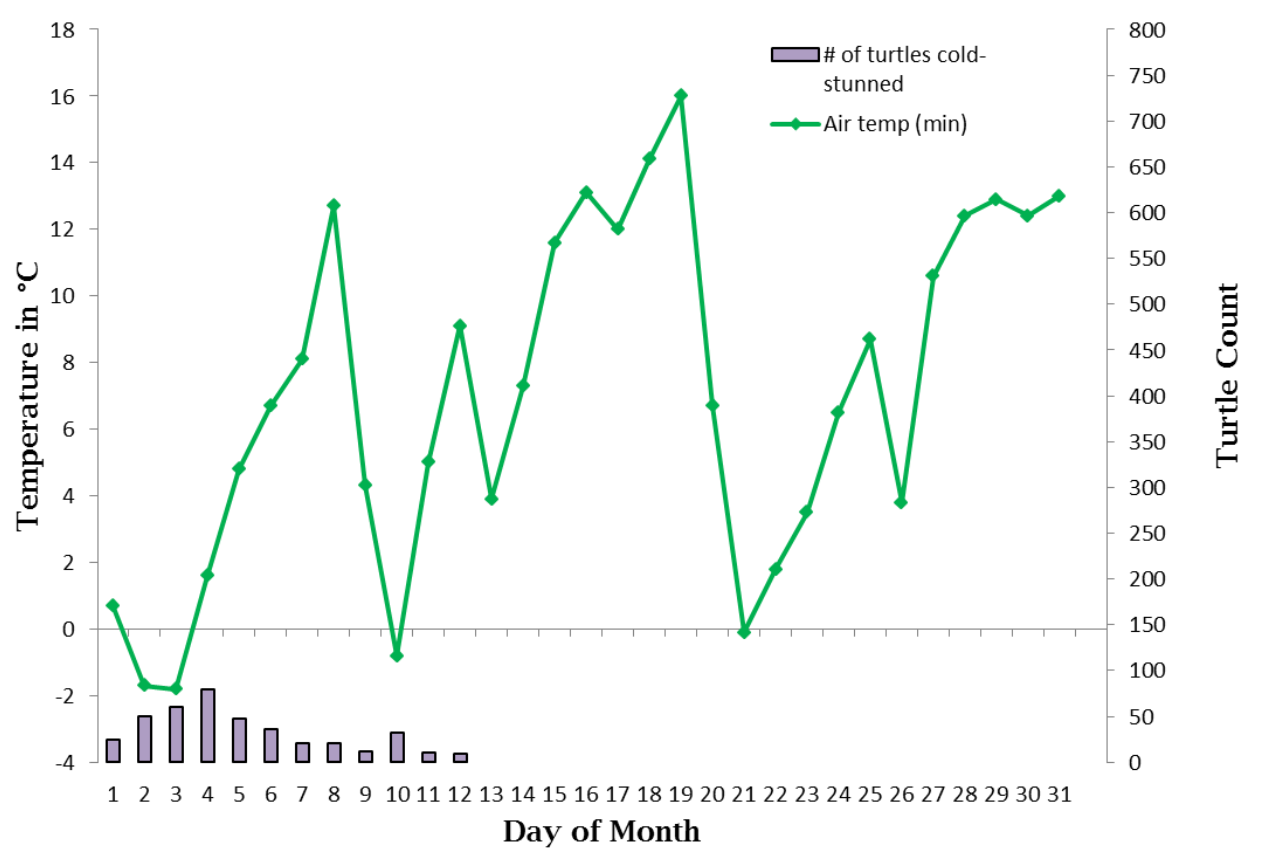

FIGURE 14. January 2001 St. Joseph Bay minimum air temperature with sea turtle coldstun numbers on maximum scale used for Mosquito Lagoon 2010 


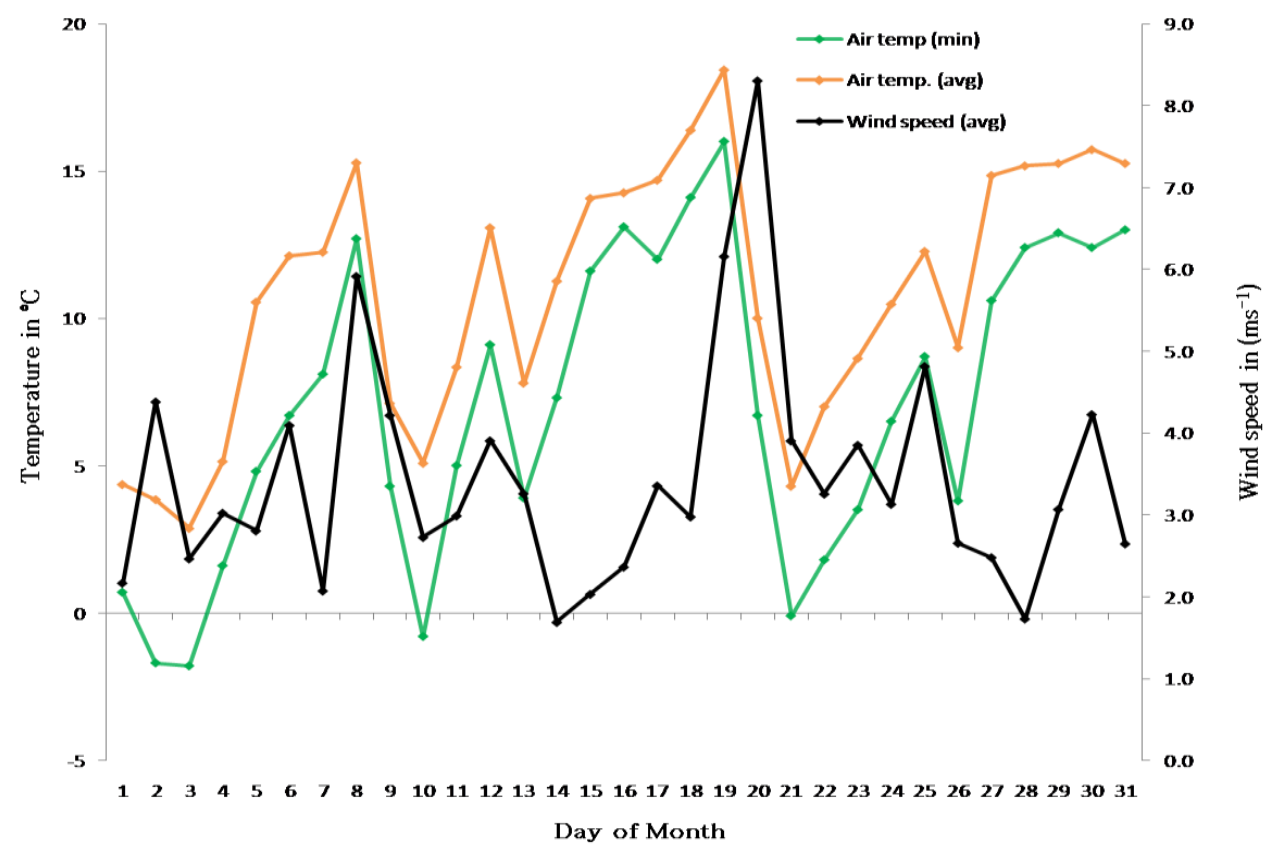

FIGURE 15. January 2001 St. Joseph Bay air temperature and wind speed

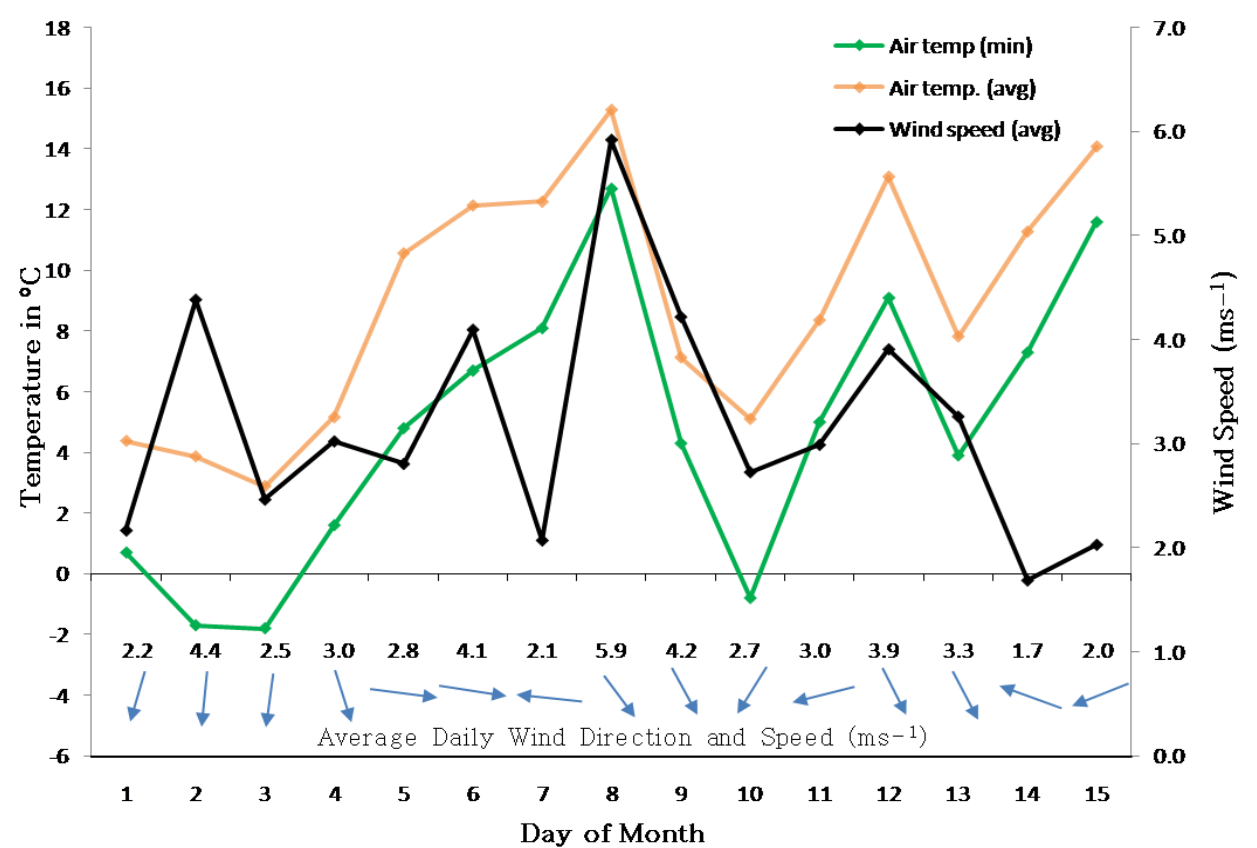

FIGURE 16. January 2001 St. Joseph Bay air temperature and wind data including surface vectors for the duration of the hypothermic stunning event 


\subsubsection{St. Joseph Bay}

A short, moderate hypothermic stunning event occurred between January $25^{\text {th }}$ and $27^{\text {th }}$. During this time period, 42 green turtles were found that exhibited symptoms of cold-stunning. An abrupt drop of over $20^{\circ} \mathrm{C}$ in air temperature between the $22^{\text {nd }}$ and $24^{\text {th }}$ is likely the cause of this event (Figure 17). Minimum air temperature reached $-5.9^{\circ} \mathrm{C}$ on the $24^{\text {th }}$, dropping from $16.3^{\circ} \mathrm{C}$ just two days prior. Twenty-two turtles were rescued on the $25^{\text {th }}, 18$ turtles on the $26^{\text {th }}$ and only 2 turtles on the $27^{\text {th }}$ (Figure 18 ). Minimum air temperature increased just as rapidly as it dropped and was already up to $6^{\circ} \mathrm{C}$ by the $27^{\text {th }}$. A variable pattern for both air temperature and wind speed is depicted on figure 19 throughout the month. Northerly winds defined the duration of this cold-stun event with relatively low wind speeds averaging around $2.8 \mathrm{~ms}^{-1}$ (Figure 20).

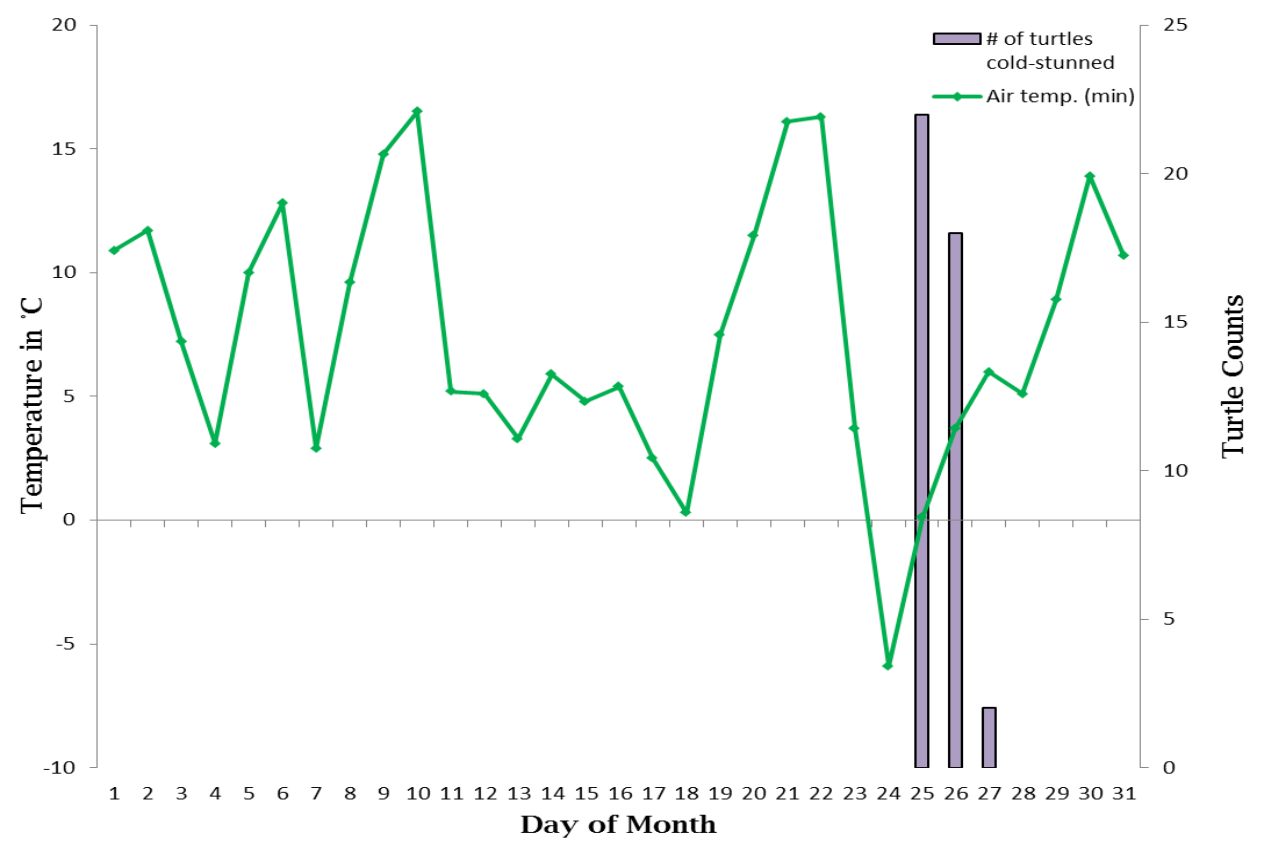

FIGURE 17. January 2003 St. Joseph Bay minimum air temperature with daily number of cold-stunned sea turtles that were rescued 


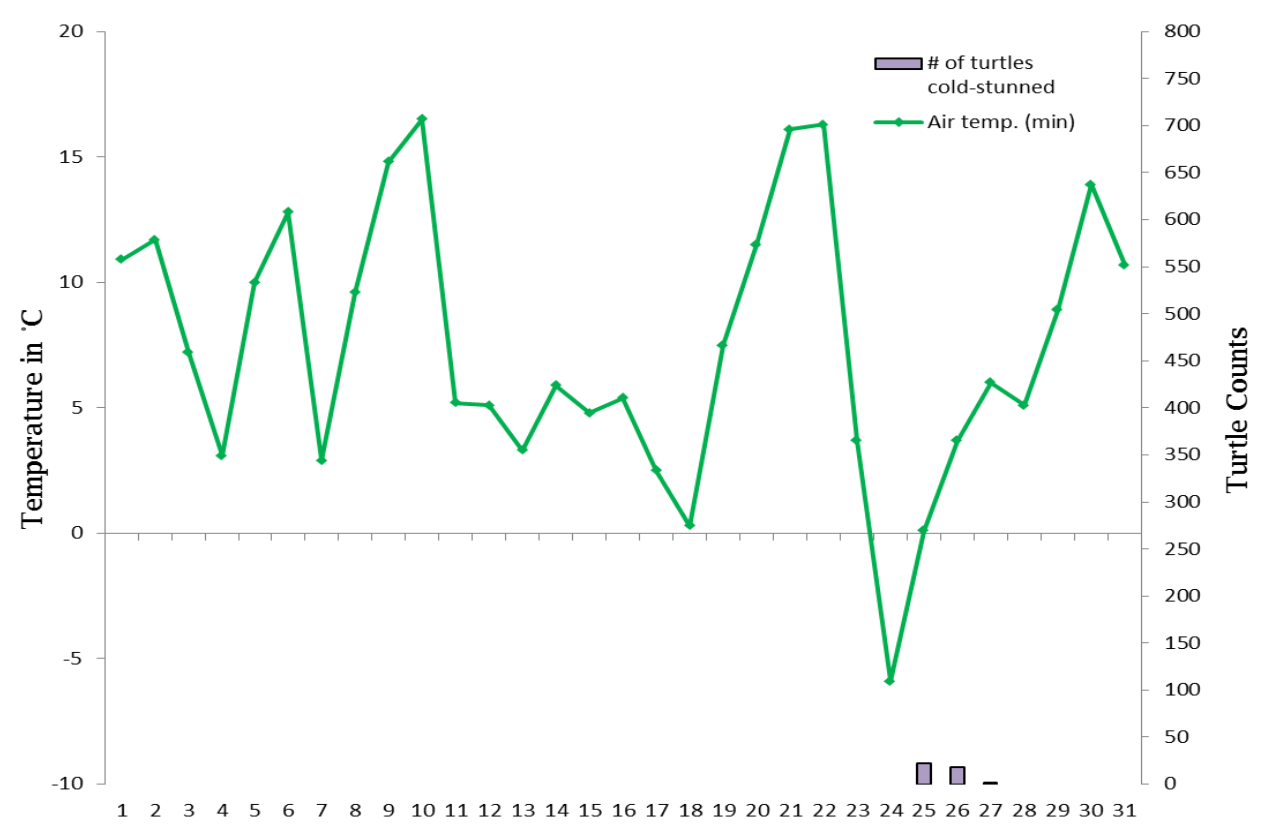

Day of Month

FIGURE 18. January 2003 St. Joseph Bay minimum air temperature with sea turtle coldstun numbers on maximum scale used for Mosquito Lagoon 2010

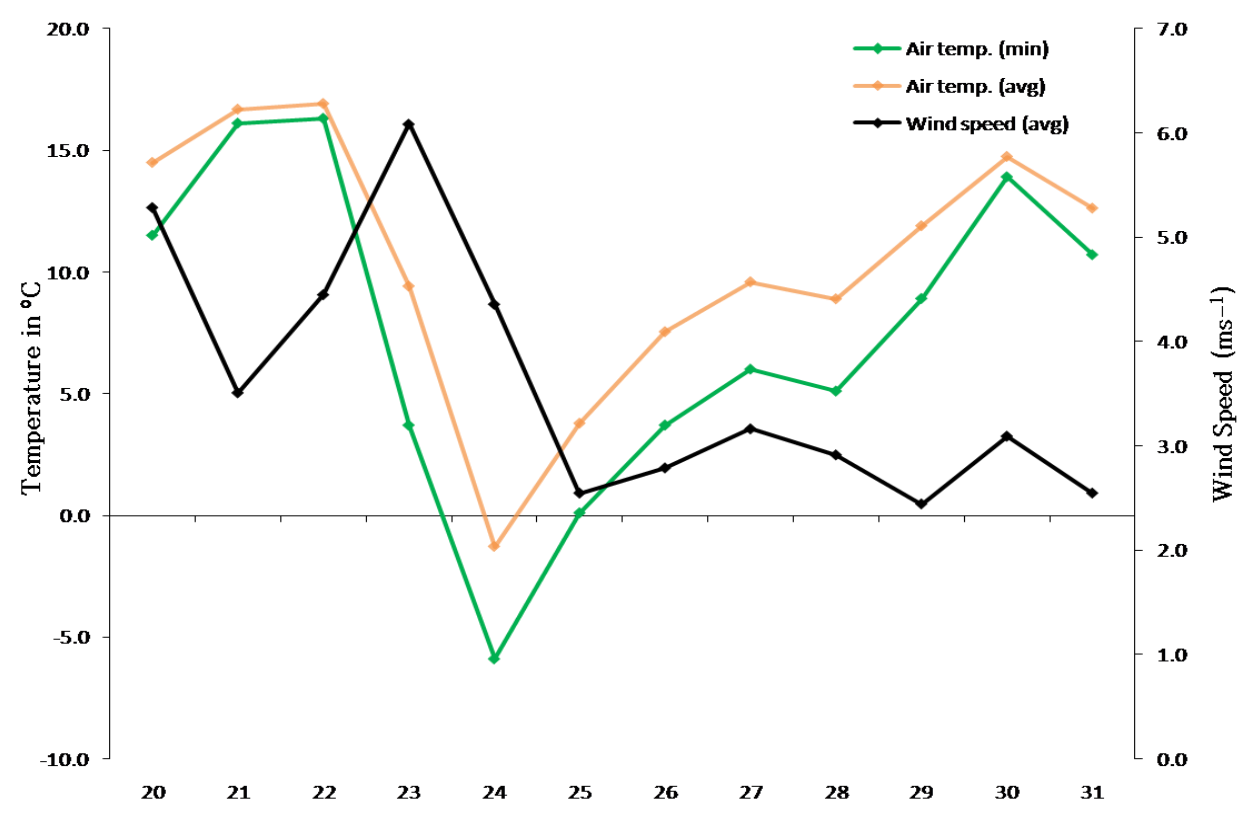

FIGURE 19. January 2003 St. Joseph Bay air temperature and wind speed 


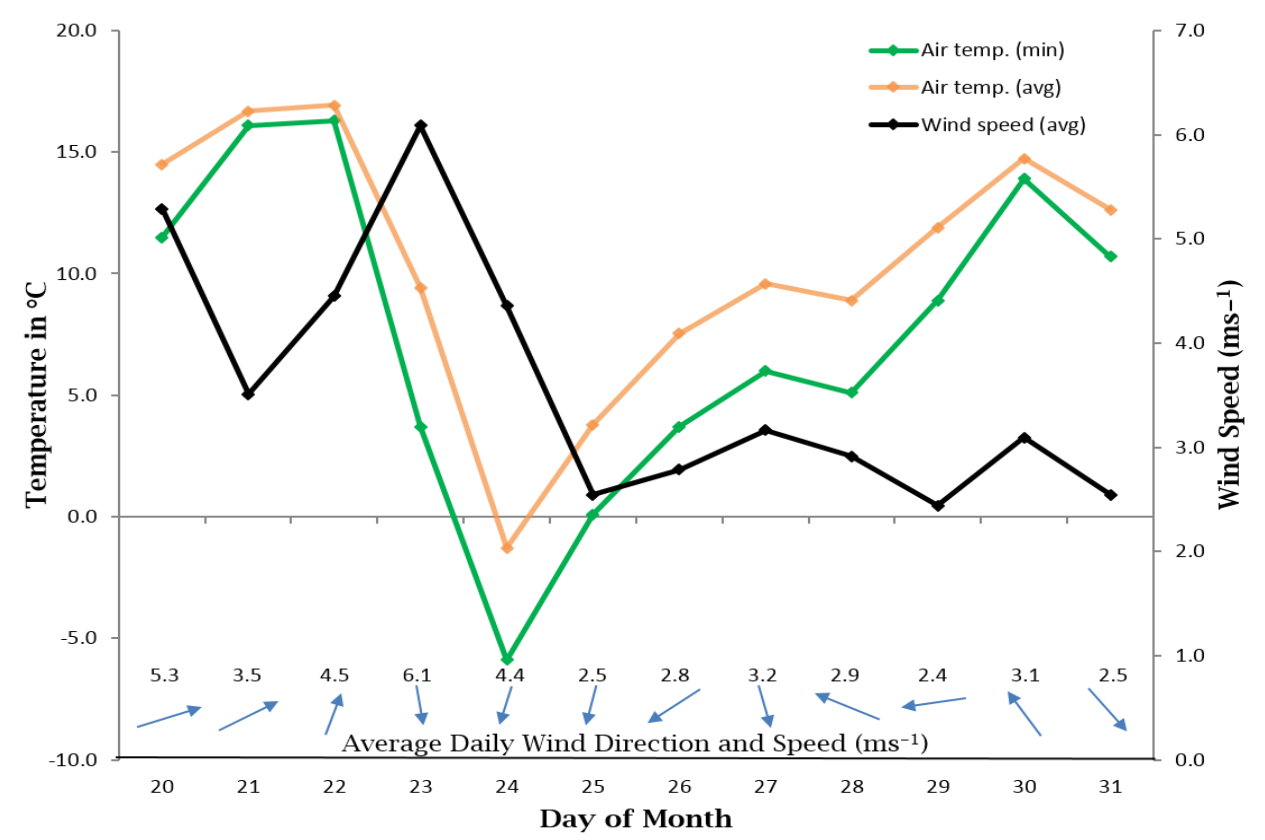

FIGURE 20. January 2003 St. Joseph Bay air temperature and wind data including surface vectors for the duration of the hypothermic stunning event

\section{St. Joseph Bay}

A moderate hypothermic stunning event was recorded throughout most of January of 2008. Turtles were recovered starting on January $3^{\text {rd }}$, up until the $23^{\text {rd }}$. The majority of cold-stunned turtles $(\mathrm{N}=89 ; 65 \%)$ were rescued on the $3^{\text {rd }}$ and $4^{\text {th }}$. Minimum air temperature fell below zero to $-4^{\circ} \mathrm{C}$ on the $3^{\text {rd }}$ and then rose to $2.6^{\circ} \mathrm{C}$ the following day (Figure 21). Air temperature, both minimum and average values, remains above $3^{\circ} \mathrm{C}$ for the next 14 days and doesn't fluctuate a great deal. During these two weeks, 27 turtles are recovered. With the exception of the $9^{\text {th }}, 12^{\text {th }}$, and $17^{\text {th }}$, at least one individual turtle is rescued per day (Figure 22). Minimum air temperature drops into the negatives; $-0.7^{\circ} \mathrm{C}$, again on the $20^{\text {th }}$ and 19 turtles were found on the $21^{\text {st }}$. The final two days of the event saw a drastic temperature increase up to almost $14^{\circ} \mathrm{C}$ and only 3 turtles were recovered between the $22^{\text {nd }}$ and $23^{\text {rd }}$. An uneven pattern in terms of wind direction and speed 
occurred throughout the month. Wind speed reached $6 \mathrm{~ms}^{-1}$ at the very beginning of the month and again towards the tail end (Figure 23).

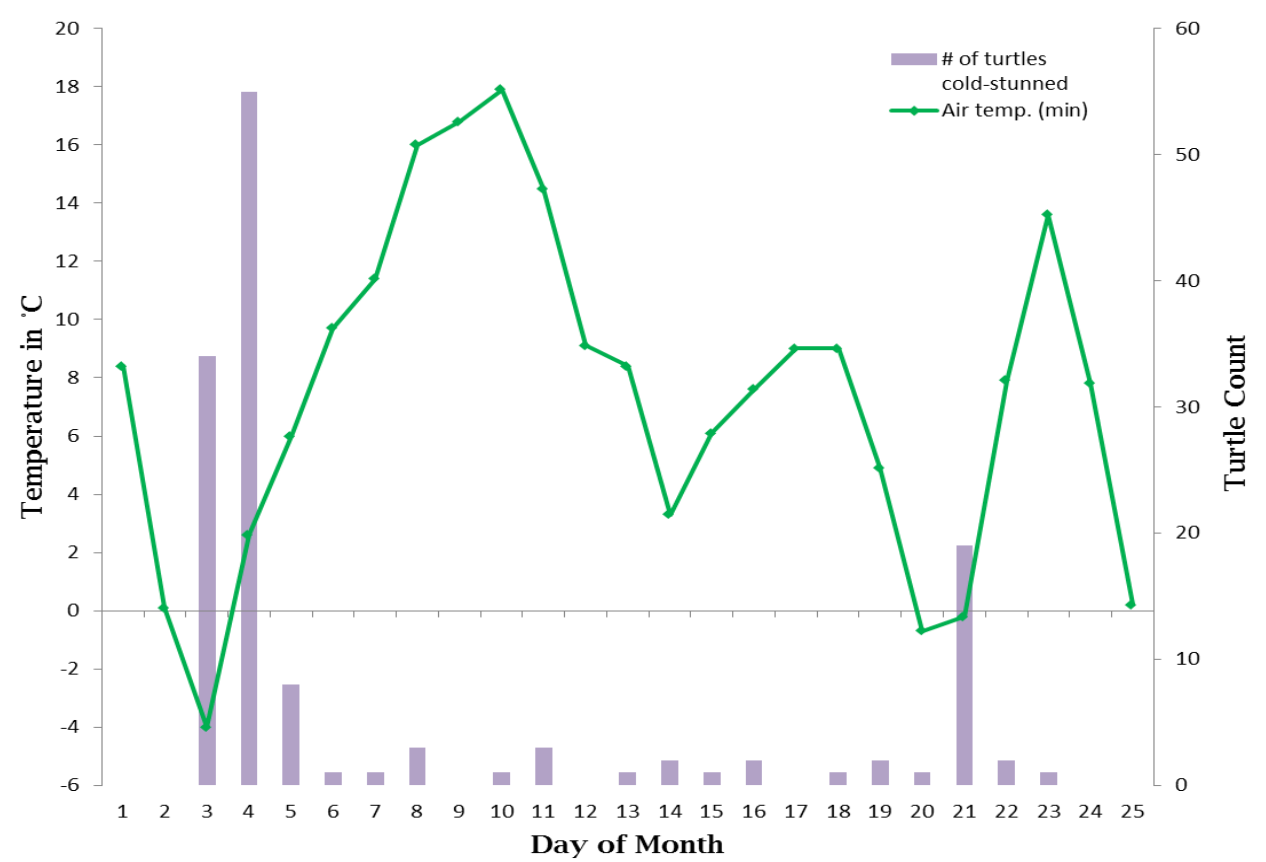

FIGURE 21. January 2008 St. Joseph Bay minimum air temperature with daily number of cold-stunned sea turtles that were rescued

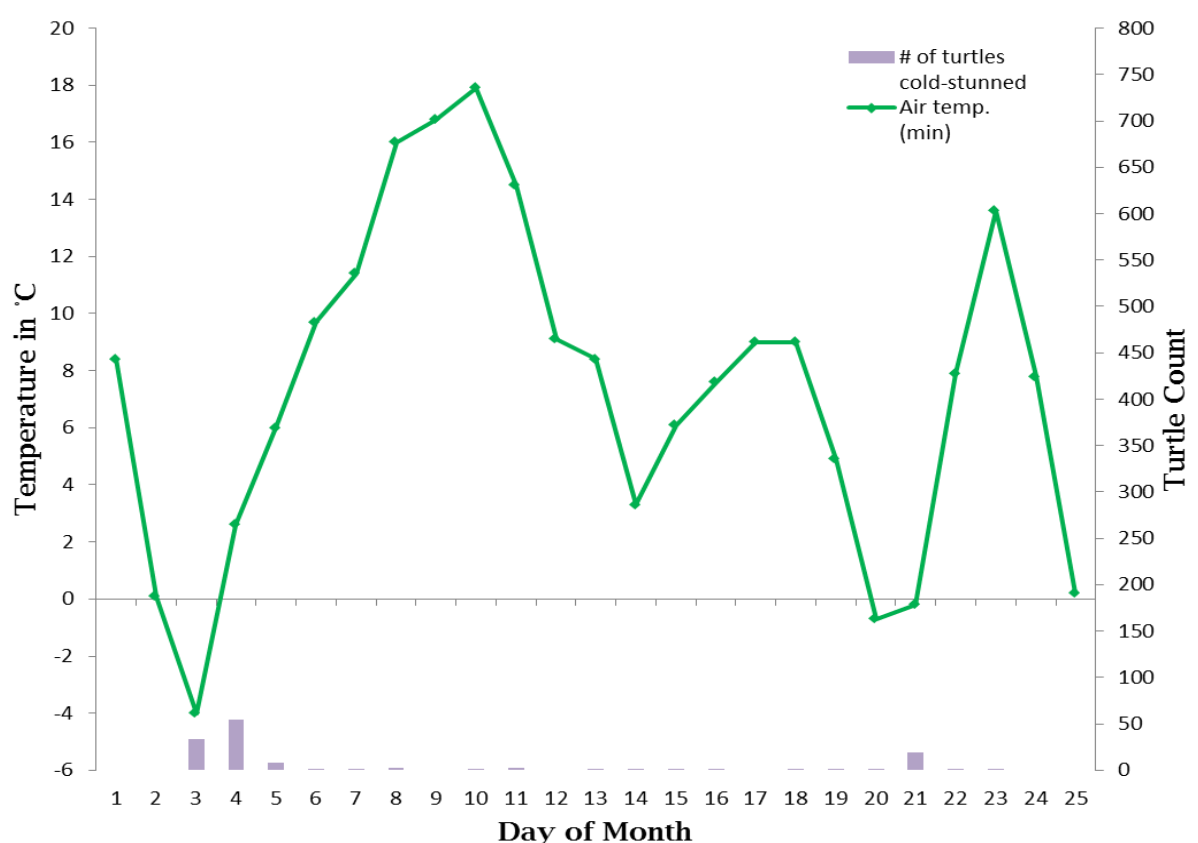

FIGURE 22. January 2008 St. Joseph Bay minimum air temperature with sea turtle coldstun numbers on maximum scale used for Mosquito Lagoon 2010 


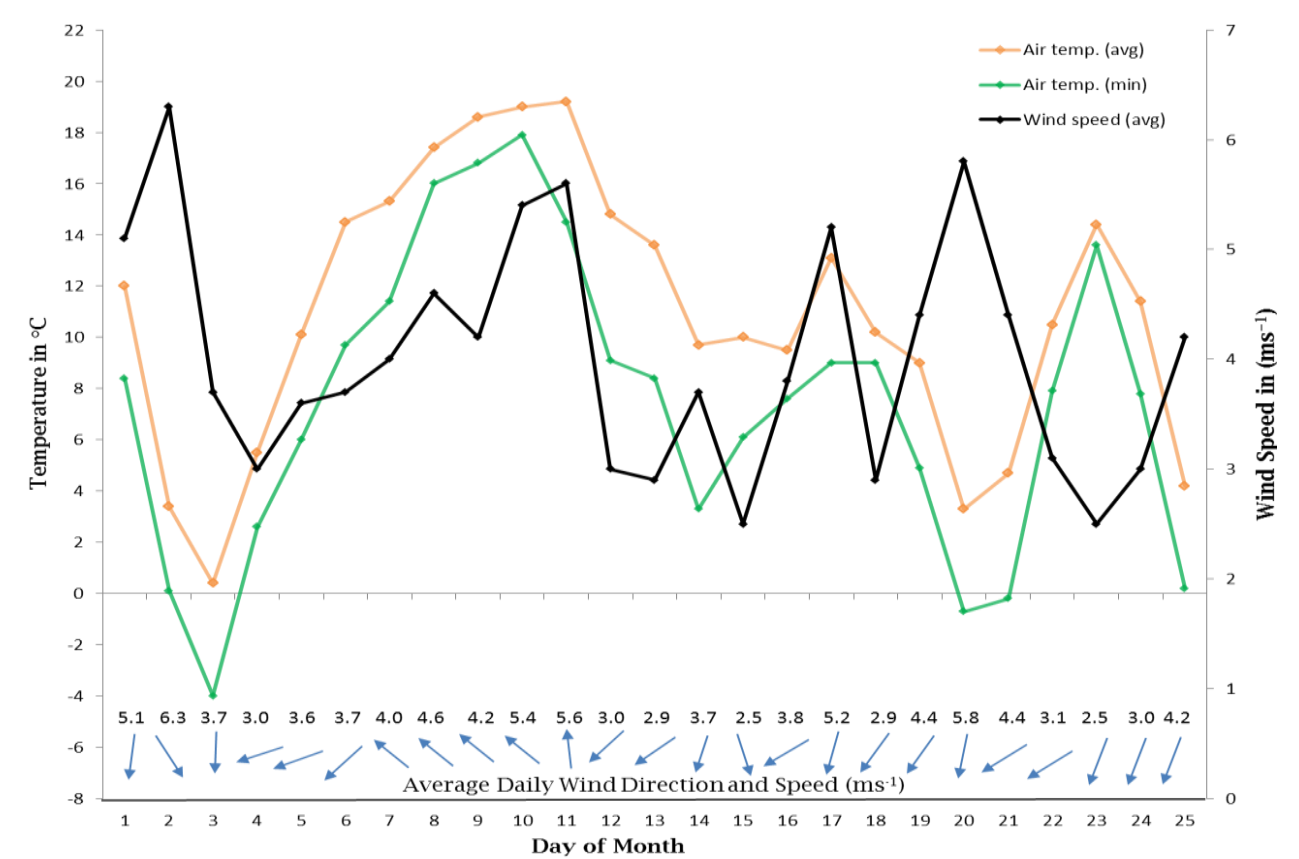

FIGURE 23. January 2008 St. Joseph Bay average air temperature and wind data including surface vectors for the duration of the hypothermic stunning event

\subsubsection{St. Joseph Bay}

While December $14^{\text {th }}-31^{\text {st }}$ was not marked by a cold-stun event, it was graphed as a supplement for better understanding of the 2010 mass hypothermic stunning event that occurred in St. Joseph Bay. Water temperature begins a steady decline on December $17^{\text {th }}$ through the $23^{\text {rd }}$ (Figure 24). A slight increase is observed on the $24^{\text {th }}$ and $25^{\text {th }}$ before minimum water temperature falls below the $10^{\circ} \mathrm{C}$ threshold on the $30^{\text {th }}$. Minimum and average air temperature display a similar pattern to water temperature; however the rate at which air temperature decreases is much faster (Figure 25). Wind speed remains somewhat consistent, averaging between 2 and $6 \mathrm{~ms}^{-1}$ up until the $28^{\text {th }}$, where it peaks at $10.4 \mathrm{~ms}^{-1}$. Wind direction is variable throughout the selected dates but originates from either the north or west during days where air and water temperature are decreasing. 


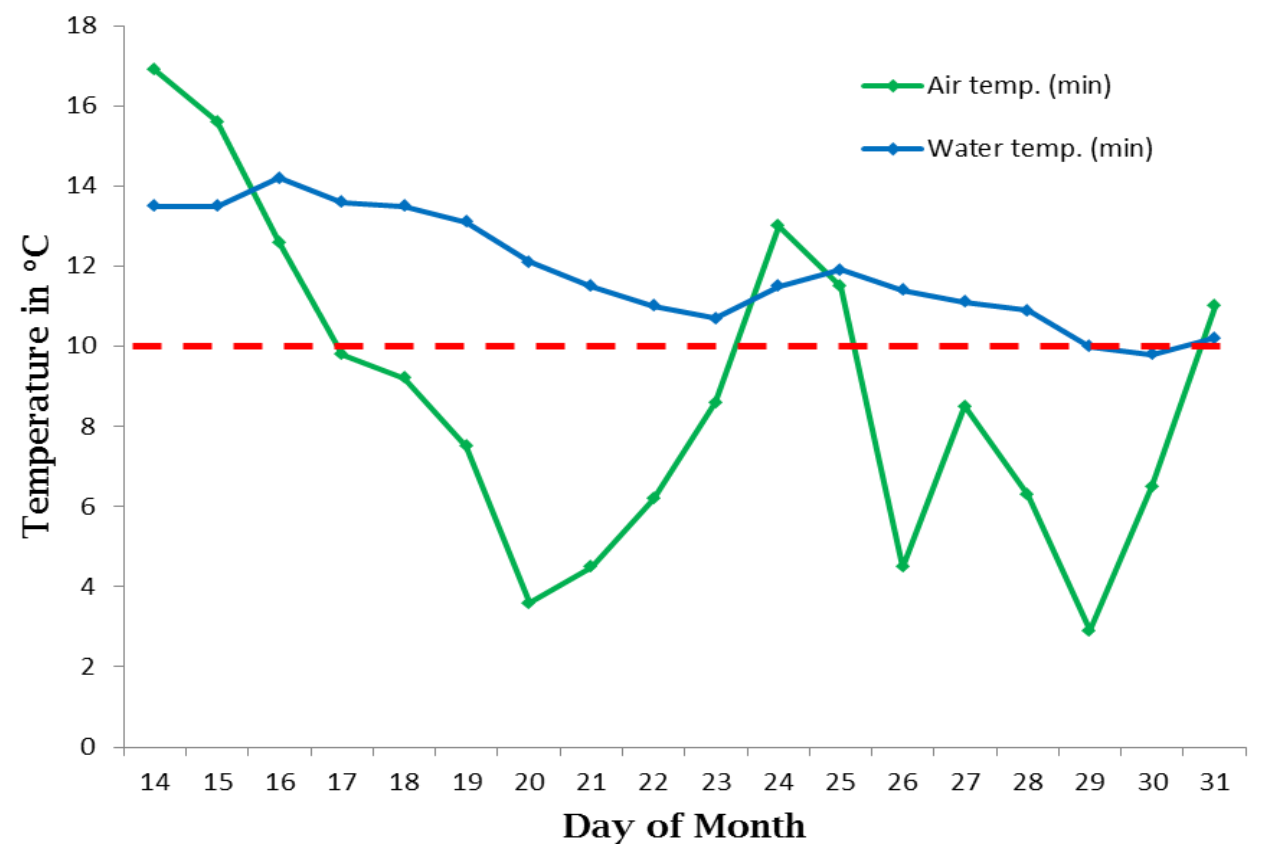

FIGURE 24. Late December 2009 St. Joseph Bay minimum air and water temperature

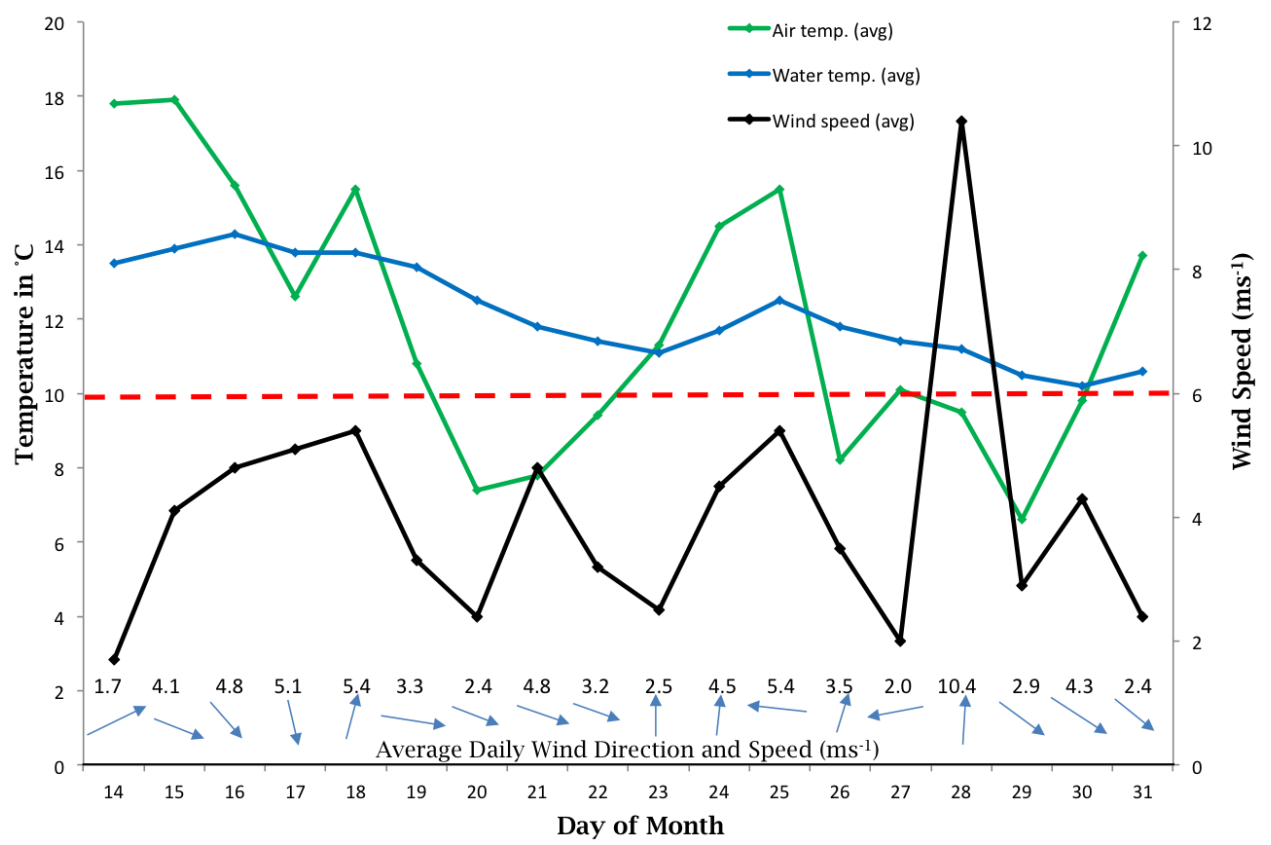

FIGURE 25. Late December 2009 St. Joseph Bay average air and water temperature with wind data (speed and surface vectors) 


\subsubsection{St. Joseph Bay}

The January 2010 hypothermic stunning event was, to date, the largest and most destructive on record. St. Joseph Bay was one of two focal points of this rare event, where over 1700 marine turtles cold-stunned and stranded over an 8-day period from January $7^{\text {th }}$ through the $14^{\text {th }}$. Water temperature fell below the $10^{\circ} \mathrm{C}$ threshold on January $3^{\text {rd }}$ and remained below that level for 15 consecutive days (Figure 26). The lowest recorded water temperature was $5^{\circ} \mathrm{C}$ on the $11^{\text {th }}$, which is the documented lethal value for green turtles (Schwartz 1978). On this day, 444 turtles were recovered from the bay. Prior to this day, 818 turtles had already been retrieved and re-located for rehabilitation (Figure 27). Minimum air temperature hovered around $0^{\circ} \mathrm{C}$ for the first week of January before plummeting to $-3.7^{\circ} \mathrm{C}$ on the $11^{\text {th }}$. The final few days of the event featured water temperatures still below $6^{\circ} \mathrm{C}$, barely positive air temperatures, and approximately 487 cold-stunned turtles. The minimum water temperature did not return above the threshold value until the $18^{\text {th }}$ of January. The minimum air temperature demonstrated a rapid increase away from negative values to $12^{\circ} \mathrm{C}$ on the $16^{\text {th }}$ over a period of just 3 days. A similar considerable 'jump' in value is also apparent for average daily air temperature (Figure 28). Wind speed averaged between 2 and $4.5 \mathrm{~ms}^{-1}$ at the start of the month, spiked on January $9^{\text {th }}$ at $5.7 \mathrm{~ms}^{-1}$, and then dropped again to between 2 and $3 \mathrm{~ms}^{-1}$ for the remainder of the cold-stun event. The extent of this record event was characterized solely by northerly winds (Figure 29). 


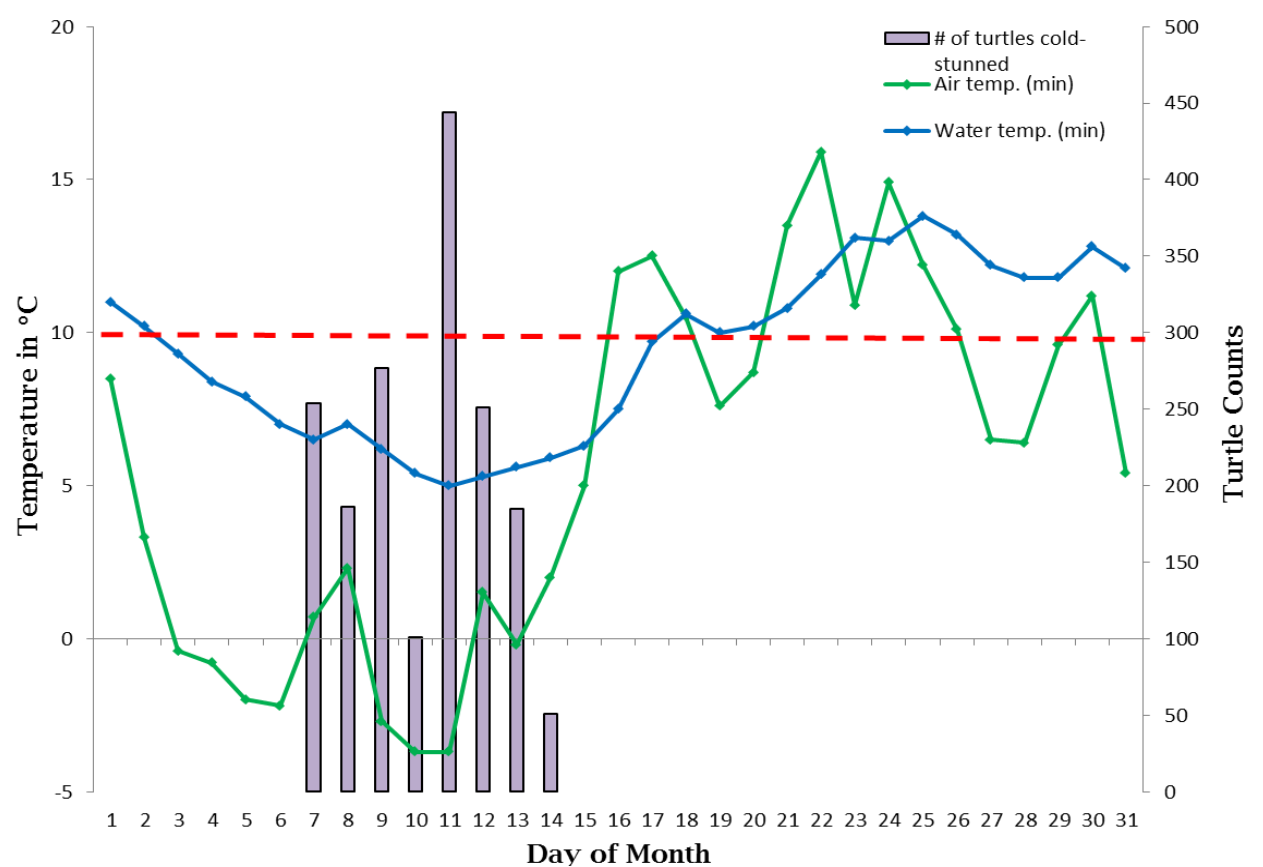

FIGURE 26. January 2010 St. Joseph Bay minimum air and water temperature with daily number of cold-stunned sea turtles that were rescued

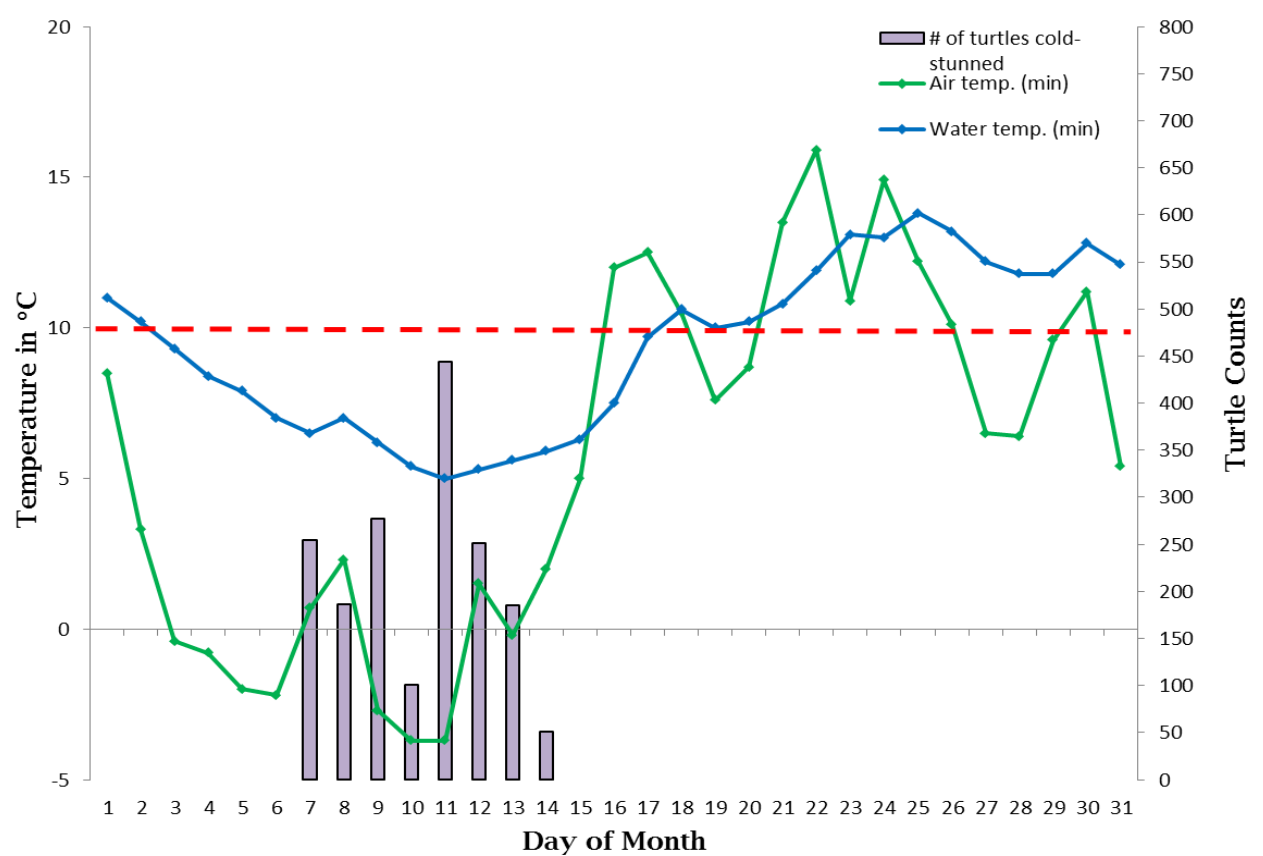

FIGURE 27. January 2010 St. Joseph Bay minimum air and water temperature with sea turtle cold-stun numbers on maximum scale used for Mosquito Lagoon 2010 


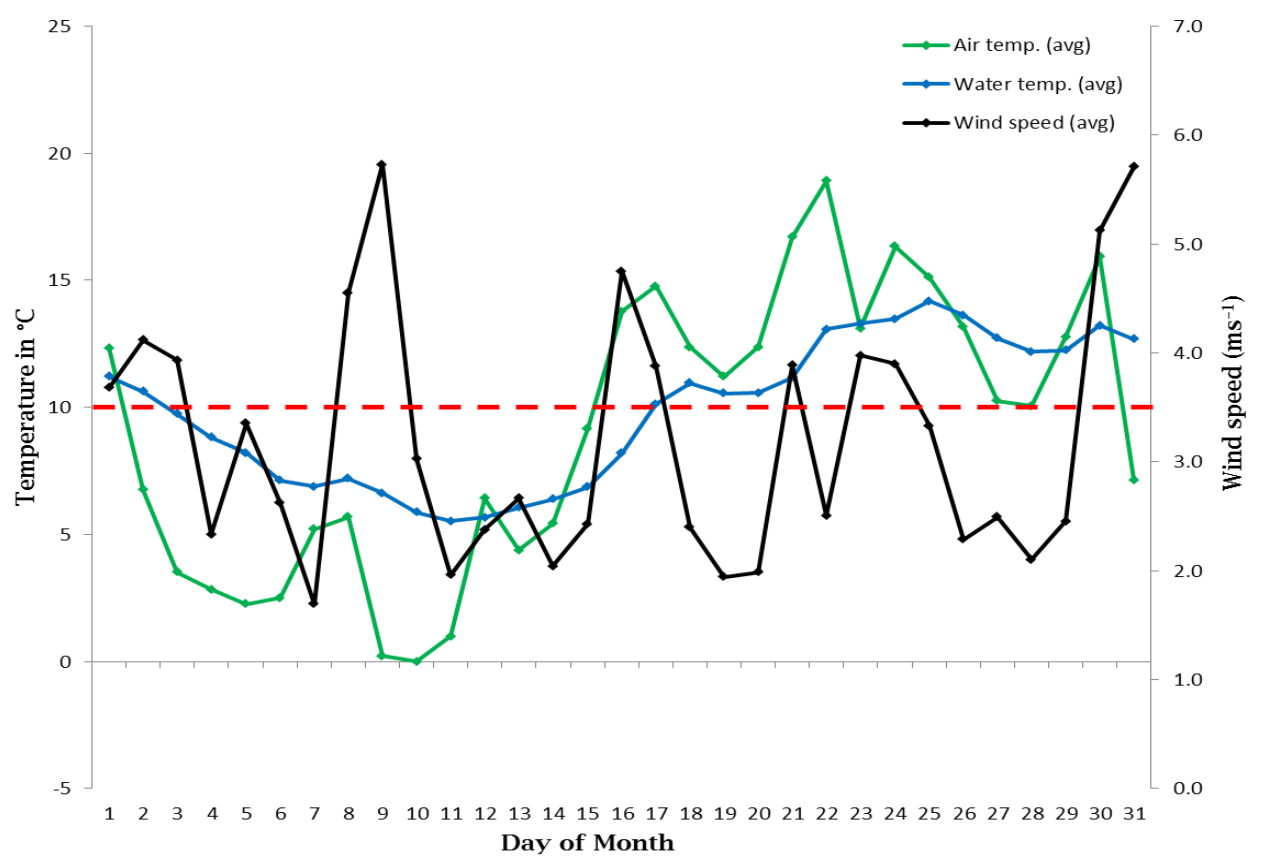

FIGURE 28. January 2010 St. Joseph Bay air temperature, water temperature and wind speed

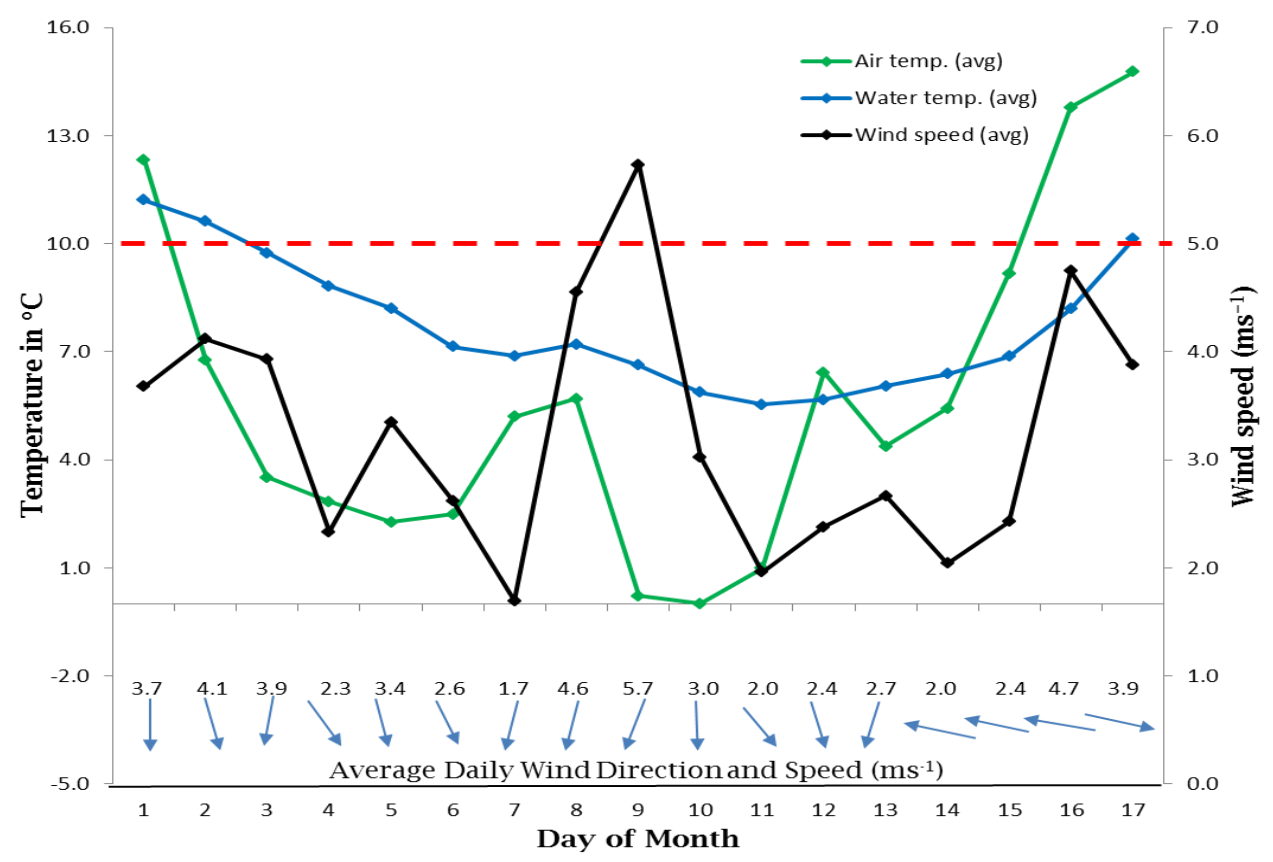

FIGURE 29. January 2010 St. Joseph Bay air temperature, water temperature and wind data including surface vectors for the duration of the hypothermic stunning event 


\subsubsection{Mosquito Lagoon}

Mosquito Lagoon on the Atlantic coast of Florida was the second focal point of the severe 2010 event. Almost 2500 sea turtles were involved in the event at this location. Minimum and average water temperature remained below the threshold value for 12 consecutive days, while turtles were found for 10 days. Minimum water temperature dropped below the $10^{\circ} \mathrm{C}$ threshold on January $4^{\text {th }}$ and turtles began cold stunning on the $6^{\text {th }}$ (Figure 30). Minimum values for air temperature demonstrated an abrupt drop from $12^{\circ} \mathrm{C}$ to $3.3^{\circ} \mathrm{C}$ in just 4 days from January $1^{\text {st }}$ to the $4^{\text {th }}$. During the first two days of this event, Florida rescue agencies already had 279 turtles to care for. Rescue personnel gained a very brief respite in terms of the scale of this event on the $8^{\text {th }}$ and $9^{\text {th }}$ when only an additional 123 individuals needed rehabilitation. This is due to a significant increase of

over $6^{\circ} \mathrm{C}$ in both average and minimum air temperature from the $7^{\text {th }}$ to the $8^{\text {th }}$ and a simultaneous slight 'bump' of $1.1^{\circ} \mathrm{C}$ in water temperature. Both parameters fell again to an extreme low for minimum water temperature on the $11^{\text {th }}$ at $3.9^{\circ} \mathrm{C}$. Average water temperature on this day was only $5^{\circ} \mathrm{C}$ (Figure 31). Air temperature was $0.7^{\circ} \mathrm{C}$ on the $10^{\text {th }}$. The majority of sea turtles involved in this event, approximately 1,900 individuals, were recovered between the $11^{\text {th }}$ and $13^{\text {th }}$ of January. An additional 89 turtles were found on the $14^{\text {th }}$, which concluded the 2010 event in this location. Minimum water temperature values had gradually climbed to $8^{\circ} \mathrm{C}$ on the $14^{\text {th }}$ and extended above the threshold on the $16^{\text {th }}$. Air temperature, both minimum and average, displayed a rapid increase beginning on the $12^{\text {th }}$ and reaching warmer values again on the $16^{\text {th }}$. The duration of this event was accompanied by either northerly or westerly winds (Figure 32). The only exception occurred on the $8^{\text {th }}$ when a southerly wind direction was present. Wind speed was also 
noticeably low on this day at only $2.8 \mathrm{~ms}^{-1}$. Maximum wind speed reached $6.4 \mathrm{~ms}^{-1}$ on the $10^{\text {th }}$.

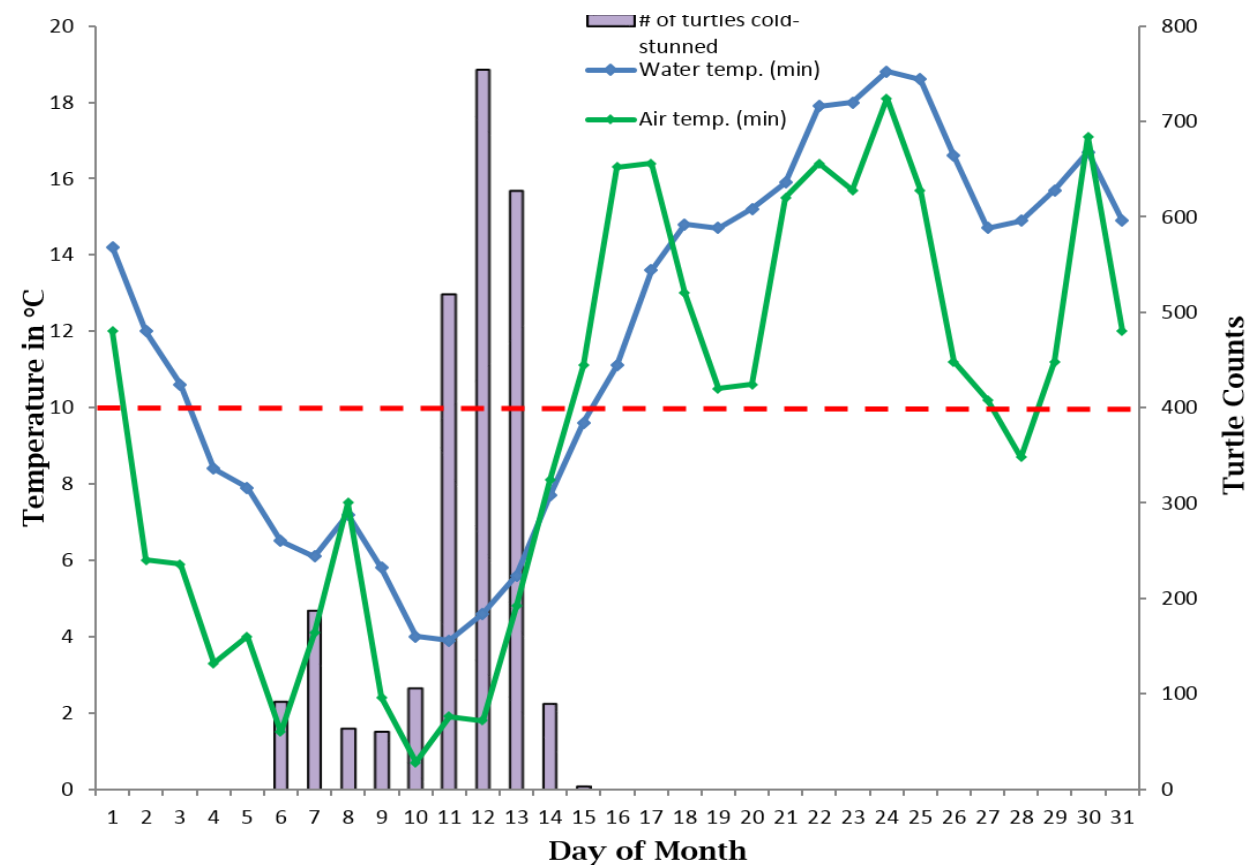

FIGURE 30. January 2010 Mosquito Lagoon minimum air and water temperature with daily number of cold-stunned sea turtles that were rescued

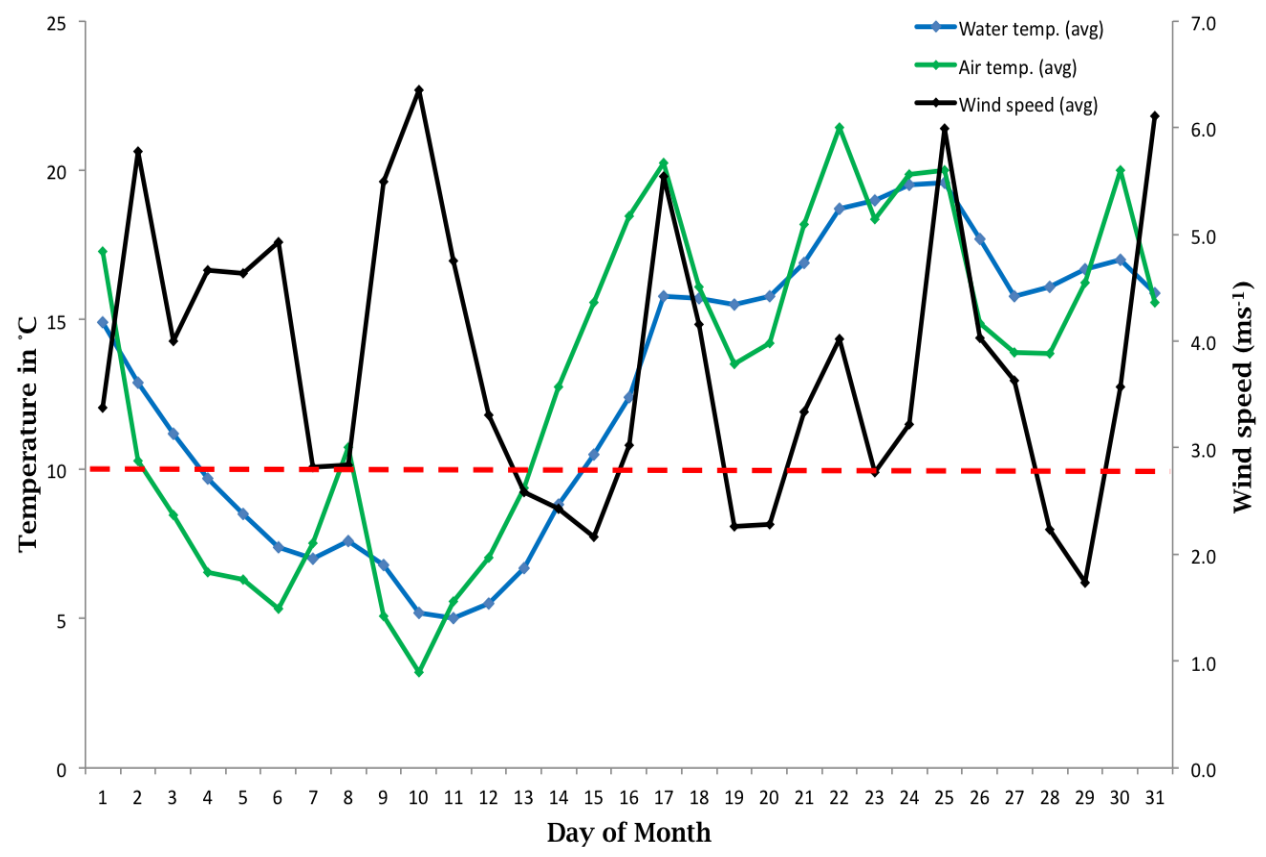

FIGURE 31. January 2010 Mosquito Lagoon air temperature, water temperature and wind speed 


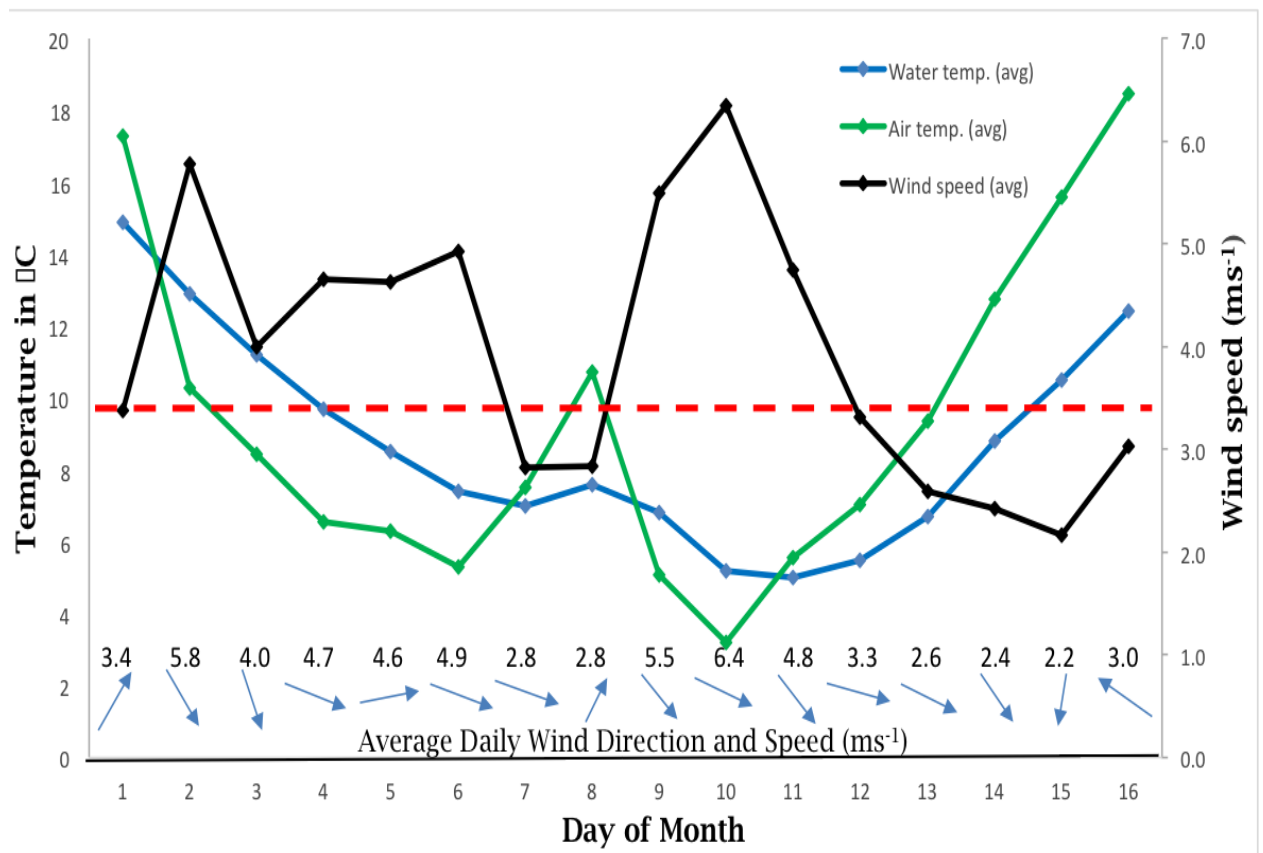

FIGURE 32. January 2010 Mosquito Lagoon air temperature, water temperature and wind data including surface vectors for the duration of the hypothermic stunning event

\subsection{Arctic and North Atlantic Oscillations}

The Arctic and North Atlantic Oscillation index values were graphed in Excel for January 2000 to March 2013 in order to determine if significant positive or negative values were associated with selected cold-stun event years (2001, 2003, 2008, and 2010). The oscillation index values are normalized by the standard deviation so no units exist on the following graphs. The North Atlantic Oscillation index did not have any documented extreme values, either positive or negative, during event years. The graph depicts a normal fluctuation pattern between positive and negative values for the time period analyzed, with a few unique spikes (Figure 33). Negative values were recorded for the month of January for all four event years but were not extremely negative. A notable negative value of -3.25 occurred in December of 2002, which may have made a slight contribution to the cold-stun event of January 2003. 


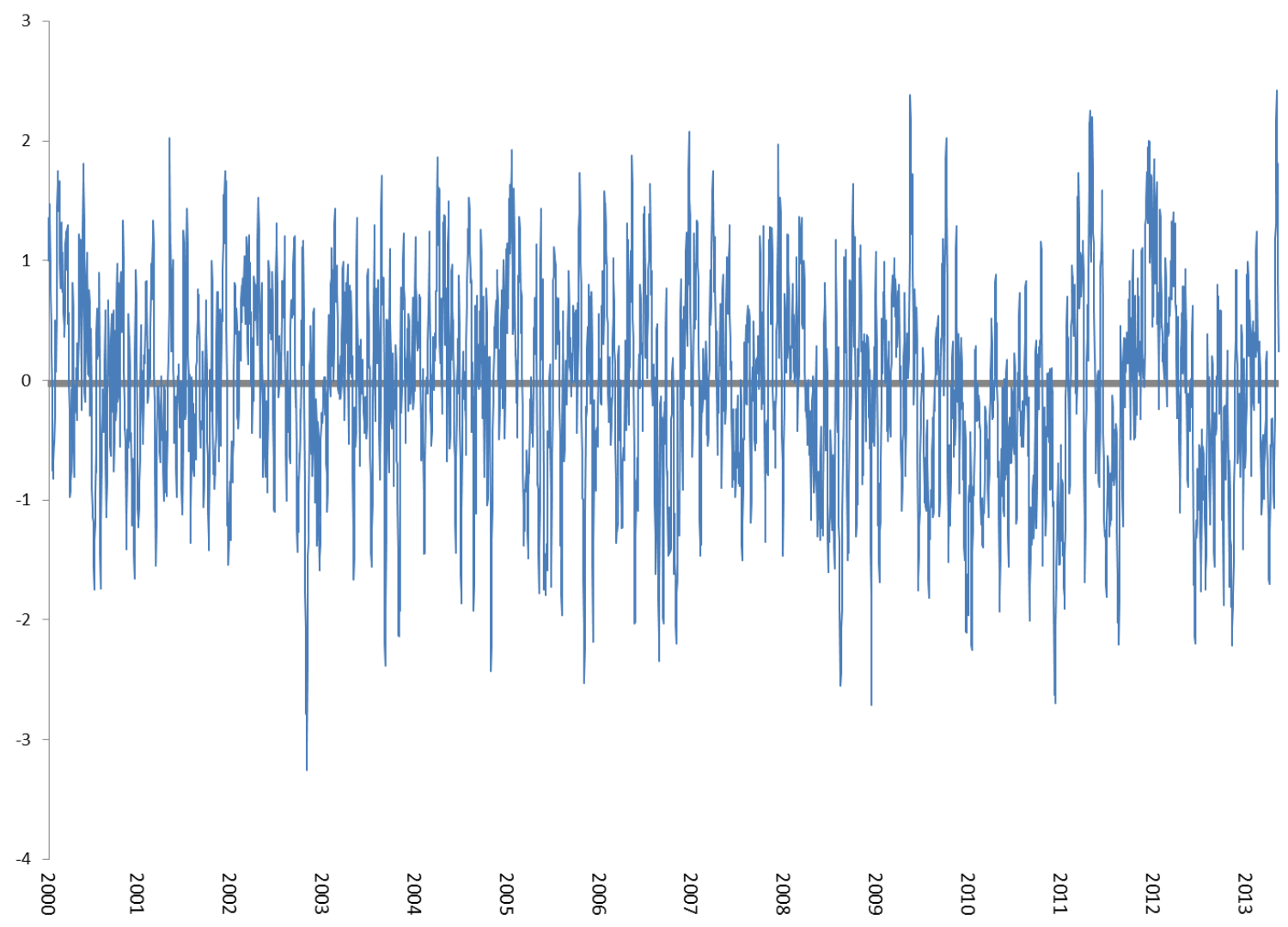

FIGURE 33. Normalized values of North Atlantic Oscillation 2000-2013

The Arctic Oscillation revealed a more influential pattern, particularly in terms of severe cold-stun event years. For both 2001 and 2010, extreme negative values were recorded throughout the month of January (Figure 34). The lowest negative value of the decade occurred in January of 2010 at -5.3 . The index did not record positive values until March of that year (Figure 35). January of 2001 also reported low negative values around -4 (Figure 36). Similar to the North Atlantic Oscillation, December of 2002 is also low into the negatives while January of 2003 is only slightly positive. This time series extends up until March of this year (2013) and very low negative values are already being reported, demonstrating a pattern similar to 2010 . 


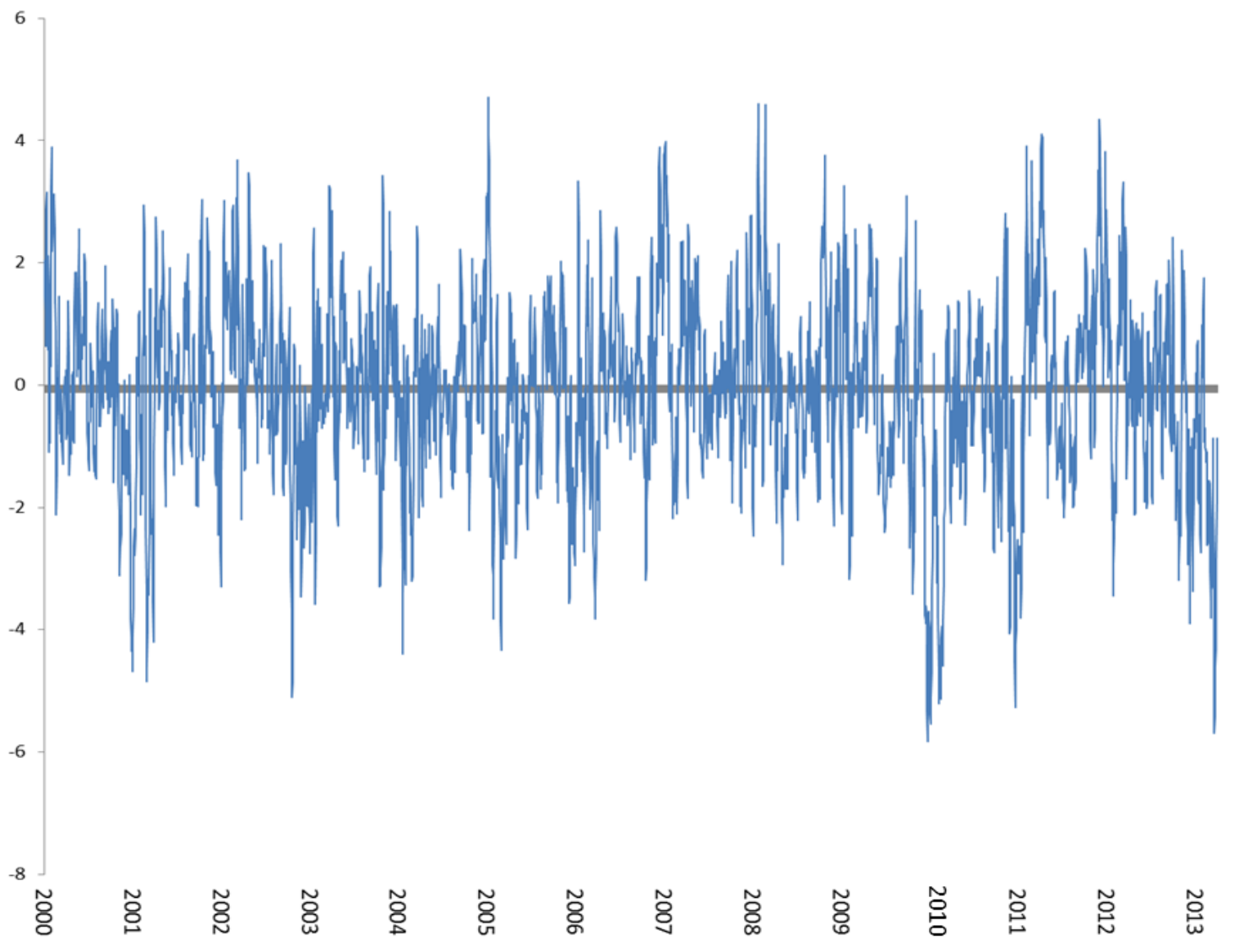

FIGURE 34. Normalized values of Arctic Oscillation 2000-2013

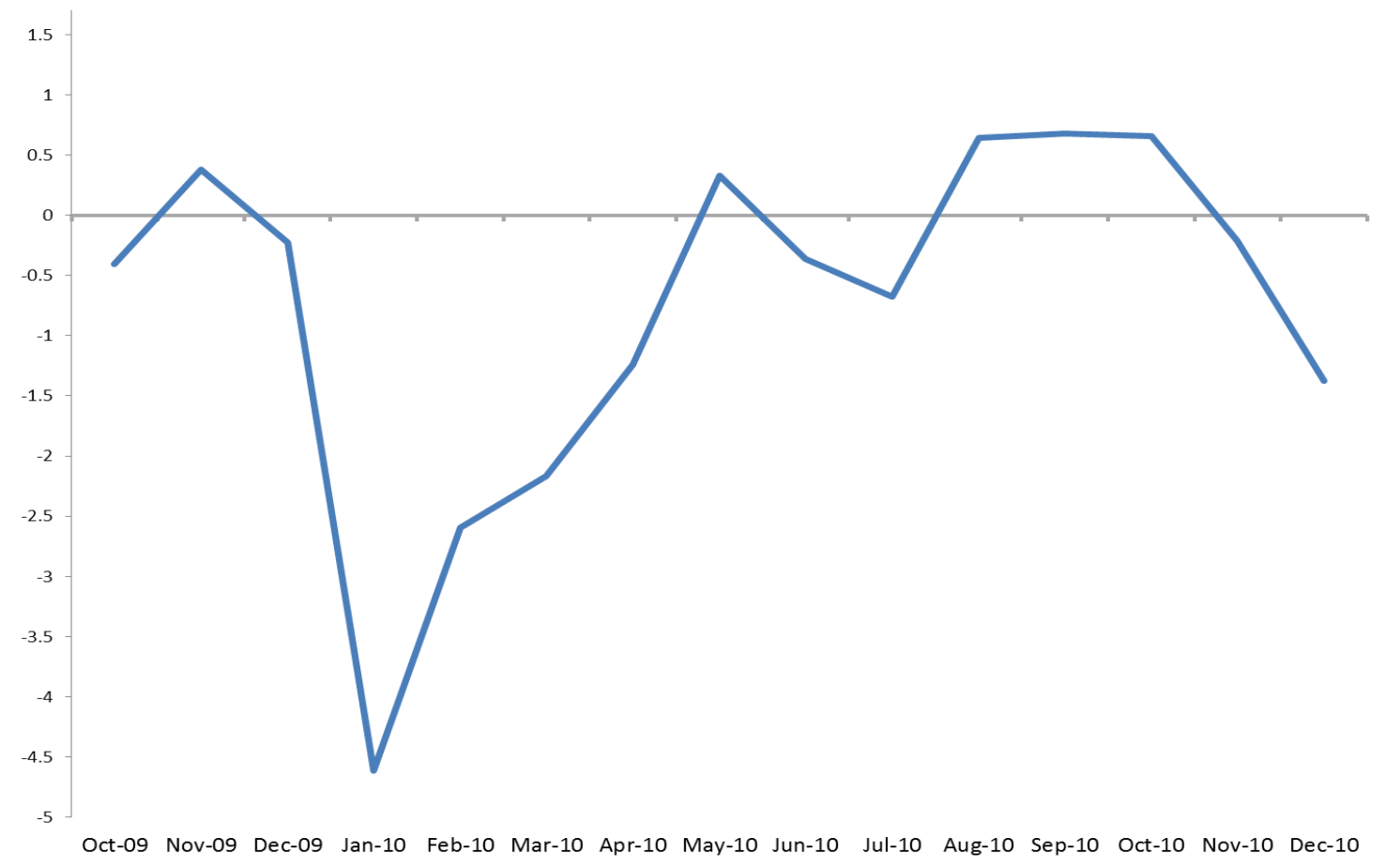

FIGURE 35. Normalized values of Arctic Oscillation October 2009-December 201 


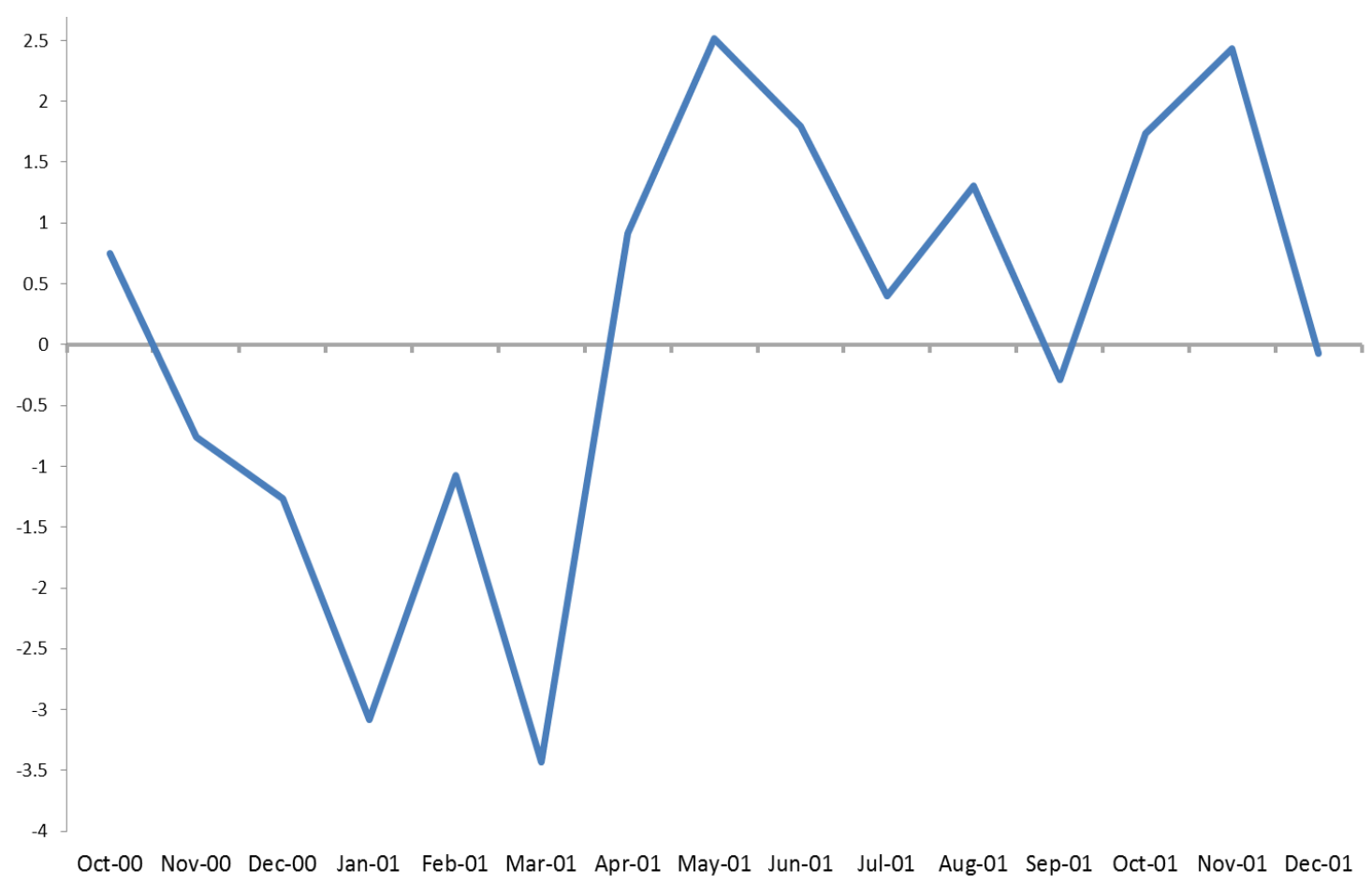

FIGURE 36. Normalized values of Arctic Oscillation October 2000-Decemeber 2001

\subsection{NCEP Reanalysis Data Composites}

Daily composites generated by NCEP illustrate the origin of the cold air mass that eventually made its way into Florida during the unprecedented winter cold snap of 2001 and 2010. January 2003 did not reach record-breaking cold temperatures but was included nonetheless as a comparison measure against the severe winters of 2001 and 2010. As atmospheric cold snaps in Florida are often associated with high winds, vector wind was another important variable examined.

\subsubsection{December 2000/January 2001}

January $1^{\text {st }}$ marked the beginning of the cold-stun event of 2001. Two days prior were viewed as well as the extent of the event, which lasted until January $12^{\text {th }}$. On December $30^{\text {th }}$, a large cold air mass, originating from Canada and Northern Alaska, was already descending into Florida. Low temperatures were concentrated along the 
panhandle before sinking into south Florida on January $1^{\text {st }}$ and $2^{\text {nd }}$. On the $1^{\text {st }}$ day of January, surface air temperature demonstrated an approximate $-14^{\circ}$ deviation from the normal based on the contour interval. The cold air mass lingered on the Florida peninsula until the $5^{\text {th }}$ before moving offshore. Although the marine turtle cold-stunning event lasted until the $10^{\text {th }}$, only minor anomalies were present on surface air temperature composites from the $6^{\text {th }}$ forward. A northerly wind flow developed in the high latitudes of Alaska or Canada before traveling across the US and bearing down on the Florida peninsula (Figure B1). Throughout the duration of the cold-stun event, wind vectors were facing west and between an 8 and $12^{\circ}$ deviation in normal wind patterns is evident on the $1^{\text {st }}-6^{\text {th }}$ of January.

\subsubsection{January 2003}

Composite plots for January of 2003 display a cold air mass similar in size to the January 2001 anomaly tracking into Florida from Northern Canada on the $23^{\text {rd }}$ (Figure A2). By the $24^{\text {th }}$, cold air had descended through the rest of the state with a $-10^{\circ}$ deviance from normal surface air temperature patterns. While the air mass is similar in size to that of 2001, the contour interval is on a lesser scale. Also unlike 2001, this system did not remain in place for long and had moved away from the peninsula by the $26^{\text {th }}$. A second cold air anomaly is evident on the composites beginning on the $25^{\text {th }}$ but never extends into Florida. The moderate classification of 2003 cold-stun event can be attributed to the short duration of this cold air mass and lack of extreme temperature anomalies apparent in 2001 and 2010. Surface winds lack the force that can be seen in the 2001 and 2010 plots from the abnormally high deviation (Figure B2). As the cold front system is shortlived, so are the prevailing winds. Vectors are facing mostly either south or southwest. 


\subsubsection{January 2010}

The anomaly plot type showed abnormal temperatures surrounding Florida on the $3^{\text {rd }}$ of January (Figure A3). The system appeared to develop in either Alaska or Northern Siberia and traveled down the US before settling over the panhandle on the $6^{\text {th }}$. By the $7^{\text {th }}$, the first day turtles were rescued from St. Joseph Bay, an approximate $-15^{\circ}$ deviance from the normal surface air temperature is present on the composite plot. Extreme temperature anomalies are visible for the following 4 days, culminating in a $-18^{\circ}$ deviance on the $11^{\text {th }}$. The system maintained its strength for 9 days since arriving in Florida and finally dissipated to the east on the $14^{\text {th }}$ of January. The wind occurrences during the several days surrounding the worst part of the cold-stunning event were approximately $10-12 \mathrm{~ms}^{-1}$ deviated from usual patterns (Figure B3). Winds appear to strengthen as the system travels across the U.S. before settling near Florida. During January 9-12 the system was hovering just offshore from Florida on either side of the peninsula with wind vectors facing primarily to the west. It appears that these windy conditions were initiated from the area of southeastern Alaska.

\subsection{NDBC and FWRI Temperature Data Comparison}

The NDBC Apalachicola buoy was found to be a fairly decent proxy for St. Joseph Bay in terms of average daily water temperature. The time period analyzed for this comparison was from January $4^{\text {th }}, 2012$, when the FWRI transmitter was deployed until February $15^{\text {th }}, 2012$ when it was retrieved (Table 4). All difference values highlighted in red indicate a greater than $2{ }^{\circ} \mathrm{C}$ difference between the two stations. Throughout the time interval, 10 days display a $>2{ }^{\circ} \mathrm{C}$ difference and only 4 days display a difference of $>3{ }^{\circ} \mathrm{C}$. The first and final few days of the time period show the largest 
difference values, with the middle values in very close agreement. The FWRI shallow water station appears to cool faster at the onset of a cold front than the Apalachicola station before the two even out. Average values for the St. Joseph Bay station also drop much lower during a cold front, which contributes to the high difference values.

TABLE 4. Daily water temperature comparison between NDBC's Apalachicola station and FWC_FWRI's St. Joseph Bay transmitter

\begin{tabular}{|c|c|c|c|}
\hline Date & $\begin{array}{c}\text { Apalachicola buoy } \\
\text { daily avg. }{ }^{\circ} \mathrm{C}\end{array}$ & $\begin{array}{c}\text { St. Joseph Bay } \\
\text { buoy daily avg. }{ }^{\circ} \mathrm{C}\end{array}$ & Difference ${ }^{\circ} \mathrm{C}$ \\
\hline $1 / 4 / 2012$ & 13.1 & 9.5 & 3.6 \\
\hline $1 / 5 / 2012$ & 12.8 & 11.2 & 1.6 \\
\hline $1 / 6 / 2012$ & 13.8 & 13.2 & 0.6 \\
\hline $1 / 7 / 2012$ & 14.1 & 14.8 & 0.7 \\
\hline $1 / 8 / 2012$ & 14.8 & 16.1 & 1.3 \\
\hline $1 / 9 / 2012$ & 15.6 & 17.2 & 1.6 \\
\hline $1 / 10 / 2012$ & 15.9 & 17.8 & 1.9 \\
\hline $1 / 11 / 2012$ & 16.1 & 16.3 & 0.2 \\
\hline $1 / 12 / 2012$ & 16.4 & 16.4 & 0 \\
\hline $1 / 13 / 2012$ & 15.7 & 13.8 & 1.9 \\
\hline $1 / 14 / 2012$ & 14.8 & 10.6 & 4.2 \\
\hline $1 / 15 / 2012$ & 14.4 & 11.8 & 2.6 \\
\hline $1 / 16 / 2012$ & 14.1 & 13.2 & 0.9 \\
\hline $1 / 17 / 2012$ & 14.1 & 14.9 & 0.8 \\
\hline $1 / 18 / 2012$ & 14.9 & 16.2 & 1.3 \\
\hline $1 / 19 / 2012$ & 14.7 & 14.8 & 0.1 \\
\hline $1 / 20 / 2012$ & 14.7 & 15.2 & 0.5 \\
\hline $1 / 21 / 2012$ & No data & 16.4 & NA \\
\hline $1 / 22 / 2012$ & No data & 17.0 & NA \\
\hline $1 / 23 / 2012$ & No data & 18.1 & NA \\
\hline $1 / 24 / 2012$ & 17.1 & 18.2 & 1.1 \\
\hline $1 / 25 / 2012$ & 17.5 & 19.3 & 1.8 \\
\hline $1 / 26 / 2012$ & 18.2 & 19.8 & 1.6 \\
\hline $1 / 27 / 2012$ & 17.8 & 18.2 & 0.4 \\
\hline $1 / 28 / 2012$ & 17.3 & 16.6 & 0.7 \\
\hline $1 / 29 / 2012$ & 16.5 & 15.5 & 1.0 \\
\hline $1 / 30 / 2012$ & 15.4 & 14.6 & 0.8 \\
\hline $1 / 31 / 2012$ & 14.9 & 15.2 & 0.3 \\
\hline 2/1/2012 & 14.9 & 16.1 & 1.2 \\
\hline $2 / 2 / 2012$ & 15.3 & 17.2 & 1.9 \\
\hline $2 / 3 / 2012$ & 15.9 & 18.8 & 2.9 \\
\hline $2 / 4 / 2012$ & 16.5 & 18.9 & 2.4 \\
\hline $2 / 5 / 2012$ & 17.0 & 19.8 & 2.8 \\
\hline 2/6/2012 & 17.3 & 19.8 & 2.5 \\
\hline $2 / 7 / 2012$ & 17.6 & 19.1 & 1.5 \\
\hline 2/8/2012 & 17.4 & 18.8 & 1.4 \\
\hline $2 / 9 / 2012$ & 16.9 & 15.7 & 1.2 \\
\hline 2/10/2012 & 16.5 & 15.1 & 1.4 \\
\hline
\end{tabular}


Table 4 (continued)

\begin{tabular}{lrrr}
\hline $2 / 11 / 2012$ & 16.2 & 18.6 & 2.4 \\
$2 / 12 / 2012$ & 14.3 & 8.4 & 5.9 \\
$2 / 13 / 2012$ & 13.0 & 9.2 & 3.8 \\
$2 / 14 / 2012$ & 12.6 & 10.8 & 1.8 \\
$2 / 15 / 2012$ & 13.3 & 12.9 & 0.4 \\
\hline
\end{tabular}

\subsection{Standard Event Pattern Composites}

It was necessary to determine typical daily patterns that were associated with severe hypothermic stunning events in terms of cold air movements and wind flow. On the days designated as 'high magnitude', a mass of unstable, abnormally cold air developing from the high latitudes is pushed southward into Florida (Figure 37). As can be seen, surface air temperatures could drop into the extreme negatives. Geopotential height contours are typically aligned with wind flow patterns as seen in figure 38 , where a flow directly into Florida can be seen for high magnitude days (NCEP Reanalysis).

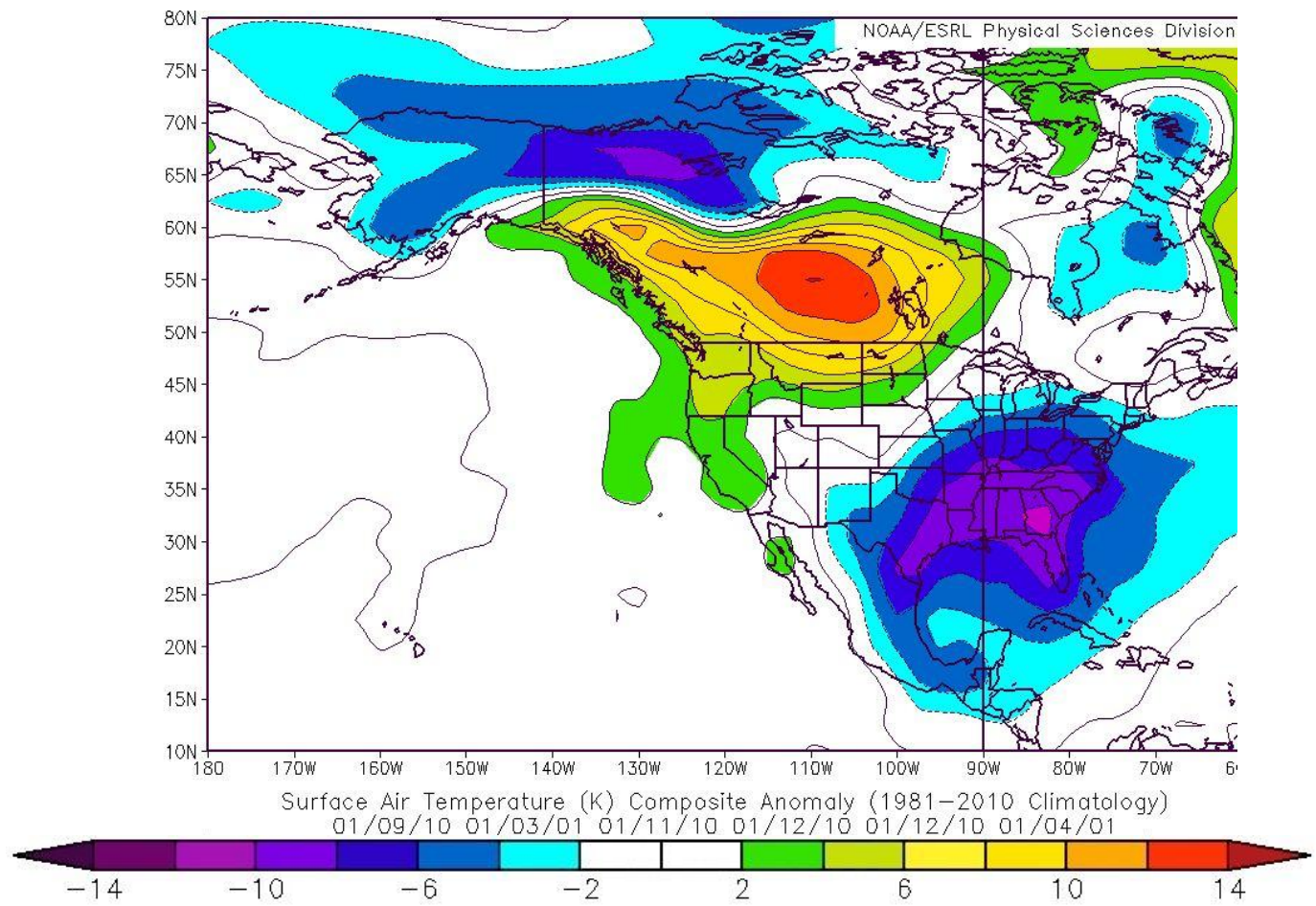

FIGURE 37. Surface air temperature composite anomaly for high magnitude days 


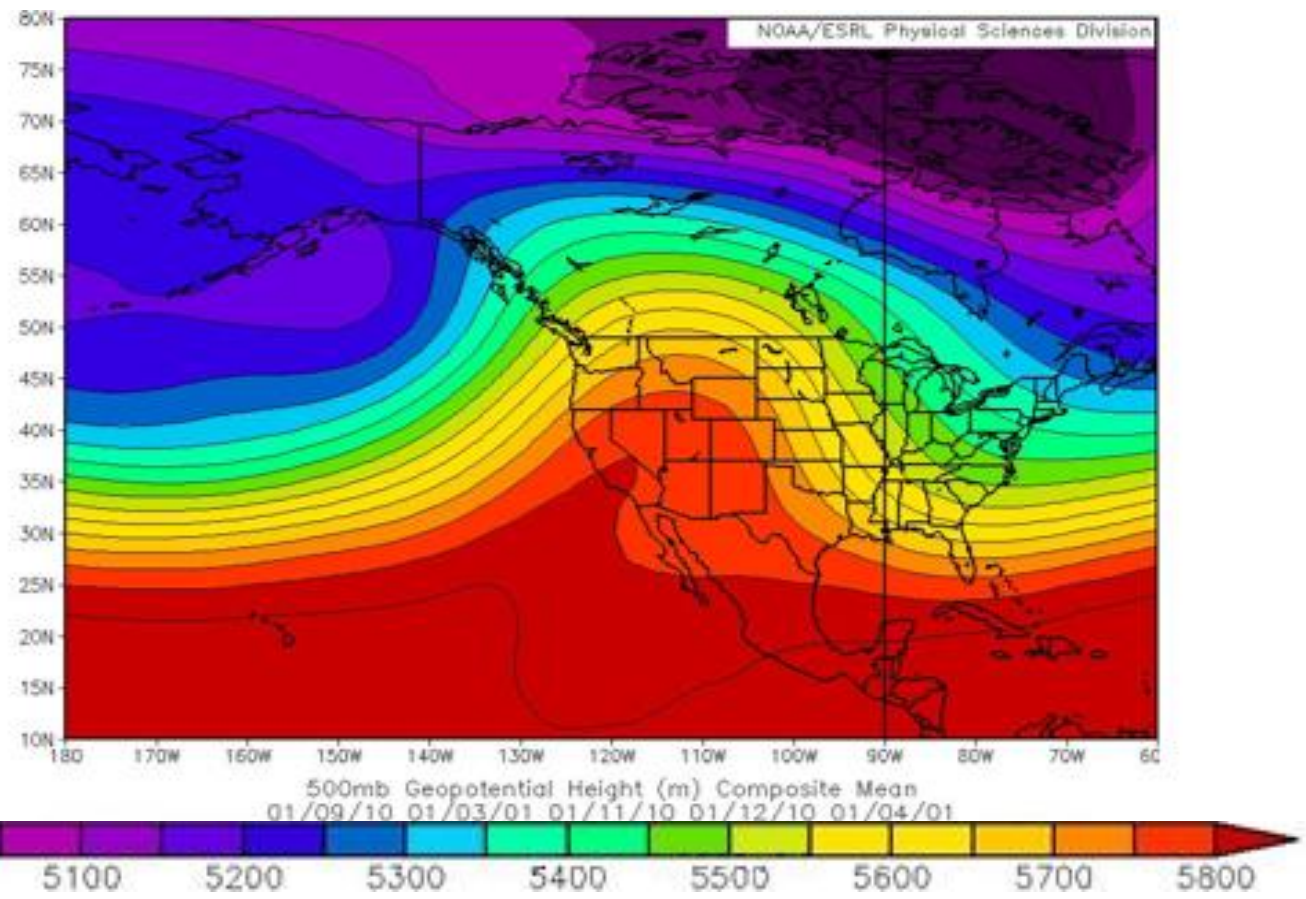

FIGURE 38. 500mb Geopotential height composite mean for high magnitude days 


\section{Chapter 4: Discussion}

Marine turtle hypothermic stunning events can vary in severity depending on the atmospheric patterns that are present. This study provides a clear indication that the variables air temperature, water temperature, wind speed and direction can all measurably influence an atmospheric cold snap that could result in a hypothermic stunning event.

\subsection{Analysis of atmospheric variables}

By examining in situ air and water temperature, it is clear that these two variables are the primary driving force behind the shaping of a green turtle cold-stun event, either moderate or severe. Air and water temperature are intimately related in the two study locations, represented by a 0.87 correlation value for January 2010. Therefore, for years when water temperature was intermittent or unavailable, inferences were drawn from air temperature patterns as to why certain events were classified as moderate or severe. In the case of January 2001, negative air temperatures were likely followed by a rapid decrease in water temperature well below the $10^{\circ} \mathrm{C}$ threshold. It is also probable, given the 12-day duration of the event that water temperatures did not recover to a tolerable range until 2 or 3 days prior to the end of the event, thus generating severe cold-stunning effects. Conversely, January 2003 received a moderate classification due to its very short extent and resulting low numbers of disabled turtles. Although, air temperature did fall into the negative values, it warmed up substantially within just a few days in this case.

Because both air and water temperatures were accessible for both study areas in January 2010, a comprehensive conclusion can be reached. Unlike 2003 atmospheric 
patterns, air and water temperature did not drop abruptly but rather displayed a slow, steady decline. Upon reaching the threshold value, water temperature continued to drop reaching lethal values for green turtles. Many comparisons can be seen between the two severe events of 2001 and 2010. While water temperature was not archived for 2001, Foley et al. (2007) reported values between 5 and $6^{\circ} \mathrm{C}$ for the first few days of January. January 2010 values were similar in St. Joseph Bay and even lower in Mosquito Lagoon. The duration of these two events was also similar, although 2010 was slightly more prolonged in terms of intolerable temperatures. Air temperature trends were vastly different between the two years, particularly since January 2010 never experienced negative values. While 2001 was considered a massive cold-stun event; it doesn't quite measure up to the sheer scale of 2010 based upon turtle numbers and the duration of temperatures below the threshold value.

An analysis of wind direction revealed that the north and westerly surface winds were by far the most influential in the formation of a cold-stunning event. In the case that a southerly wind is present during an event, as occurred during 2010 Mosquito Lagoon, a brief warm-up for both air and water temperature occurs, resulting in fewer cold-stunned sea turtles in need of rehabilitation. Wind direction is an essential variable to be aware of in the case of a rescue initiative following a cold-stun event. A cold-stunned, disabled sea turtle will float to the surface and be subject to the wind and current. Rescue personnel can utilize wind direction measurements from buoys to assist them in locating stranded turtles. 


\subsection{Formation of a hypothermic stunning event}

The Florida STSSN should be alerted of certain patterns that have contributed to the development of past events as analyzed in this study. Beginning on a broad scale, the two severe events examined can be connected to extreme negative values of the Arctic Oscillation. As evident in the NCEP data composites, a cold air mass will likely form over Alaska or Canada and travel across the U.S. before arriving in Florida. The cold air will typically impact the panhandle first before descending throughout the rest of the state. Depending on how long the mass of cold air lingers in Florida, as many as several thousand sea turtles could be impacted by abnormally cold temperatures. Such cold air masses are usually associated with high wind speeds and north or westerly facing surface vectors.

On a more local scale, shallow areas such as St. Joseph Bay and Mosquito Lagoon will be affected by a cold front system much more abruptly than offshore, deeper environments. Water temperatures could begin to cool as soon as air temperatures start to drop and just several hours could be the difference between tolerable and fatal temperatures for green turtles in shallow water environments. A combination of freezing air, high wind speeds, and north or westerly vector winds could result in water falling temperatures well below $10^{\circ} \mathrm{C}$. In order to circumvent a possible repeat of the chaos associated with the 2010 cold front, results suggest that ecosystem managers be made aware of a developing cold air mass in the northern latitudes and begin to prepare staff and required equipment. This requires a dependable connection between the NWS forecasting and the Florida STSSN. Agencies such as FWC now have the capability to monitor water temperature fluctuations but cannot predict duration of cold temperatures, 
the most pivotal characteristic of cold-stun events (personal communication, Dr. Allen Foley, October 2013). Similar to hurricane forecasting, percentages of impact and multiple track possibilities of a cold air mass can be highly beneficial. Such precautionary measures can ensure that in the case of a severe cold-stunning event, green turtle mortality rates can be kept at a minimum. Preemptive action can also provide better organization during an event, which can allow for increased sampling methods and tagging efforts. 


\section{Chapter 5: Conclusions}

Previous research supports the idea that only very favorable conditions will shape a cold snap that can strike Florida, given the rarity of such an event. Generally, cold snaps are a succession of cold fronts which can circulate for up to five days and typically last for two or three days. Water temperatures will cool with each day a cold snap lasts and can drop rapidly if the cold snap is severe. Strong winds and a resulting high wind chill factor are frequently associated with cold snap formation. Results from this research demonstrate that frigid air temperatures, resulting low water temperatures, high wind speeds, and north or westerly prevailing winds will produce a cold snap that could stun sea turtles.

This study supports the research conducted by Schwartz (1978) that green turtles will begin to show symptoms of cold-stunning at $10^{\circ} \mathrm{C}$ and die of hypothermia under $6^{\circ} \mathrm{C}$. It is convenient for rescue agencies that $10^{\circ} \mathrm{C}$ has proved to be a reliable threshold value even 30+ years after Schwartz's original experiment. If water temperature falls below this level for longer than 12-24 hours, it is very likely that green turtles will be found coldstunned (personal communication, Dr. Allen Foley, October 8, 2013). Longer durations below this threshold temperature will result in more severe cold-stunning events, similar to the 2001 and 2010 event. Other marine turtle species, like loggerheads and Kemps ridleys that are more aggregated in deeper water, will also begin to cold-stun if prolonged cold temperatures impact offshore waters. Also consistent with Schwartz's findings, 
results suggest that the severity of an event has little to do with how rapidly water temperatures drop after exposed to frigid air temperatures.

It is important to develop a forecasting strategy or model in conjunction with the NWS to achieve the utmost level of preparedness for a future cold-stun event. Once a model or strategy is created, an efficient mechanism for relaying such information to Florida agencies is needed. While it is expected that forecasts can change abruptly, lag times in communication can be detrimental to sea turtles and other marine species that rely on rescue personnel, adequate space and equipment in the event of a prolonged cold spell. Familiarity with atmospheric patterns that could or have contributed to hypothermic stunning events, as shown in this study, can ensure improved forecasting and response times, as well as minimal damage to the green turtle population.

\subsection{Limitations and Future Work}

A primary limitation of this research was data availability. While the NDBC data for nearby regions were accessible, a continuous water temperature-monitoring buoy has yet to be deployed in St. Joseph Bay. Data was retrieved from a nearby buoy in Apalachicola. It was also a challenge to locate historical data for both study areas. It was necessary to gain insight into past documented cold-stun events back to 2001 . Unfortunately, water temperature was not archived for either study area until 2004. This required generalizations based solely upon air temperature. Atmospheric data was not consistently available from just one web interface per location. It was necessary to utilize multiple web interfaces, which could have led to inaccurate data.

Another study limitation was the fact that trends in juvenile green turtle populations throughout the region are not defined. These fluctuations could be a pivotal 
factor influencing the number of turtles rescued during a hypothermic stunning event (personal communication, Robert Hardy, October 2013). The data set retrieved from FWRI contained limited information as cold-stun events are not designed to perform a population assessment. The priority of these events is to rescue and rehabilitate individuals and then to release them when water temperatures have exceeded the threshold value.

This study has multiple future implications. Sea turtles are certainly not the only species that can fall victim to cold stress. As previously mentioned coral reefs can quickly die off from cold temperatures. Mass strandings due to hypothermia have also been documented in several marine mammal species such as dolphins and manatees. The cold snap of January 2010 resulted in a record number of manatee deaths in Florida. Similar to the simultaneous sea turtle cold-stun event, the magnitude was related to the unusual duration of cold-water temperatures. A total of 480 manatee deaths were recorded from January to April 2010, with the majority ( $N=252)$ of manatees' determined cause of death documented as cold stress (b et al. 2011). The methodology utilized in this research can be improved upon and applied to analyze such events for other endangered or protected species. It would also be beneficial to compare buoy data to archived satellite data for sea surface temperature (SST). It is possible with satellite data to derive SST and other variables from virtually any location at specified time increments. Such accuracy would be useful in gaining exact temperature records for St. Joseph Bay and Mosquito Lagoon rather than utilizing alternate locations as a proxy. As a continuation of this research, the methodology could be extrapolated to other species of sea turtles that are less impacted by extreme temperature drops in shallow environments as in deeper, 
offshore waters. It would be interesting to determine the time interval between when shallow water bodies fall below $10^{\circ} \mathrm{C}$ and when deeper waters begins to cool. Remote sensing techniques would be necessary for that objective. 


\section{References}

Ambaum, M.H.P., B.J. Hoskins, and D.B. Stephenson. 2001: Arctic Oscillation of North Atlantic Oscillation?. J. Climate, 14, 3495-3507.

Avens, L., C. Harms, E. Anderson, L. Goshe, A. Goodman, W. Cluse, M. Godfrey, J. Braun-McNeill, and B. Stacy, 2012: 448 Turtles in the freezer: and population assessment of green sea turtles stranded dead in St. Joseph Bay, Florida, USA, during the January 2010 mass cold-stunning. Proceedings of the thirty-first annual symposium on sea turtle biology and conservation, NOAA Technical Memorandum NMFS-SEFSC-631.

Balazas, G.H. and M. Chaloupka, 2003: Thirty-year recovery in the once depleted Hawaiian green sea turtle stock. Biological Conservation, 117, 491-498.

Baldwin, M.P. and T.J. Dunkerton. 1999: Propagation of the Arctic Oscillation from the stratosphere to the troposphere. Journal of Geophysical Research: Atmospheres, 104, 30937-30946.

Barlas, M.E., C.J. Deutsch, M. Witt, and L.I. Ward-Geiger, 2011: Florida Manatee Cold-related Unusual Mortality Event, January -April 2010. Final report to USFWS (grant 40181AG037). Florida Fish and Wildlife Conservation Commission, St. Petersburg, FL.

Belskis, L., W. Teas, R. Bailey, N. Evou, A. Hoffman, S. Holmes, L. Staggs, and A. Foley, 2012: St. Joseph Bay: Pocket of cold turtles. Proceedings of the thirtyfirst annual symposium on sea turtle biology and conservation, NOAA Technical Memorandum NMFS-SEFSC-631.

Bjorndal, K.A, and A.B. Bolten. 1988: Growth rates of immature green turtles, Chelonia mydas, on feeding grounds in the southern Bahamas. Copeia, 1988, 555-564.

Blumenthal, J.M., T.J. Austin, C.D. Bell, J.B. Bothwell, A.C. Broderick, G. EbanksPetrie, J.A. Gibb, K.E. Luke, J.R. Olynik, M.F. Orr, J.L. Solomon, and B.J. Godley, 2009: Ecology of Hawksbill Turtles, Eretmochelys imbricata, on a Western Caribbean Foraging Ground. Chelonian Conservation and Biology, 8, 110. 
Bouchard, S.S. and K.A. Bjorndal, 2000: Sea Turtles as Biological Transporters of Nutrients and Energy from Marine to Terrestrial Ecosystems. Ecology, 81, 23052313.

Brock, K.A., Reece, J.S., and L.M. Ehrhart, 2007: The Effects of Artificial Beach Nourishment on Marine Turtles: Differences between Loggerhead and Green Turtles. Restoration Ecology, 10: 1-11.

Bugoni, L., L Krause, M.V. Petry, 2001: Marine Debris and Human Impacts on Sea Turtles in Southern Brazil. Marine Pollution Bulletin, 42, 1330-1334.

Butler, K.R, 1998: Coastal Protection of Sea Turtles in Florida. Florida State University Journal of Land Use and Environmental Law. Retrieved from http://www.law.fsu.edu/journals/landuse/vol132/butl.htm.

Carr, A, 1987: New perspectives on the pelagic stage of sea turtle development. Conservation Biology, 1, 103-117.

Colella, M.A., R.R. Ruzicka, J.A. Kidney, J.M. Morrison, and V.B. Brinkhuis, 2012: Cold-water event of January 2010 results in catastrophic benthic mortality on patch reefs in the Florida Keys. Coral Reefs, 10, 1-12.

Crowder, L.B., D.T. Crouse, S.S. Heppell, and T.H. Martin, 1994: Predicting the Impact of Turtle Excluder Devices on Loggerhead Sea Turtle Populations. Ecological Applications, 4, 437-445.

Ehrenfeld, D. 1982. Options and limitations in the conservation of sea turtles. Biology and Conservation of sea turtles, Smithsonian Institution Press, 457-463.

Foley, A.M., K.E. Singel, P.H. Dutton, T.M. Summers, A.E. Redlow, and J Lessman, 2007: Characteristics of a Green Turtle Assemblage in Northwestern Florida Determined During a Hypothermic Stunning Event. Gulf of Mexico Science, 25, $131-143$.

Foley, A.M., D. Bagley, R. Bailey, L. Belskis, B. Brost, N. Evou, R. Hardy, S. Hirama, A. Hoffman, M. Koperski, A. Meylan, K. Minch, L. Patrick, J. Provancha, S. Schaf, B. Schroeder, B. Stacy, W. Teas, R. Trindeli, and B. Witherington, 2012: Report on a massive hypothermic stunning event of sea turtles in Florida during January 2010. Proceedings of the thirty-first annual symposium on sea turtle biology and conservation, NOAA Technical Memorandum NMFS-SEFSC-631.

Fowler, Lynn, 1979: Hatching Success and Nest Predation in the Green Sea Turtle, Chelonia Mydas, at Tortuguero, Costa Rica. Ecology, 60, 946-955. 
Gilman, E., E. Zollett, S. Beverly, H. Nakano, K. Davis, D. Shiode, P. Dalzell, I. Kinan, 2006: Reducing Sea Turtle By-catch in Pelagic Longline Fisheries. Fish and Fisheries, 7, 2-23.

Hart, K.M., D.G. Zawada, I. Fujisaki, and B.H. Lidz, 2013: Habitat use of breeding green turtles Chelonia mydas tagged in Dry Tortugas National Park: Making use of local and regional MPAs. Biological Conservation, 161, 142-154.

Henry, J.A., K.M. Portier and J. Coyne, 1994: The Climate and Weather of Florida. Pineapple Press, Inc. 1-216.

Henson, B. and Z. Gallon. 2011: From Arctic Oscillation to Pineapple Express: A weather-maker patterns glossary. University Corporation for Atmospheric Research (UCAR). Retrieved from https://www2.ucar.edu/news/backgrounders/weather-maker-glossary\#_nao.

Hidore, J.J., J.E. Oliver, M. Snow, and R. Snow, 2010: Climatology: an Atmospheric Science. Pearson Education, Inc. 150-157.

Hirth, H.F., 1997: Synopsis of the Biological Data on the Green Turtle Chelonia mydas (Linnaeus 1758). U.S. Department of Interior, Biological Report 97, 1, 1-129.

Lagueux, C.J., 2001: Status and Distribution of the Green Turtle, Chelonia mydas, in the Wider Caribbean Region. Wildlife Conservation Society, 1-5.

Lirman, D., S. Schopmeyer., D. Manzello, L.J. Gramer, W.F. Precht, F. Muller-Karger, K. Banks, B. Barnes, E. Bartels, A. Bourque, J. Byrne, S. Donahue, J. Duquesnel, L. Fisher, D. Gilliam, J. Hendee, M. Johnson, K. Maxwell, E. McDevitt, J. Monty, D. Rueda, R. Ruzicka, and S. Thanner, 2011: Severe 2010 cold-water event caused unprecedented mortality to corals of the Florida Reef Tract and reversed previous survivorship patterns. PLoS ONE 6, e23047.

Lutz, P.L and J.A. Musick. 1997: The Biology of Sea Turtles, Volume 1. CRC Press, Inc., Boca Raton, FL.

Lutz, P.L., Musick, J.A., and Vyneken J, 2003: The Biology of Sea Turtles, Volume 2. CRC Press, Inc., Boca Raton, FL.

Makowski, C., J.A. Seminoff, and M. Salmon, 2006: Home range and habitat use of juvenile Atlantic green turtles (Chelonia mydas) on shallow reef habitats in Palm Beach, Florida, USA. Marine Biology, 148, 1167-1179. 
McKenzie, C., B.J. Godley, R. W. Furness, and D.E. Wells, 1999: Concentrations and patterns of organochlorine contaminants in marine turtles from Mediterranean and Atlantic waters. Marine Environmental Research, 47, 117-135.

Mendonca, M.T. 1983: Movements and feeding ecology of immature green turtles (Chelonia mydas) in a Florida lagoon. Copeia, 1983, 1013-1023.

Meylan, A.B., 1982: Sea turtle migration-evidence from tag returns. K. A. Bjorndal (ed.), Biology and Conservation of Sea Turtles, Smithsonian Institution Press, 91-100.

Meylan, A.B., B.W. Bowen, and J.C. Avise, 1990: A genetic test of the natal homing versus social facilitation models for green turtle migration. Science, 248, 724-727.

Meylan, P.A., A.B. Meylan, and J.A. Gray, 2011: The ecology and migrations of sea turtles: tests of the developmental habitat hypothesis. Bulletin of the American Museum of Natural History, 357, 1-70.

Mogil, H.M. and K.L. Seaman, 2008: Florida's Climate and Weather. Weatherwise, 61, 14-19.

National Marine Fisheries Service and US Fish and Wildlife Service, 1991: Recovery Plan for the US population of the Atlantic Green Turtle. Retrieved from www.nmfs.noaa.gov/pdf

National Marine Fisheries Service and US Fish and Wildlife Service, 2007: Green Sea Turtle 5-Year Review: Summary and Evaluation. Retrieved from www.nmfs.noaa.gov/pdf

NCEP_Reanalysis data provided by the NOAA/OAR/ESRL PSD, Boulder, Colorado, USA. Retrieved from http://www.esrl.noaa.gov/psd.

NOAA, National Weather Service, Weather Forecast Office, Miami, Florida, 2010: Summary of Historic Cold Episode of January 2010: Coldest 12-day Period Since at least 1940.

NOAA Weather Facility, 2010: January and February 2010 Weather Watch. Weatherwise, May/June2010.

Provancha, J.A., E.A. Reyier, K. Minch, R. Cancro, R.H. Lowers, D.M. Scheidt, C.M. Garreau, K. Holloway-Adkins, and S.L. Gann, 2012: January 2010 cold-stun: turtles in the north central Indian River Lagoon and fate of 60 turtles subsequently tracked. Proceedings of the thirty-first annual symposium on sea turtle biology and conservation, NOAA Technical Memorandum NMFS-SEFSC-631. 
Ray-Culp, Melody, 2007: A living shoreline initiative for the Florida Panhandle: Taking a softer approach. National Wetlands Newsletter, 29, 9-11.

Richardson, J.I., 1999: Priorities for studies of reproduction and nest biology. Research and Management Techniques for the Conservation of Sea Turtles, IUCN/SSC Marine Turtle Specialist Group Publication, 4, 1-3.

Roberts, H.H., L.J. Rouse, N.D. Walker, and J.H. Hudson, 1982: Cold-Water Stress in Florida Bay and Northern Bahamas: A Product of Winter Cold-Air Outbreaks. Journal of Sedimentary Petrology, 52, 0145-0155.

Scott, R., D.J. Hodgson, M.J. Witt, et al. 2012: Global analysis of satellite tracking data shows that adult green turtles are significantly aggregated in Marine Protected Areas. Global Ecology and Biogeography, 21, 1053-1056.

Schwartz, F. J, 1978: Behavioral and tolerance responses to cold water temperatures by three species of sea turtles (Reptilia, Cheloniidae) in North Carolina. Florida Marine Research Publications, 33, 16-18.

Seminoff, J. 2004: Sea turtles, Red Listing, and the need for regional assessments. Marine Turtle Newsletter, 106, 4-6.

Spotilla, J.R, 2004: Sea Turtles: A Complete Guide to Their Biology, Behavior, and Conservation. The John Hopkins University Press, Baltimore, Maryland. 94-110.

Still, B.M., C.R. Griffin, and R. Prescott, 2005: Climatic and oceanographic factors affecting daily patterns of juvenile sea turtles cold-stunning in Cape Cod Bay, Massachusetts. Chelonian Conservation and Biology, 4, 883-890.

Wilbur, H.M., D.W. Tinkle, and J.P. Collins, 1974: Environmental Certainty, Trophic Level, and Resource Availability in Life History Evolution. The American Naturalist, 108, 805-817.

Winsberg, M. D., J. J. O’Brien, D. F. Zierden, and M. Griffin. 2003: Florida Weather, 2nd Edition, University Press of Florida, Gainesville, 1-220.

Witherington, B.E. and L.M. Ehrhart, 1989: Hypothermic Stunning and Mortality of Marine Turtles in the Indian River Lagoon System, Florida. Copeia: American Society of Ichthyologists and Herpetologists, 3, 696-703.

Witherington, B.E., 1992: Behavioral Responses of Nesting Sea Turtles to Artificial Lighting. Herpetologica, 48, 31-39.

Witherington, B.E., M. Bresette, and R. Herren, 2006: Chelonia mydas - Green Turtle. Biology and Conservation of Florida Turtles, 3, 90-104. 
Witherington, B.E., P. Kubilis, B. Brost, and A. Meylan, 2009: Decreasing annual nest counts in a globally important loggerhead sea turtle population. Ecological Applications, 19, 30-54.

Witherington, B.E., S. Hirama, and R. Hardy, 2012: Young sea turtles of the pelagic Sargassum-dominated drift community: habitat use, population density, and threats. Marine Ecology Progress Series, 463, 1-22.

Yntema, C.L., and N. Mrosovsky, 1982: Critical periods and pivotal temperature for sexual differentiation in loggerhead sea turtles. Can. J. Zool, 60, 1012-1016. 
Appendices 


\section{Appendix A: Surface Air temperature composites}

Figure A1: Surface air temperature composite anomaly Dec 30-Jan 12, 2001
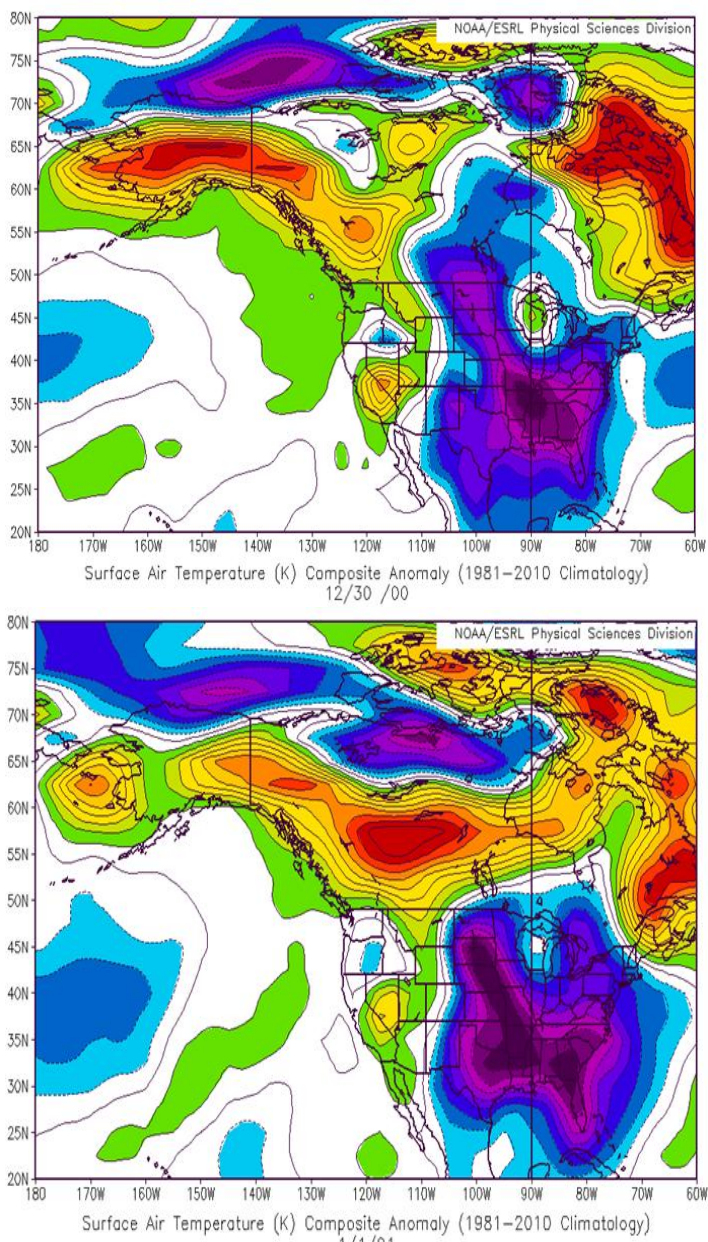

$1 / 1 / 01$
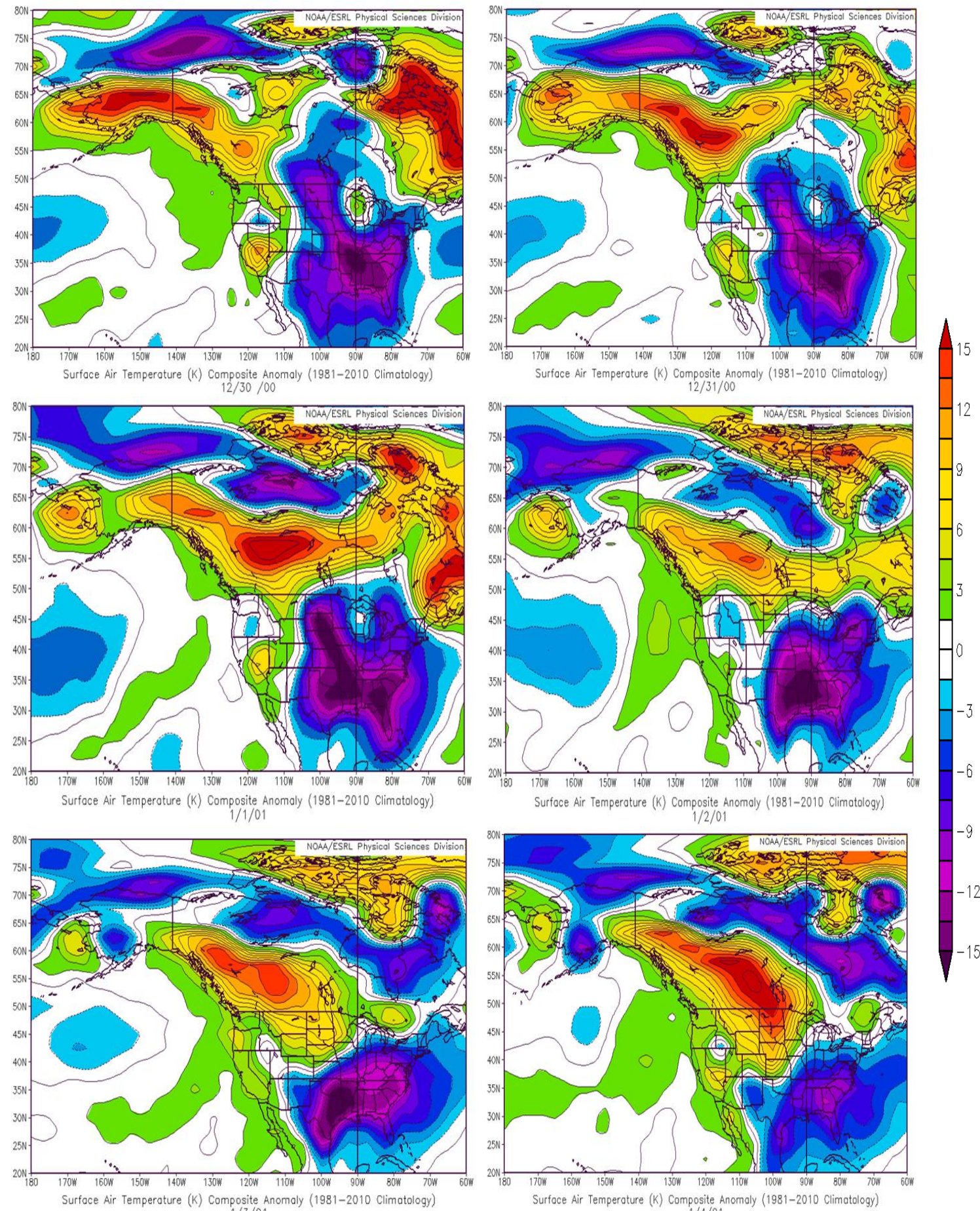

$1 / 3 / 01$

Surface Air Temperoture ( $K$ ) Composite Anomaly (1981-2010 Climatology)

$1 / 4 / 01$ 
Figure A1 (continued).

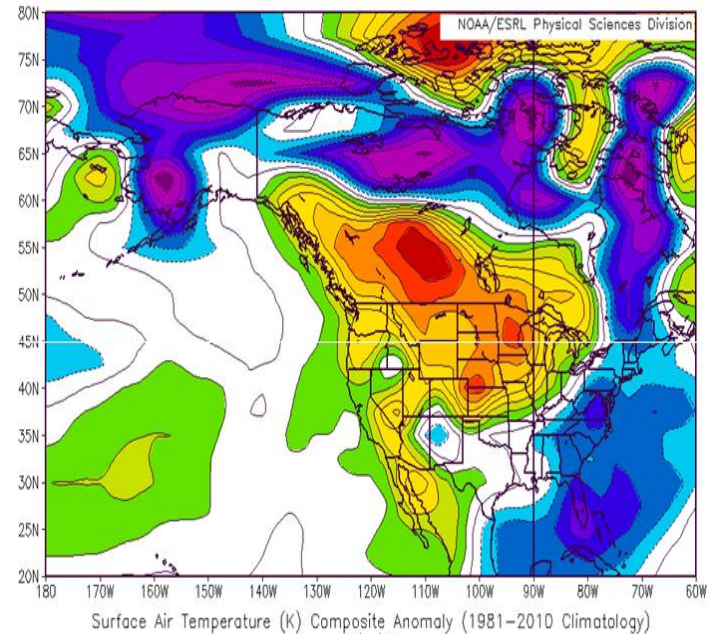
$1 / 5 / 01$

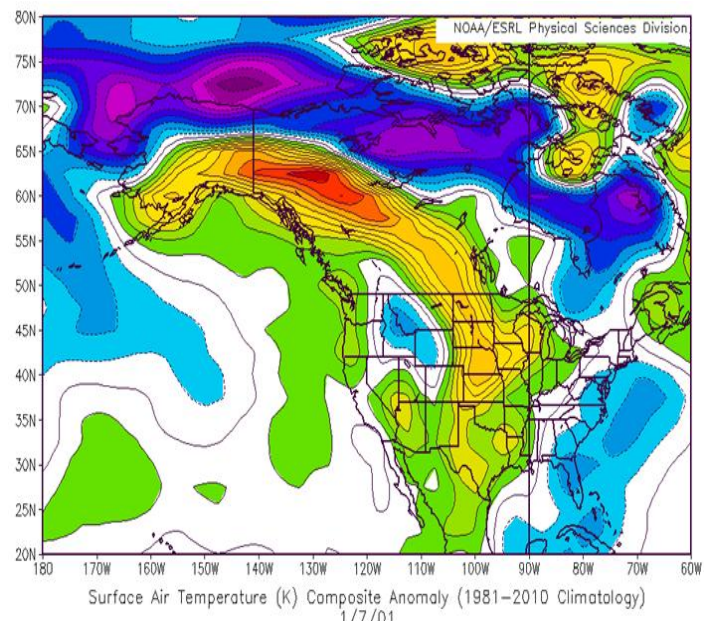

$1 / 7 / 01$

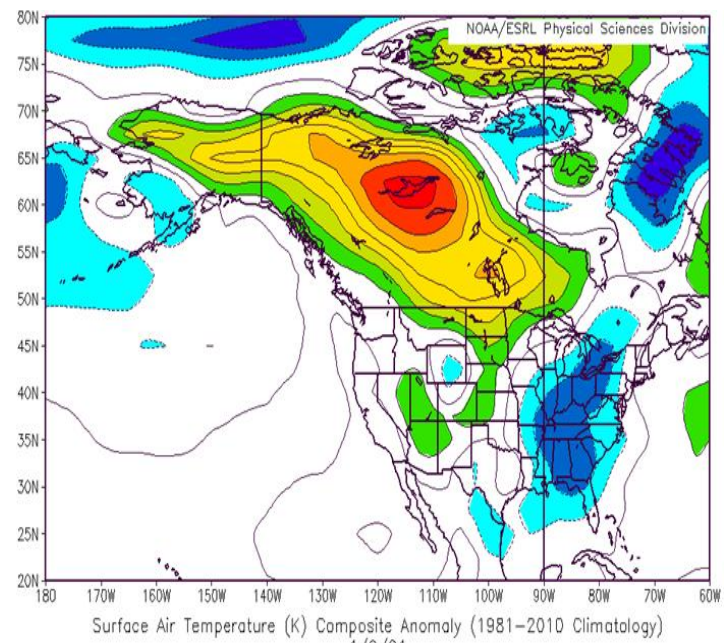
$1 / 9 / 01$
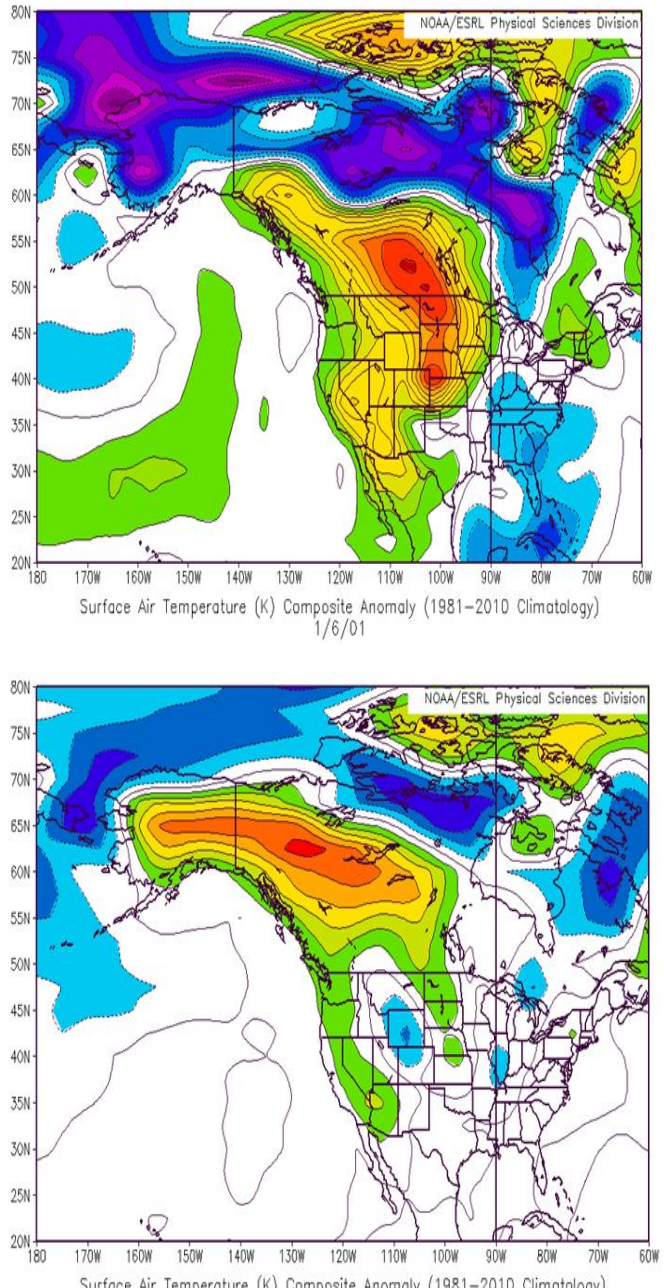
Surface Air Temperoture (K) Composite Anomaly (1981-2010 Climatology)
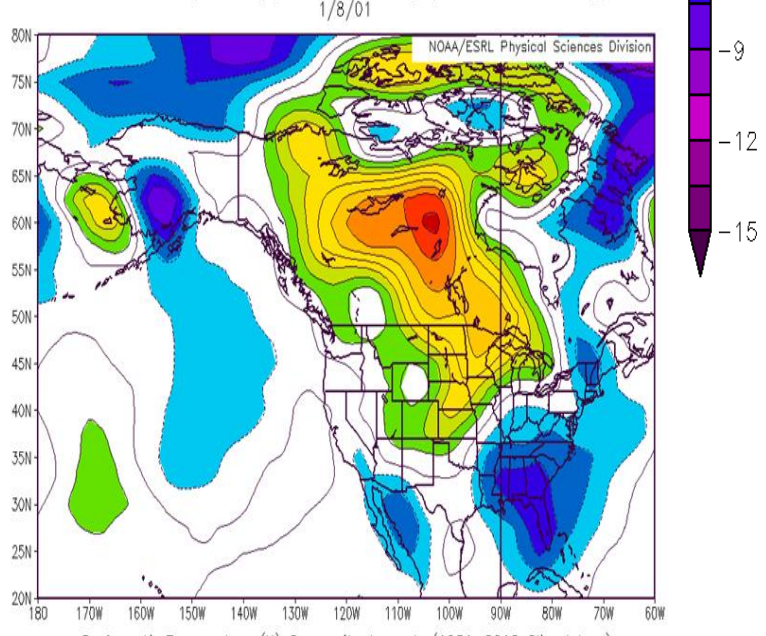

Surfoce Air Temperature (K) Composite Anomaly (1981-2010 Climatology)

$1 / 10 / 01$ 
Figure A1 (continued).
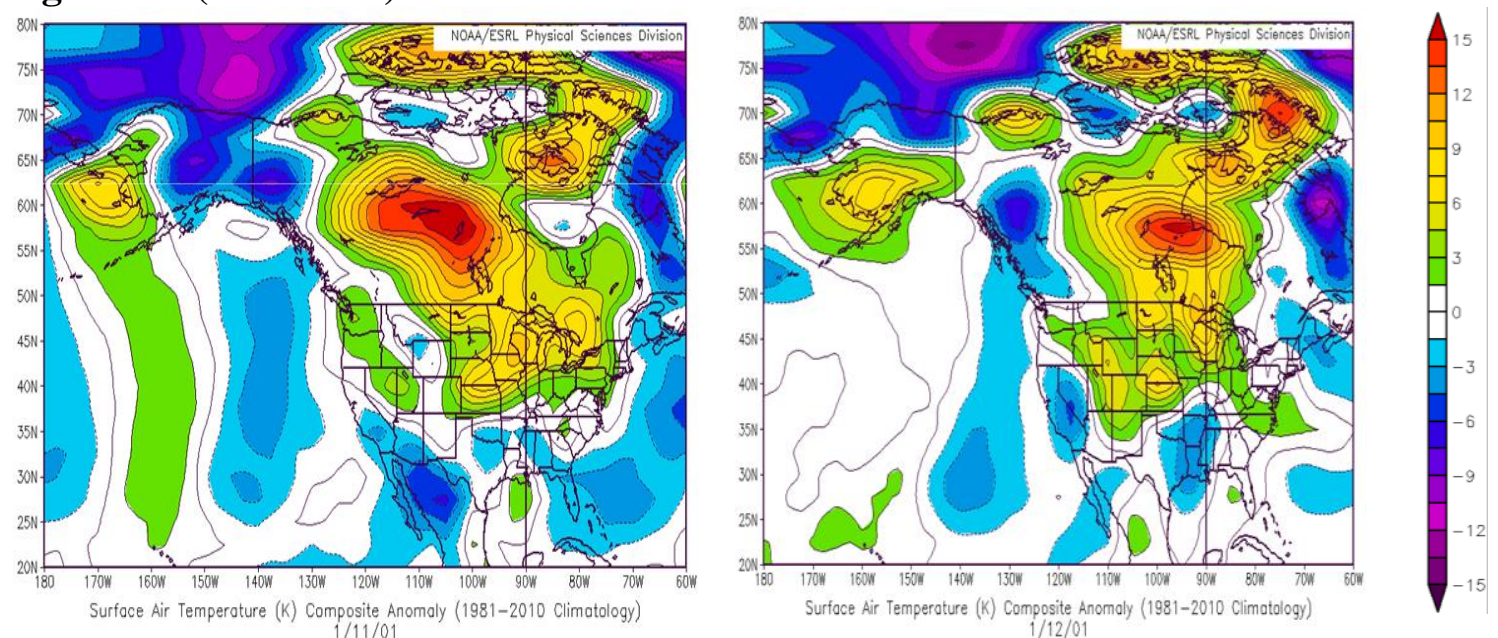
Figure A2. Surface air temperature composite anomaly January 23-29, 2003
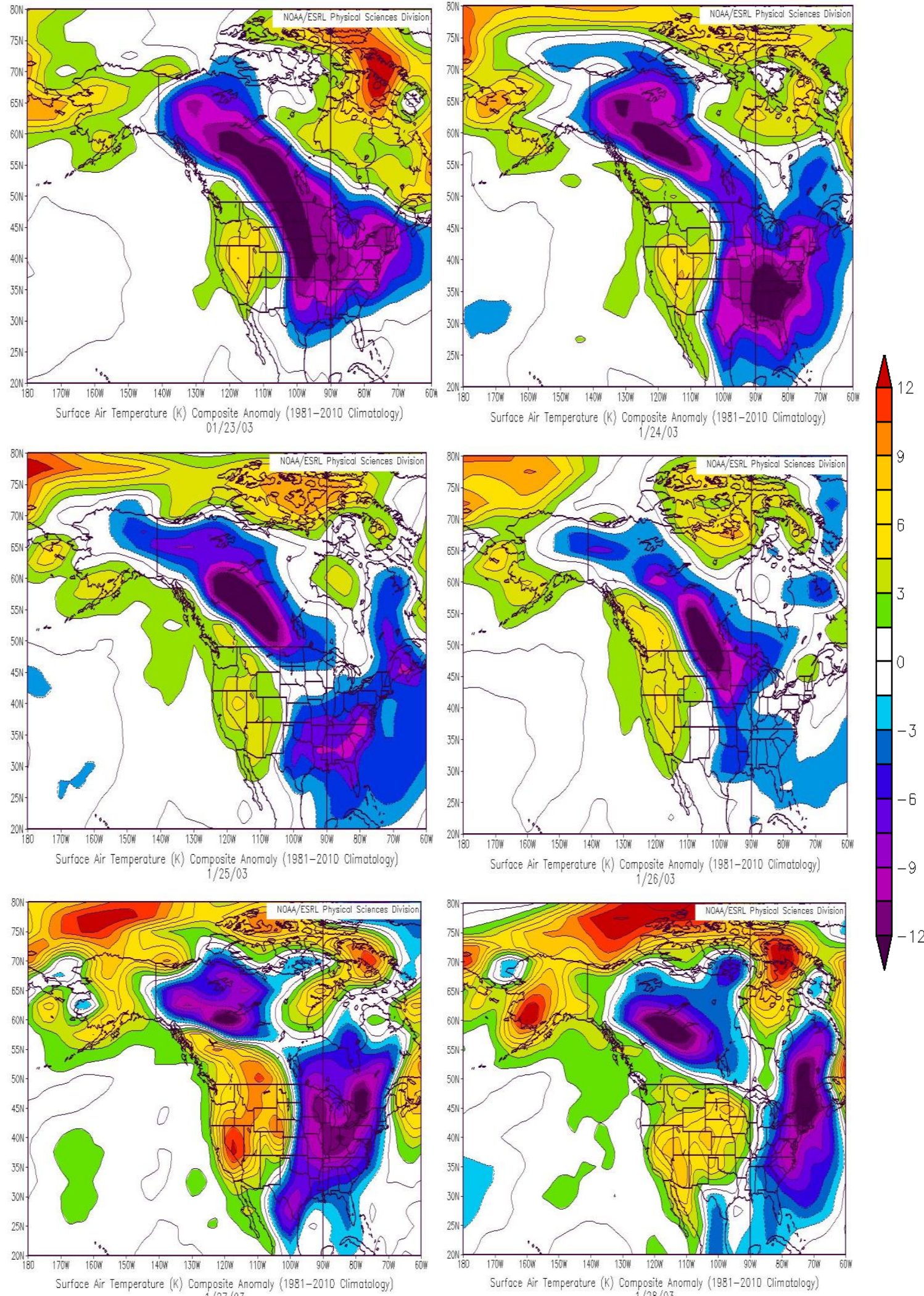

$1 / 27 / 03$

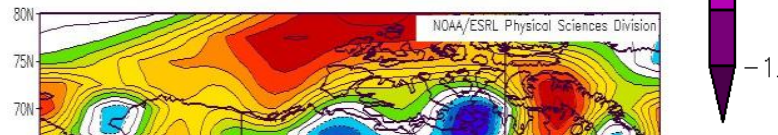


Figure A3. Surface air temperature composite anomaly Dec. 30, 2009- Jan. 16, 2010
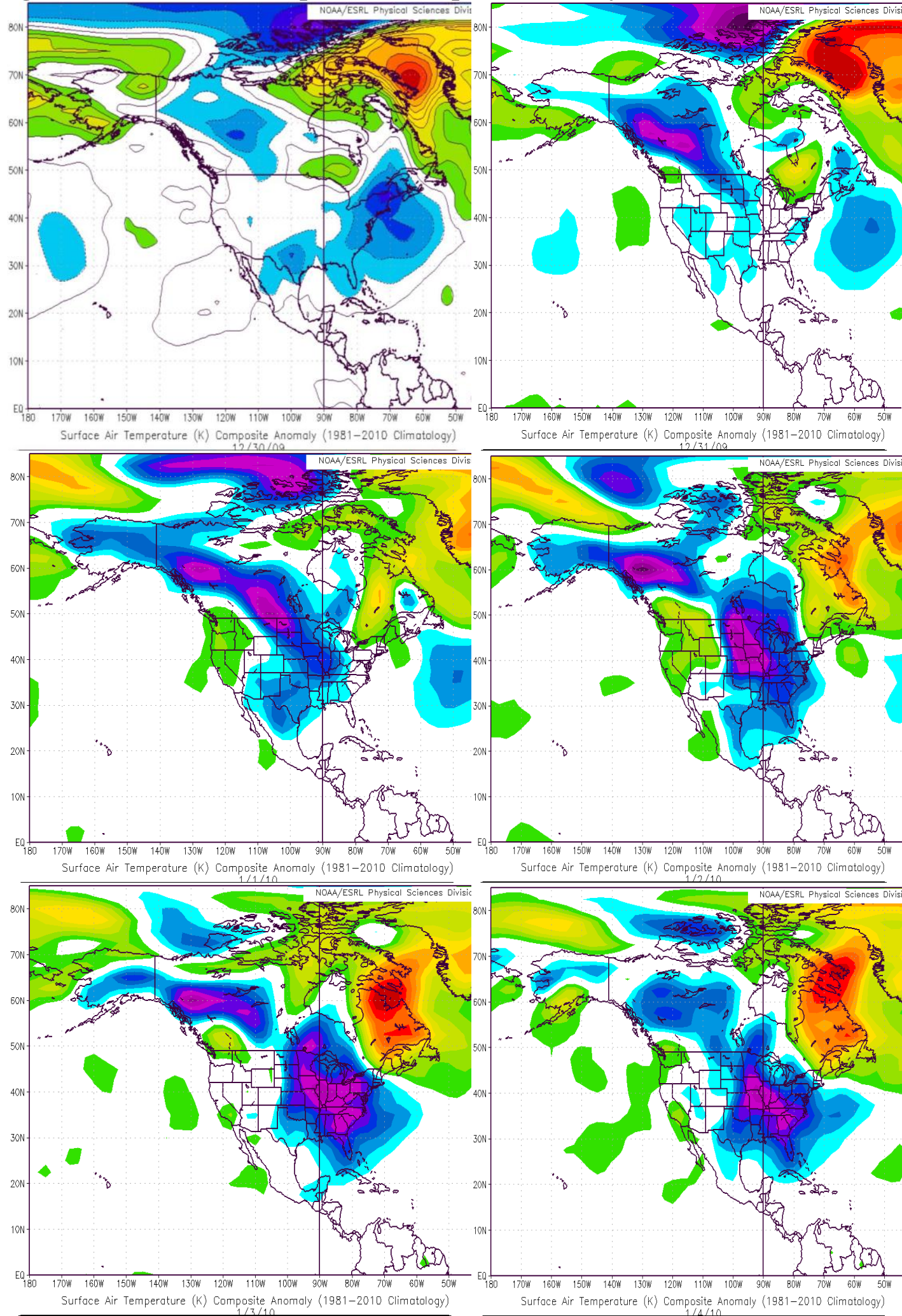

Surface Air Temperature (K) Composite Anomoly (1981-2010 Climatology)

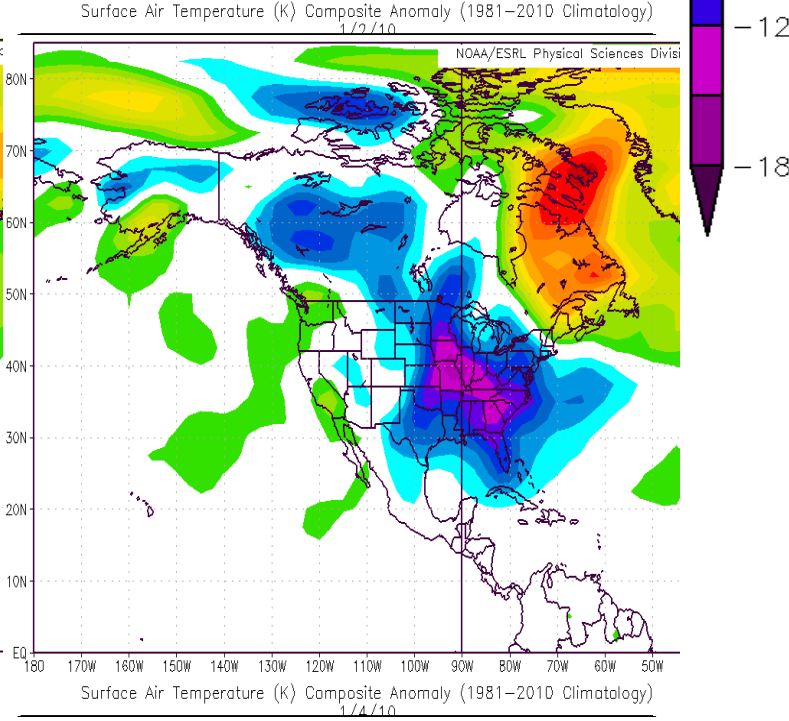


Figure A3 (continued).

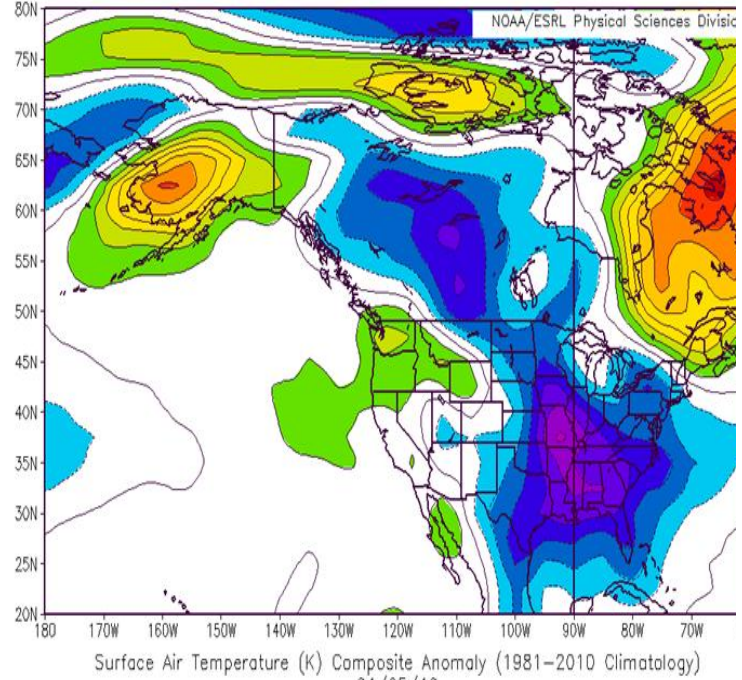

Surface Air Temperature (K) Composite Anomaly (1981-2010 Climatology)

01/05/10

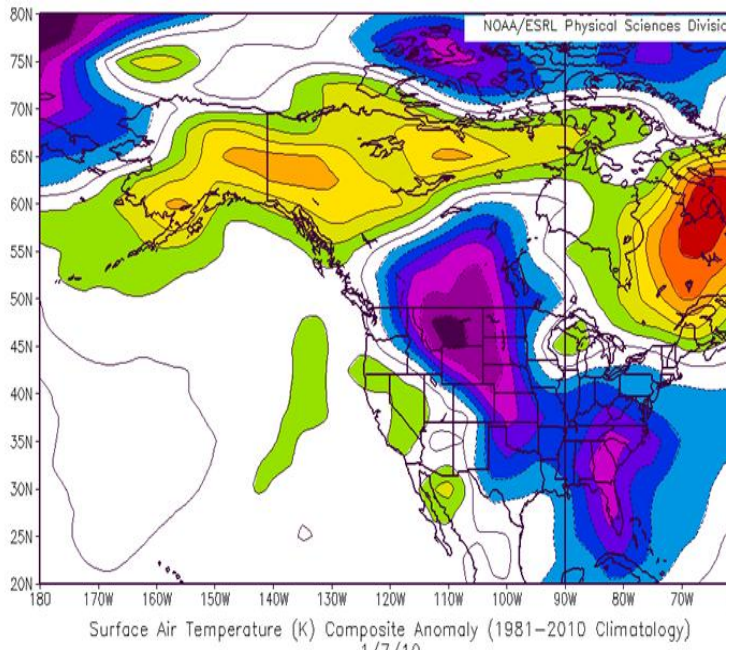

$1 / 7 / 10$
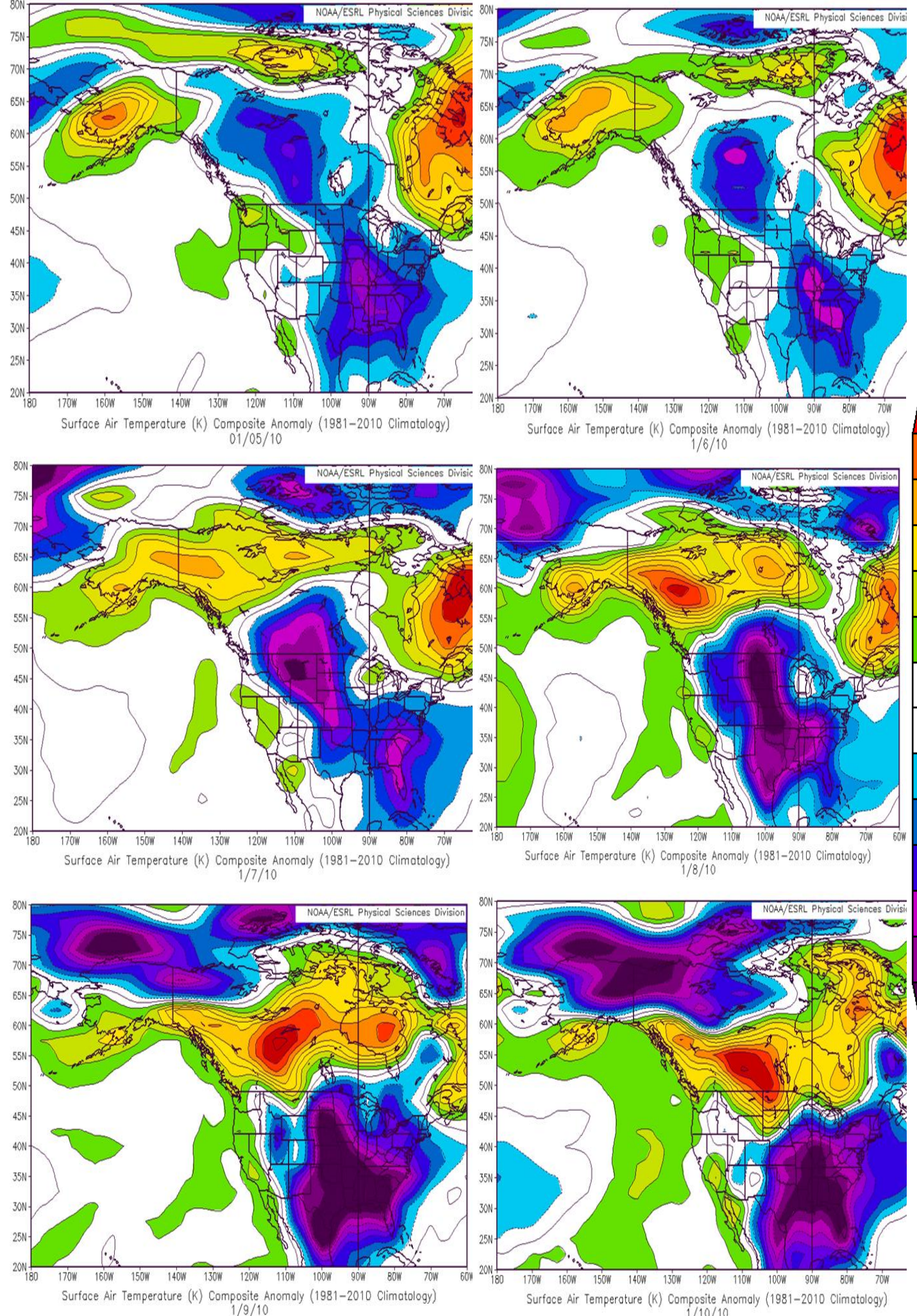

$1 / 6 / 10$

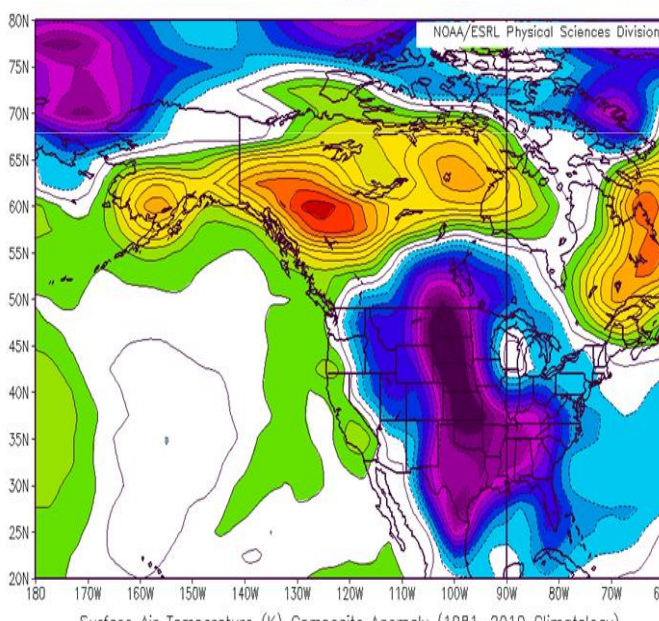

$1 / 8 / 10$

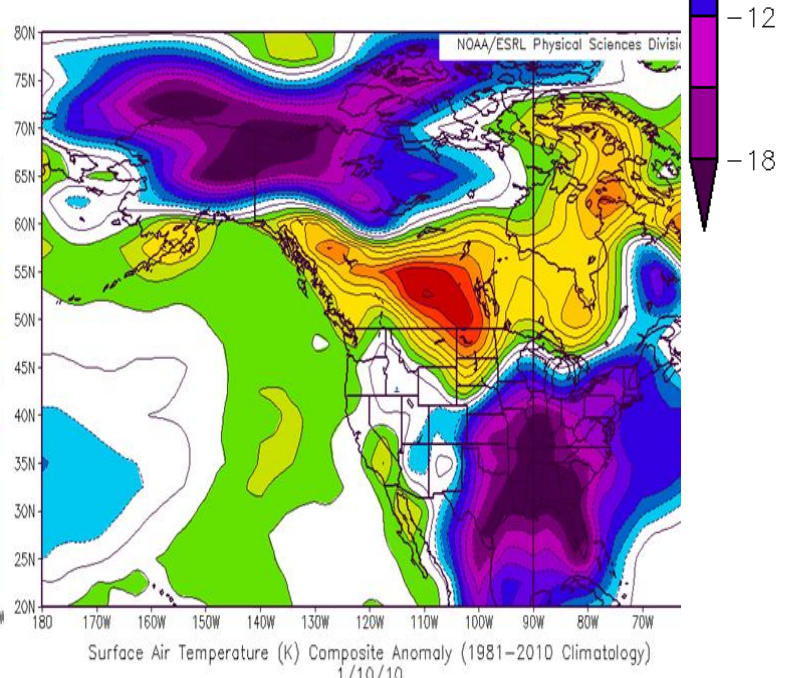

$-12$

$1 / 10 / 10$ 
Figure A3 (continued).
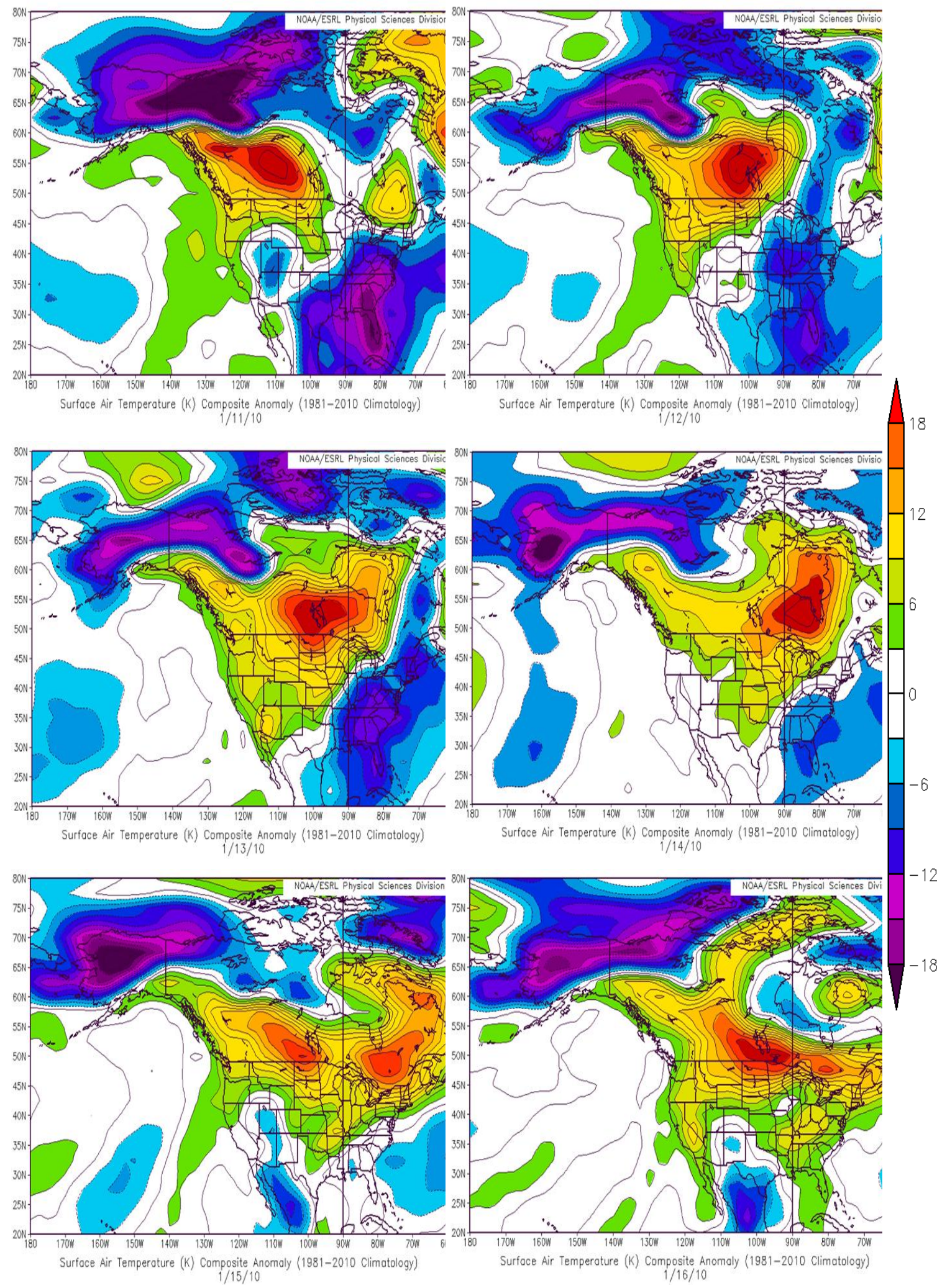


\section{Appendix B: Vector Wind composites}

Figure B1. Vector wind composite anomaly December 30- January 12, 2001
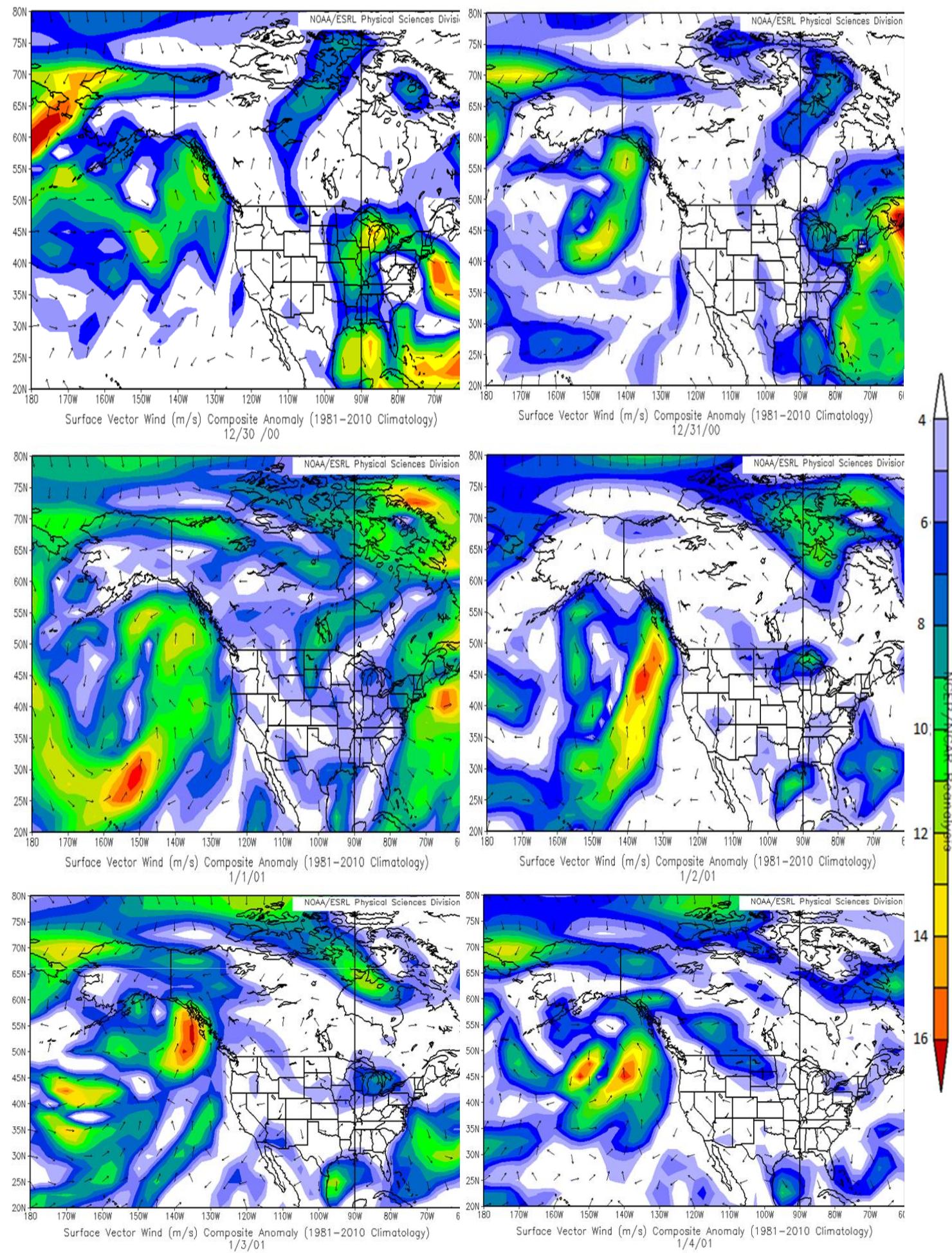
Figure B1 (continued).

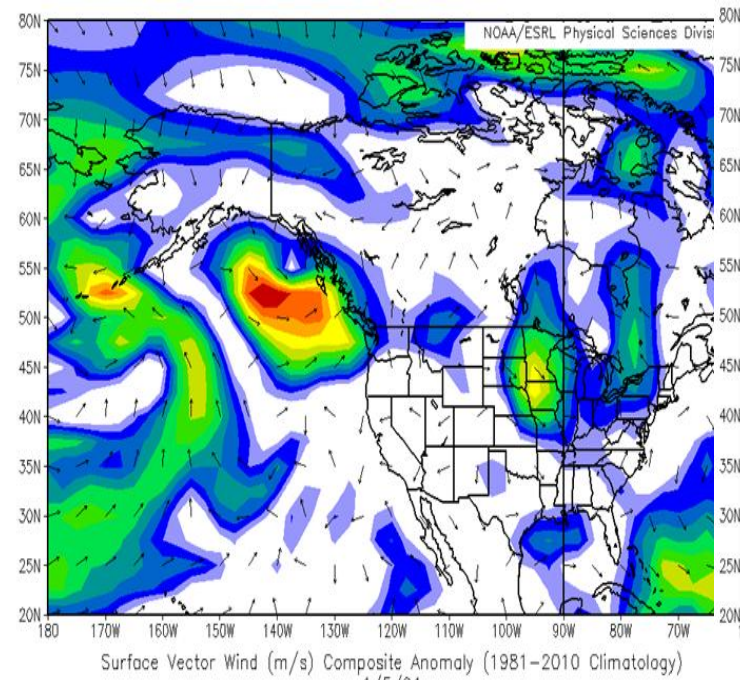

Surface Vector Wind (m/s) Composite Anomaly (1981-2010 Climotology) $1 / 5 / 01$

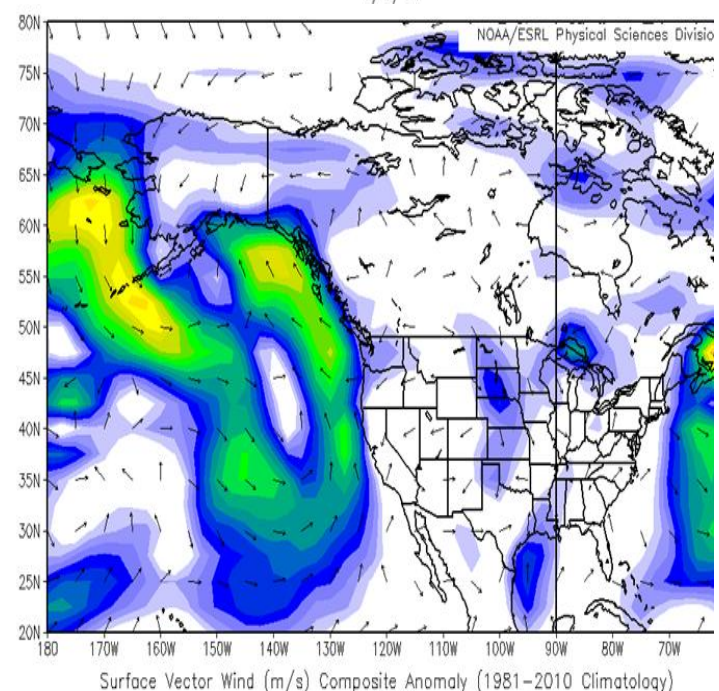
Surface Vector Wind (m/s) Composite Anomaly (1981-2010 Climotology) $1 / 7 / 01$
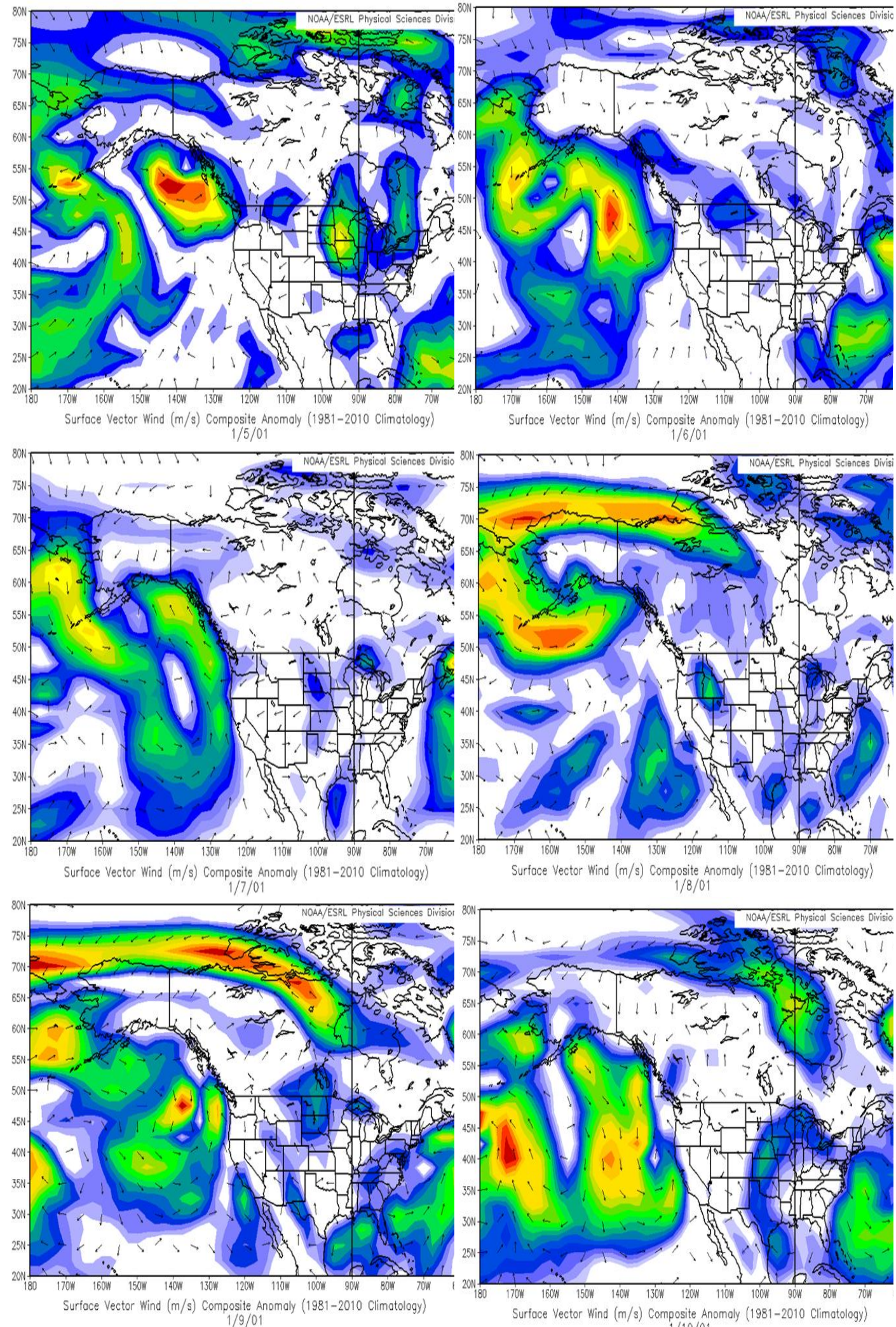

Surface Vector Wind (m/s) Composite Anomaly (1981-2010 Climatology)

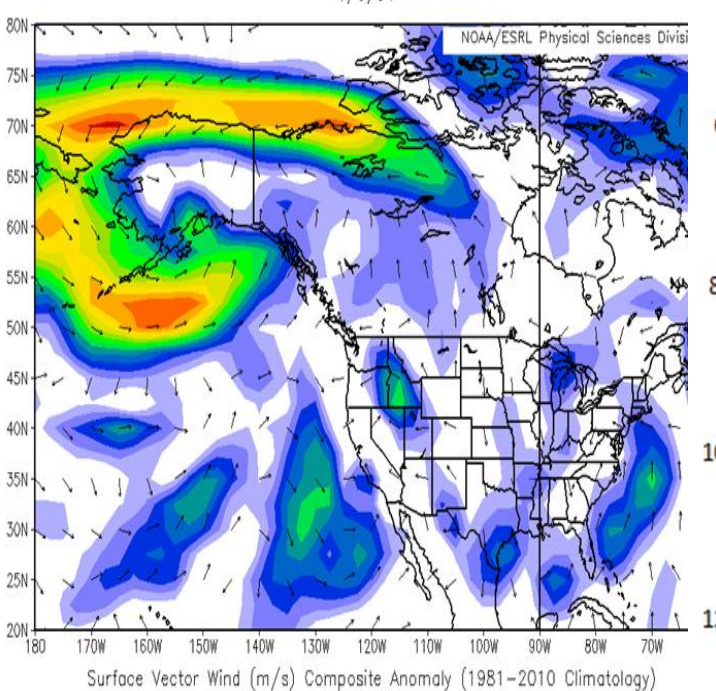

A $18 / 01$

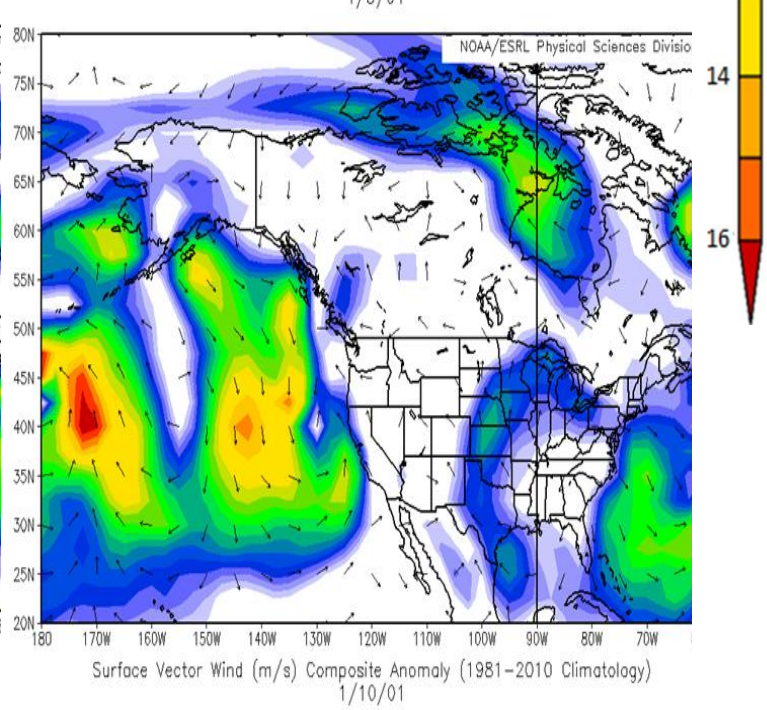


Figure B1 (continued).

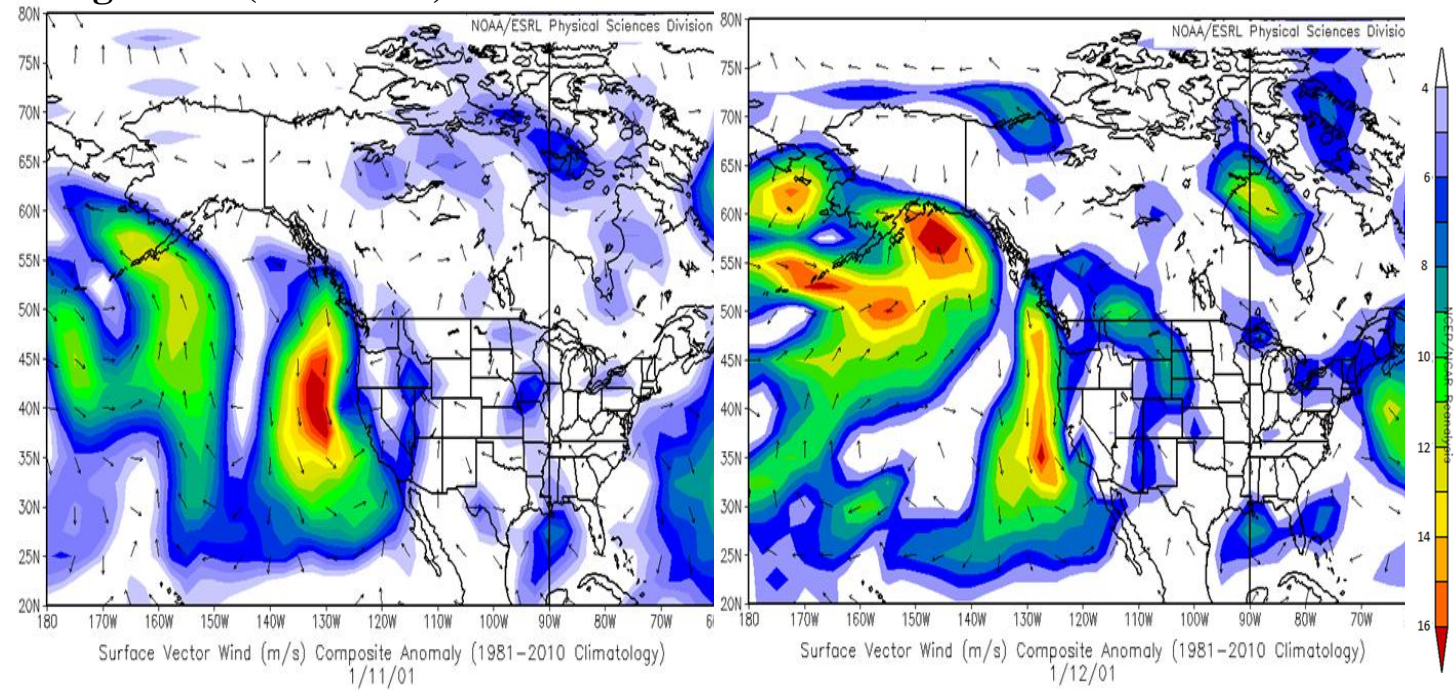


Figure B2. Vector wind composite anomaly January 23-28, 2003
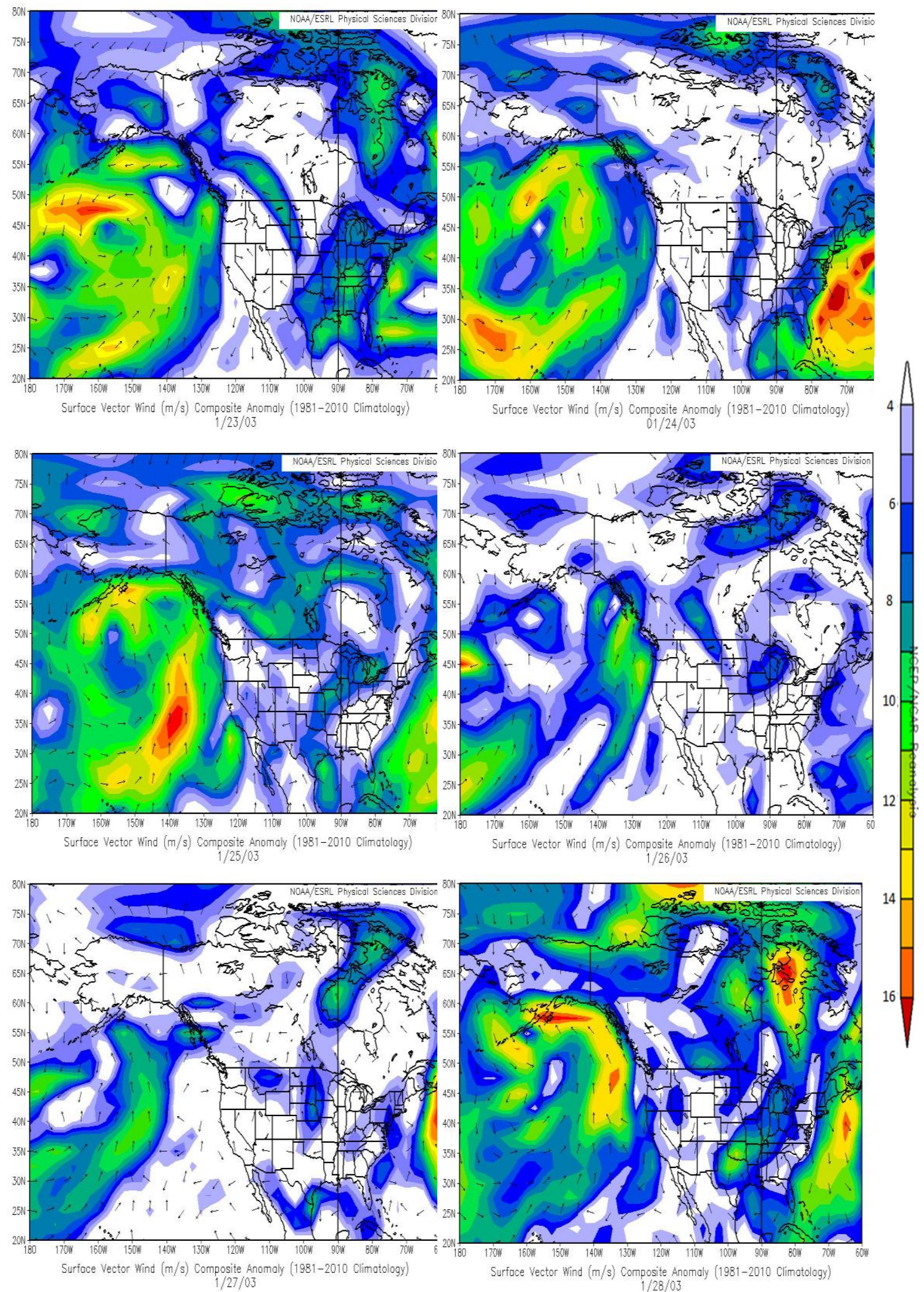
Figure B3. Vector wind composite anomaly January 5-16, 2010
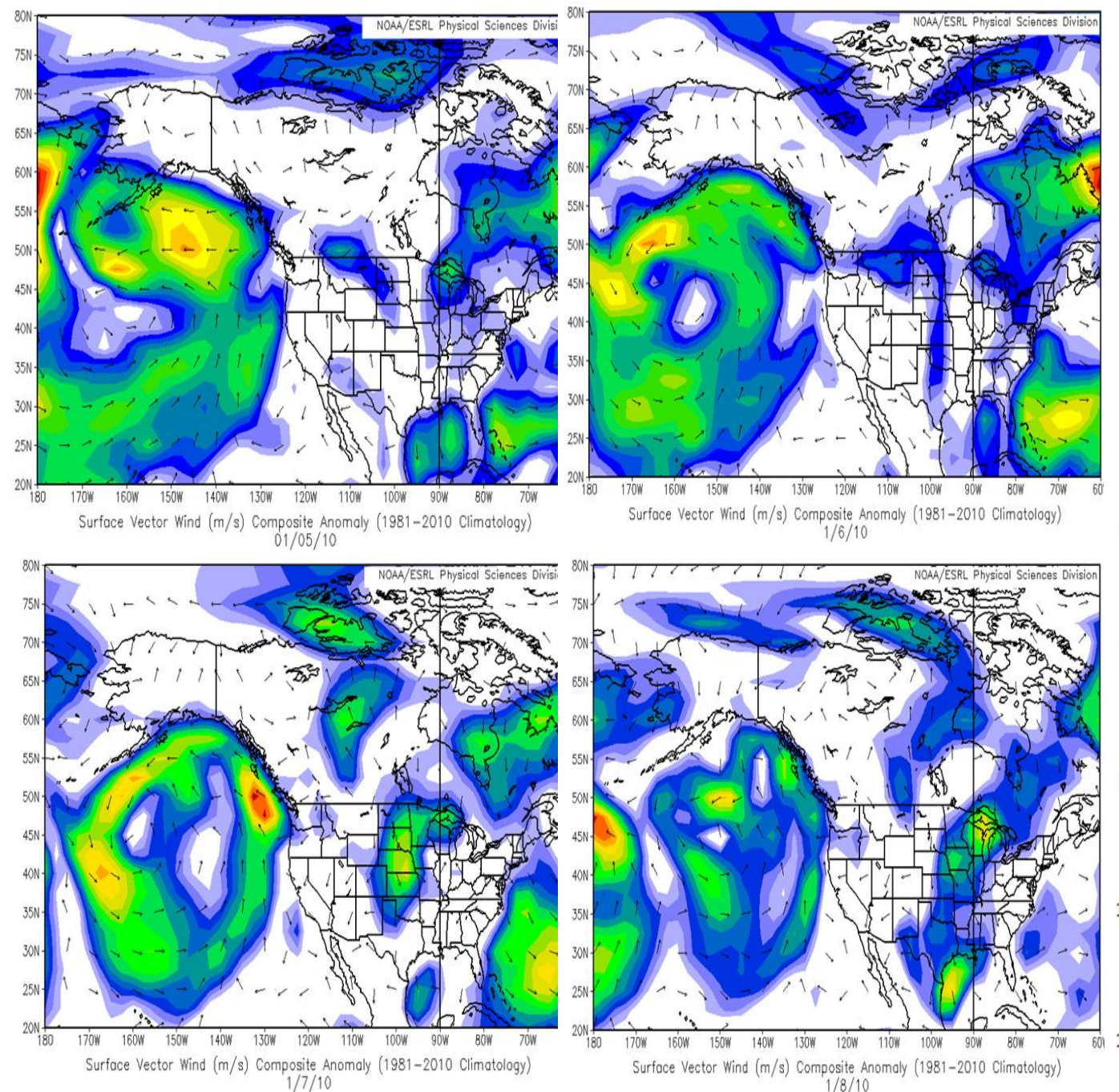

${ }_{4}$
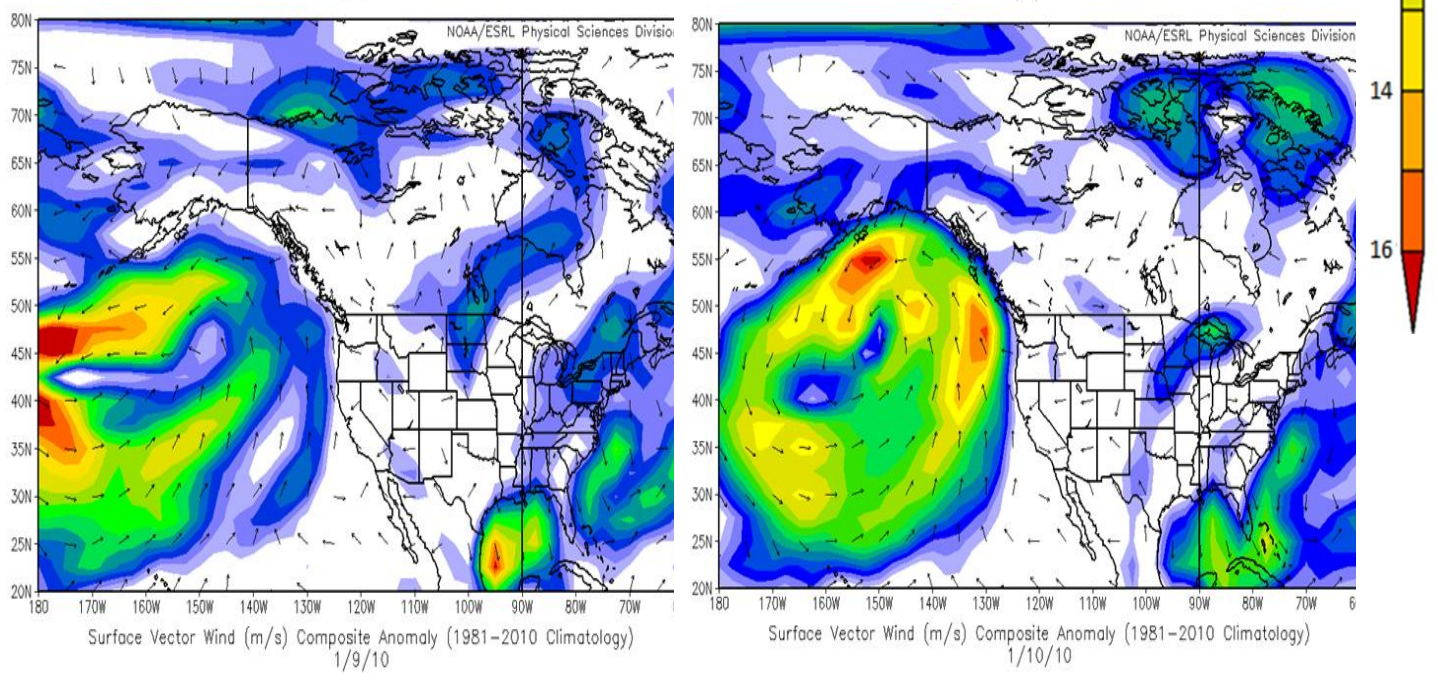
Figure B3 (continued).

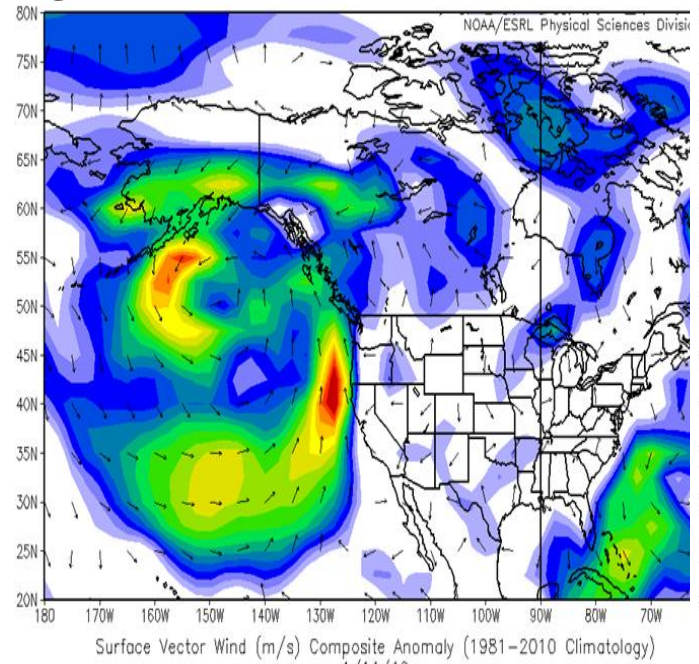

Surface Vector Wind (m/s) Composite Anomaly (1981-2010 Climatology)

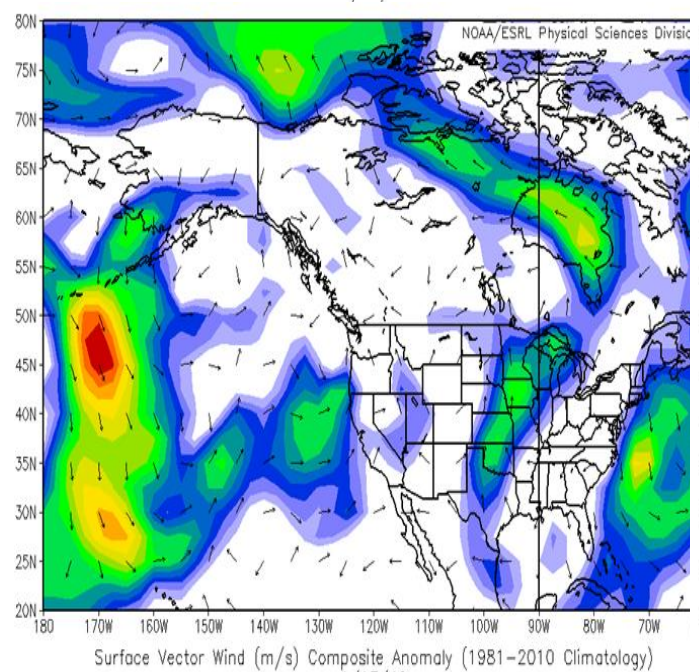

Surface Vector Wind (m/s) Composite Anomaly (1981-2010 Climatology)

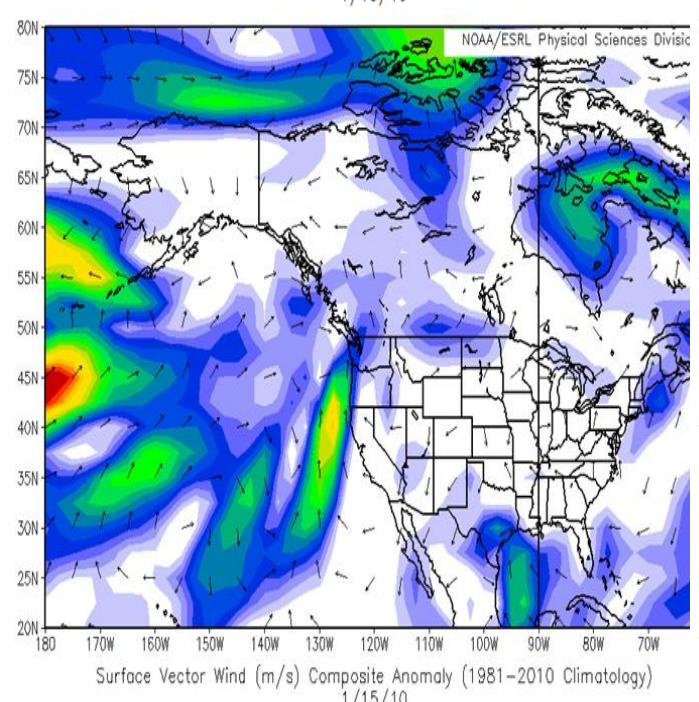

$1 / 15 / 10$

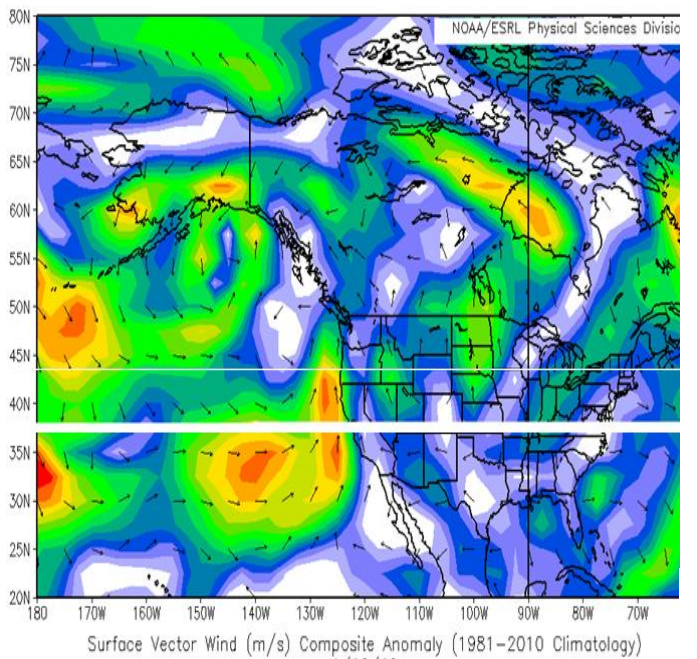

$1 / 12 / 10$

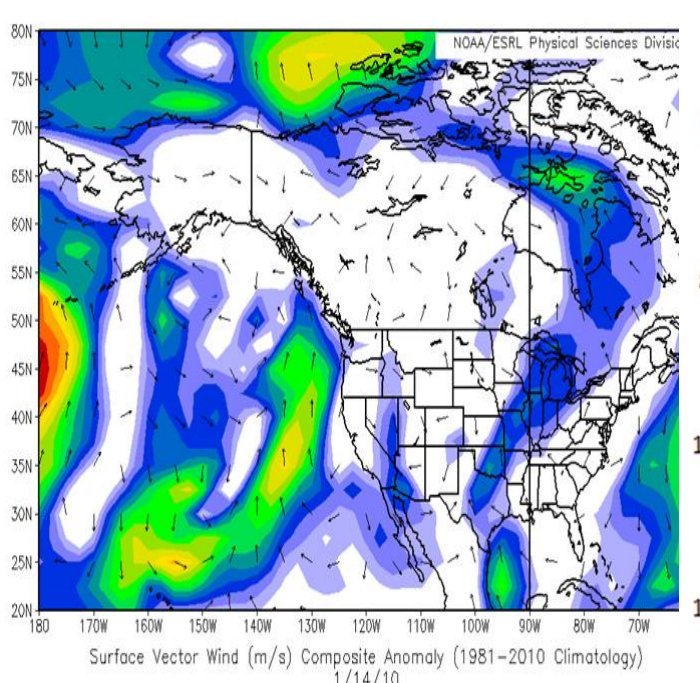

$1 / 14 / 10$

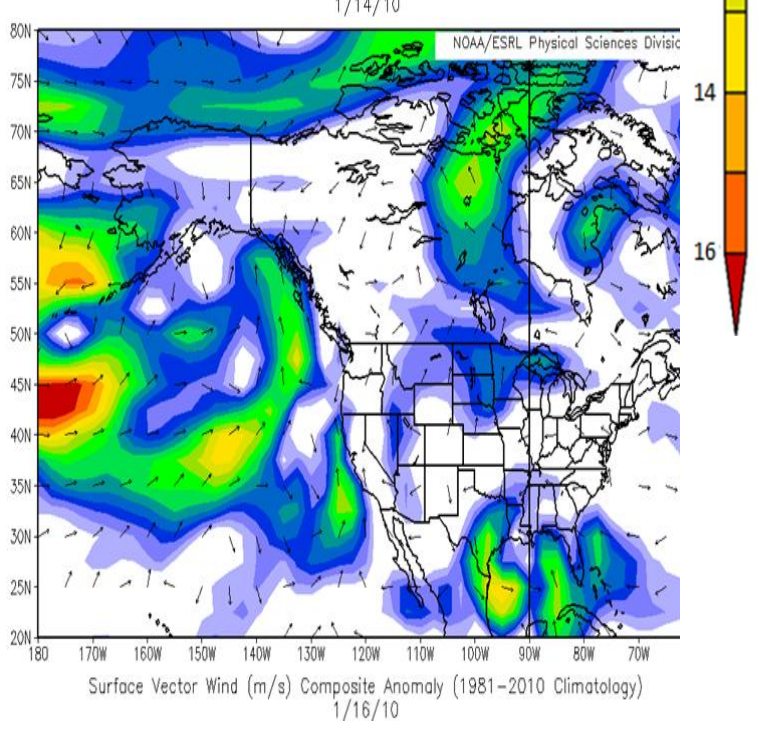




\section{Appendix C: Permissions}

Kelsey Roberts <robertsk@mail.usf.edu>

Thu, Oct 3, 2013 at 4:16 PM

To: "Bailey, Rhonda" <Rhonda.Bailey@myfwc.com>

Hello Rhonda,

I am in the formatting stage of my thesis and I would like to request to use the pictures that you sent me (above) of the sea turtle cold stun search areas for St. Joesph Bay in my paper. I have been citing FWC FWRI marine turtle research for any of the data I have utilized from you but please let me know if you would like it cited differently.

Thanks,

Kelsey

[Quoted text hidden]

Bailey, Rhonda <Rhonda.Bailey@myfwc.com>

To: Kelsey Roberts <robertsk@mail.usf.edu>

Tue, Oct 8, 2013 at 3:36 PM

Cc: "Hardy, Robert" <Robert.Hardy@myfwc.com>

Kelsey, that looks fine!

Rhonda Bailey, Biologist

Florida Fish and Wildlife Conservation Commission

Fish and Wildlife Research Institute

Sea Turtle Stranding and Salvage Network

Ioo 8th Ave SE

St. Petersburg, FL 337 or

Phone: (727) 502-4742

Fax: $(727) 893-9176$

Wildlife Alert Hotline: 1-888-404-FWCC (3922)

http://research.myfwc.com 


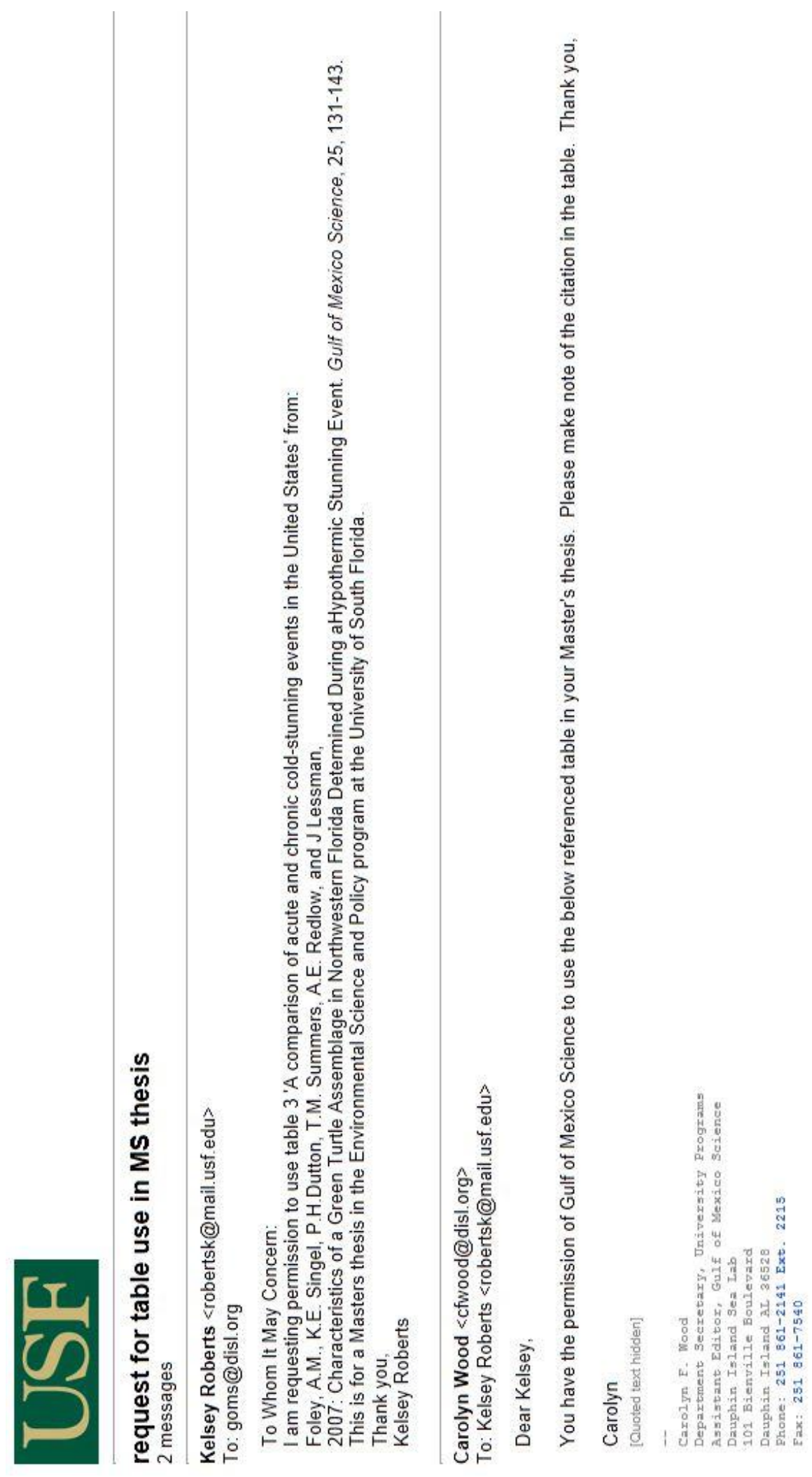


Anders Rhodin <rhodincrf@aol.com>

To: robertsk@mail.usf.edu

no problem. permission granted

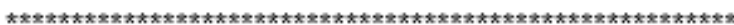

Anders G.J. Rhodin, M.D.

Chairman Emeritus, IUCN/SSC Tortoise and Freshwater Turtle Specialist Group

Director, Chelonian Research Foundation

Founding Editor, Chelonian Conservation and Biology

Co-Chair, Turtle Conservation Fund

Permanent Address: 168 Goodrich St., Lunenburg, MA 01462 USA

Current Mailing Address: 564 Chittenden Dr., Arlington, VT 05250 USA

Phone (work and home) 1-978-807-2902 (cell)

rhodincrf@aol.com; a.rhodin@gmail.com

www.chelonian.org; www.iucn-fftsg.org; www.turtleconservationfund.org

----Original Message-----

From: Kelsey Roberts <robertsk@mail.usf.edu>

To: RhodinCRF <RhodinCRF@aol.com>

Sent: Tue, Oct 15, 2013 9:10 pm

Subject: Contact: request for figure use in MS thesis

Name: Kelsey Roberts

Email: robertsk@mail.usf.edu

Subject: request for figure use in MS thesis

Message: Hello,

I am requesting permission to use Figure 4-5. The distribution of green turtle nesting on Florida beaches in 'Witherington, B.E., M. Bresette, and R. Herren, 2006: Chelonia mydas ậ" Green Turtle. Biology and Conservation of Florida Turtles, Chelonian Research Monographs, 3, 90-104.'

This is for a MS thesis at the University of South Florida. 


\section{Smithsonian Institution}

DIGITAL AND NON-DIGITAL ASSET REQUEST AND USAGE FORM if you would like to (i) make a commercial use* of a Smithsonian digital or non-digital asset (ii) use a Smithsonlan asset beyond what is permitted at www.sl.edu/termsofuse $\mathcal{L}$ or (iil) obtain or use for non-commerciai purposes a digital or non-digital asset that is not pubilicly accessible on the Smithsonian website; or (iv) request that the te a digital asset where it does not yet exist, complete this form and send or fax it to the approprlate museum or unit. See http://www.si.edu/termsofuse/for contact information. Do not use this form for requests to use assets in filming projects or

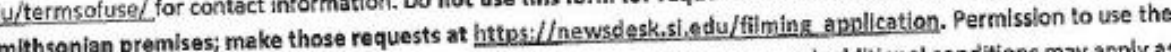
asset is subject to review and approval by the Smithsonian. General conditions are on the reverse and additional conditions may apply as set forth on this Form. The Smithsonian reserves the right to charge a fee. product, publication, or media-form that is marketed, promoted, and/or soid. Examples inciude, but are not limited to, consumer merchandise, journals and periodicals, books, trade publications, advertisements, websites with paid advertising and fundralsing materials.

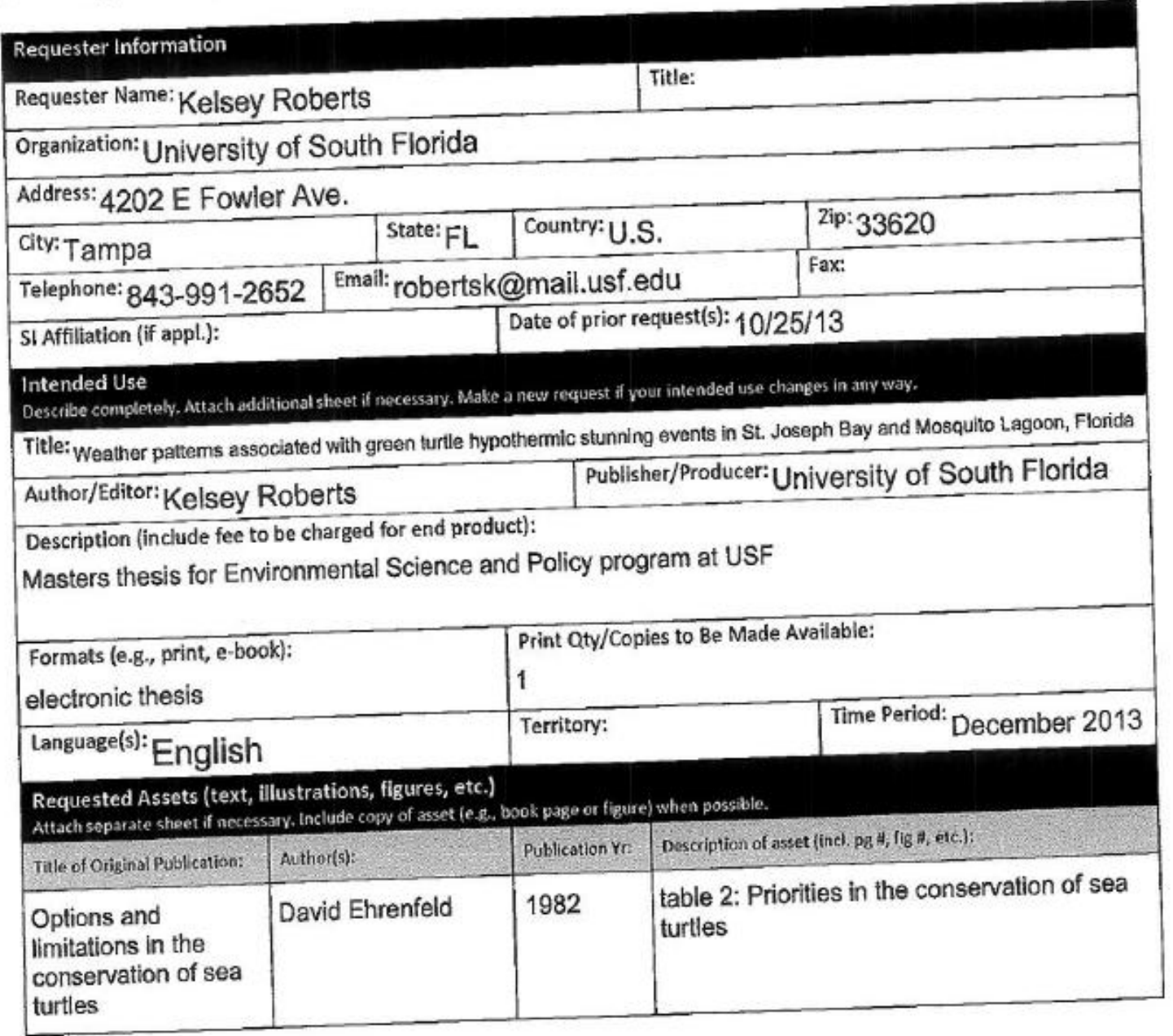


General Conditions on Reproduction and Use

The following conditions apply unless otherwise specified in writing by the Smithsonian.

1. Permission is for one-time, non-exclusive use only within the project described on the reverse. Requestor may not crop, alter, manipulate, superimpose, enhance, or otherwise change the asset in any manner without obtaining the prior written permission of the Smithsonian. Requestor may not make further use without the Smithsonian's prior written approval and compliance with any additional conditions.

2. This permission extends only to such rights as the Smithsonian may have to authorize reproduction and does not purport to include any rights that persons other than the Smithsonian may have under copyright law of the United States or the laws of other countries in which the requestor's works may be published or distributed. Certain images may be protected by copyright, trademark, privacy, or publicity rights, or other interests not owned by the Smithsonian. It is requestor's responsibility to determine whether any such rights exist, and to obtain all necessary permissions to use the image for the purposes set forth herein.

3. Requestor agrees to indemnify and hold harmless the United States, Smithsonian, its regents, agents, and employees, from all claims, actions, judgments, and expenses (including reasonable attorney fees) arising from requestor's use of the material provided pursuant to this request.

4. Requestor shall: acknowledge the donor and/or creator as specified below; give credit to the Smithsonian as specified below; and comply with all additional conditions specified below by the Smithsonian.

5. If fees are assessed, requestor must pay all fees in advance of delivery.

6. Any advertising or promotion by Requestor that uses the digital asset must be approved in advance by the Smithsonian. Requestor shall not use, reproduce, or refer to the name or logo of Smithsonian or any of its museums or units for publicity, advertising, or promotion purposes.

\begin{tabular}{|c|c|c|}
\hline $\begin{array}{l}\text { Additional Conditions on Use } \\
\text { For Snithsonian Use Only }\end{array}$ & & \\
\hline Fee for Digitizatlon: & Fee for Usage: & $\begin{array}{l}\text { Total Fees to Be Paid: } \\
\end{array}$ \\
\hline $\begin{array}{l}\text { Payment type: } \\
\text { Check made payable to Smithsc }\end{array}$ & In Scholarly Press & Date Received: \\
\hline Donor/creator acknowledgem & & \\
\hline $\begin{array}{l}\text { Smithsonian credit line: } \\
\text { Reprinted from B.pondul(1982), }\end{array}$ & permission of Smithsonian Inst & \\
\hline Additional Conditions: & Bibliography must include full $c$ & n of original publication. \\
\hline
\end{tabular}

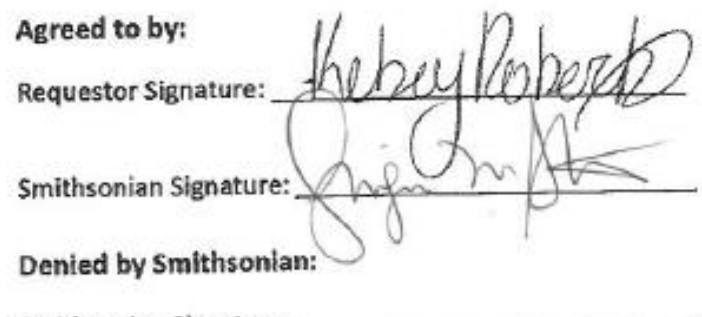

Smithsonian Signature:
Date:

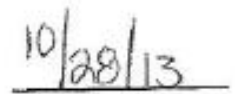

Date:

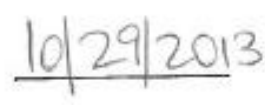

Date: 